\title{
EXPERIMENTS ON THE RESPONSE OF RIGID AND FLEXIBLE REACTOR VESSEL MODELS TO A SIMULATED HYPOTHETICAL CORE DISRUPTIVE ACCIDENT
}

By: D. J. CAGLIOSTRO, Project Leader
C. M. ROMANDER MASTER

Contributor: A. L. FLORENCE, Project Supervisor

Prepared for:

ARGONNE NATIONAL LABORATORY

REACTOR ANALYSIS AND SAFETY

9700 SOUTH CASS AVENUE

ARGONNE, ILLINOIS 60439

Contract 31-109-38-2655

STANFORD RESEARCH INSTITUTE

Menlo Park, California 94025 - U.S.A. 


\section{DISCLAIMER}

Portions of this document may be illegible in electronic image products. Images are produced from the best available original document. 


\section{EXPERIMENTS ON THE RESPONSE OF RIGID} AND FLEXIBLE REACTOR VESSEL MODELS TO A SIMULATED HYPOTHETICAL CORE DISRUPTIVE ACCIDENT

By: D. J. CAGLIOSTRO, Project Leader C. M. ROMANDER

Contributor:

A. L. FLORENCE, Project Supervisor
- DISCLAIMER

This book was prepared as an account of work sponsored by an agency of the United States Government. Neither the United States Government nor any agency thereof, nor any of their employees, mekes any warranty, express or implied, or assumes any legal liability or responsibility for the accuracy represents that in we wiss of any information, apparatus, product, or process disclosed, or commercial product not necessarily constitute or imply its endore ne, trademark, manufacturer, or otherwise, does States Government or any agney the United

Prepared for:

ARGONNE NATIONAL LABORATORY

REACTOR ANALYSIS AND SAFETY

9700 SOUTH CASS AVENUE

ARGONNE, ILLINOIS 60439

Contract $31-109-38-2655$

SRI Project PYD-1960

Approved by:

G. R. ABRAHAMSON, Director

Poulter Laboratory 
A simulated HCDA loading was applied in simple, thick-walled and thin-walled, $1 / 30-$ scale models of a fast breeder reactor vessel. The loading and resulting vessel response were measured to verify the modeling techniques used in the REXCO computer code.

The sodium coolant is simulated by water, and the HCDA load is simulated by the expansion of the detonation products of a low-density explosive detonated in the vessel core. The detonation products expand from an initial pressure of 3700 psi down to 360 psi for a volume change of $410 \mathrm{~cm}^{3}$, equal to the cover gas volume. The expansion produces $2.87 \mathrm{~kW}-\mathrm{sec}$ of gas work up to slug impact on the vessel cover. Piezoelectric quartz pressure transducers measure the loading pressure in the core and on the core support platform, the vessel wall, and the cover. Foil strain gages measure circumferential and axial strains on the vessel wall. From the strain measurements and the posttest deformation profiles of the vessel, the strain energy absorbed by the vessel before and after slug impact is calculated.

In the thick-walled vessel, the peak pressures are 3000 psi on the core support platform, 6000 psi on the vessel wa11, and 14,000 psi on the cover; the cover pressure rapidly drops to 7000 psi corresponding to slug impact pressure.

In the thin-walled vessel the platform and wall pressures are $50 \%$ lower and the cover pressure is $7 \%$ lower. Peak vessel strains are $3.5 \%$ in the circumferential direction 1-1/4 inches below the cover. The effect of core barrel flexibility on the loads in a thin-walled vessel is negligible for the HCDA load simulated. The strain energy absorbed in the flexible vessel is about 1.84 $\mathrm{kW}-\mathrm{sec}$, about $61 \%$ of the gas work to slug impact and about $71 \%$ of the slug kinetic energy at impact. The posttest deformations of the vessel with a rigid core are the same as those with a flexible core barrel in the upper half of the vessels, but are about twice as large in the lower half.

To further verify REXCO's modeling of reactor components we recommend experiments in scale-modeled reactor vessels with upper internal structures and high-density fluids above the core to model the fission gas region. 
$\bullet$

.

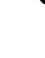




\section{PREFACE}

The program described here was performed and analyzed during fiscal years 1974, 1975, and 1976. The program was monitored technically by S. H. Fistedis and G. Nagumo, Reactor Analysis and Safety Division, Argonne National Laboratory.

We wish to adknowledge C. E. Blahnik, who designed the vessels, J. H. Busma, who coordinated the design and construction of the vessels, and G. R. Greenfield, who helped in the assembly, instrumentation, and performance of the experiments. 
$\bullet$

. 


\section{CONTENTS}

ABSTRACT

PREFACE

LIST OF ILLUSTRATIONS ix

LIST OF TABLES

I INTRODUCTION AND SUMMARY 1

A. Background 1

B. Objective 3

C. Approach 3

$\begin{array}{lll}\text { D. Summary of Results } & 7\end{array}$

E. Recommendations for Future Work $\quad 8$

I I EXPERIMENTAL PROGRAM 9

A. Energy Source Calibration Experiments 9

B. Rigid Vessel Experiments 9

C. Flexible Vessel Experiments 9

I I RESULTS

A. Energy Source Characteristics 15

B. Pressure Loadings in the Rigid Vessel 15

C. Pressure Loadings and Deformations in Flexible Vessels 22

1. Comparison of Pressure Loading in Rigid and Flexible Vessels 22

2. Effects of Core Barrel Flexibility on Vessel Loading 24

3. Effects of Core Barrel Flexibility on Vessel Strain and Deformation

APPENDICES
A DETAILS OF THE ENERGY SOURCE CALIBRAT ION
B DETAILS OF THE RIGID VESSEL EXPERIMENTS
$\mathrm{B}-1$
C STRESS-STRAIN PROPERTIES OF FLEXIBLE VESSEL MATERIAIS
$\mathrm{C}-1$
D DETAILS OF THE FLEXIBLE VESSEL EXPERIMENTS
D-1 
$\circ$

- 


\section{ILLUSTRATIONS}

1 Clinch River Breeder Reactor Vessel

2 Schematic of Source Calibration, Rigid, and Flexible Vessels

3 Calibration Vessel with Instrumentation

4 Rigid Vessel with Instrumentation

$5 \quad$ Flexible Vessel Assembly

6 Pressure- and Gas Work-Volume Change Relationships for Energy Source

7 Gas Work-Time Relationship for Energy Source

8 Loading Pressures in Rigid Vessel with Cover Gas Volume (RV 111, RV 112, and RV 113)

9 Effect of Cover Gas Volume on Loading Pressures in Rigid Vessel

10 Loading Pressures in Rigid and Flexible Vessels with Rigid Core Barrels

11 Effect of Core Barrel Flexibility on Loading Pressures in Flexible Vessels

12 Effect of Core Barrel Flexibility on Strain-Time Response of Flexible Vessels

13 Effect of Core Barrel Flexibility on Deformation-Time Profiles of Flexible Vessels

14 Effect of Core Barrel Flexibility on Strain Energy Absorbed during Flexible Vessel Experiments

A.1 Calibration Vessel with Instrumentation

A.2 Sample Pressure Oscillograms from Calibration Experiment RV 102

A.3 Pressure-Volume Change Relationship from Pressure and Displacement Histories

A.4 Reproducibility of Pressure-Volume Change and Gas Work Measurements for Energy Source

A.5 Pressure-Volume Change and Gas Work-Volume Change Relationships for Energy Source 
A.6 Pressure-Volume Change and Gas Work-Volume Change Relationships: 14-g Charge of PETN/Microballoon Mixture (65/35 by wt)

\section{A.6 Pressure-Volume Change and Gas Work-Volume Change Relationships:}

A.7 Pressure-Volume Change and Gas Work-Volume Change Relationships: 5.8-g Charge of PETN/Microsphere Mixture (90/10 by $w t$ )

B.1 Rigid Vessel with Instrumentation

B-2

B.2 Sample Pressure Oscillograms from Rigid Vessel Experiment RV 112 B-6

B.3 Reproducibility of Pressure-Time Loadings from Rigid Vessel Experiments

B.4 Pressure-Time Loading: Experiment RV 111

$\mathrm{B}-\mathbf{8}$

B.5 Pressure-Time Loading: Experiment RV 112

B-10

B.6 Pressure-Time Loading: Experiment RV 113

B-12

B.7 Pressure-Time Loading: Experiment RV 114

B-14

C.1 Tensile Specimen for Ni 200 stress-Strain Test

$\mathrm{C}-2$

C.2 Measured Stress-Strain Curves for Ni 200

$\mathrm{C}-5$

C.3 Averaged Stress-Strain Curves for Each Flexible Vessel

C-6

C.4 Stress-Strain Properties for Flexible Core Barrel Materials

$\mathrm{C}-7$

D. I Flexible Vessel Assembly

D-2

D.2 Flexible Core Barrel Assembly

D-4

D.3 Vessel End Flange and Clamp Ring

D-6

D.4 Instrumentation Layout for Flexible Vessel Experiments

D-8

D.5 Sample Pressure Oscillograms from Flexible Vessel Experiment FV 101

D-11

D.6 Sample Strain Records from Flexible Vessel Experiment FV 101 D-12

D.7 Pressure-Time Loadings: Experiment FV $101 \quad$ D-14

D.8 Strain-Time Response: Experiment FV $101 \quad$ D-16

D.9 Cover Displacement: Experiment FV $101 \quad$ D-19

D.10 Final Deformed Shape of Flexible Vessel FV $101 \quad$ D-20

D.11 Pressure-Time Loadings: Experiment FV $102 \quad$ D-22

D.12 Strain-Time Response: Experiment. FV $102 \quad$ D-24

D.13 Final Deformed Shape of Flexible Vessel FV $102 \quad$ D-28 


\section{TABLES}

\section{$\underline{\text { Page }}$}

1 Calibration Experiments 11

2 Rigid Vessel Experiments 12

$3 \quad$ Flexible Vessel Experiments 14

4 Energy Partitioning in Flexible Vessel Experiments 31

A.1 Specifications of Calibration Experiments

A-6

B.1 Specifications of Rigid Vessel Experiments

$\mathrm{B}-5$

C.1 Stress-Strain Tests of Ni 200

$\mathrm{C}-2$

D.I Specifications of Flexible Vessel Experiments

D-9

D.2 Radial Displacements of Flexible Vessel Experiment FV 101

D-21

D.3 Radial Displacements of Flexible Vessel Experiment FV 102

D-29 
I INTRODUCTION AND SUMMARY

\section{A. Background}

The safety of liquid metal fast breeder reactors (LMFBRs) (Figure 1) depends in part on maintaining the reactor's primary containment (reactor vessel and primary cooling loops) during a hypothetical core disruptive accident (HCDA). An HCDA may be caused by a power mismatch or a loss of coolant flow to the reactor core that allows the fuel in the fuel pins to heat up and melt. As the fuel melts its pressure and temperature increase until the fuel pins burst, and then the high-pressure, hightemperature liquid fuel flashes, or vaporizes, into the surrounding sodium coolant. The flashing fuel mixes with the sodium and expands rapidiy as a liquid-vapor mixture of fuel and sodium out of the core and into the sodium pool above. The mixture expands as a bubble, loading the core and vessel walls and accelerating the sodium coolant upward into the vessel cover. When the sodium slug impacts the cover, part of its kinetic energy is absorbed by the vessel walls, cover, and internal structures; the remaining kinetic energy is dissipated through heat transfer and viscous work within the coolant slug and the liquid-vapor bubble.

To help evaluate the safety of LMFBRs, Argonne National Laboratory has developed the computer code $\mathrm{REXCO}^{*}$ to predict the structural response of LMFBRs to HCDAs. Before the code can be relied on, its modeling of reactor structures must be verified by comparing its predictions with measurements from experiments. The code has been used to predict the response of simple and complex $1 / 30$ - and 1/10-scale models of the Fast

Y. W. Chang, J. Gvildys, and S. H. Fistedis, "Calculations of the Dynamic Response of the Primary Containment Using a Two-Dimensional HydrodynamicElastic-Plastic-Plastic Code," Trans. Am. Nucl. Soc. 15, 818 (1972). 


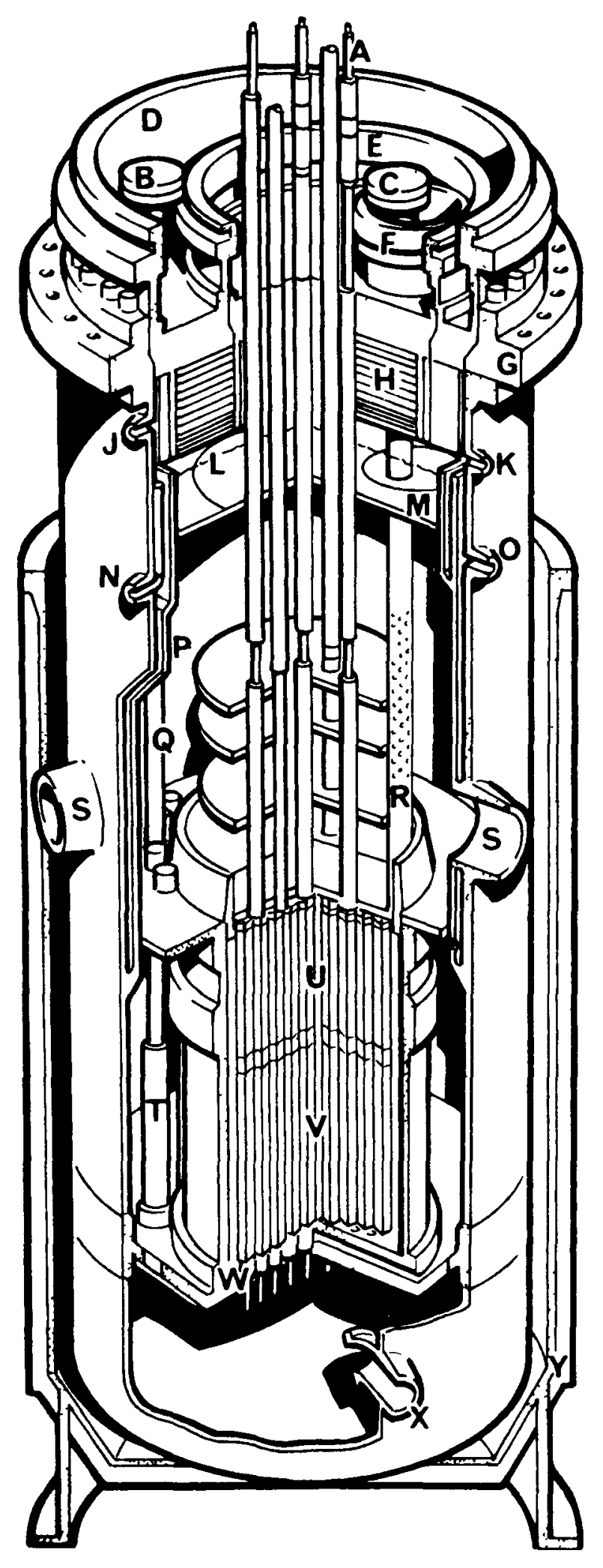
A. CONTROL ROD DRIVE MECHANISM
B. EX-VESSEL TRANSPORT MACHINE
c. IN-VESSEL TRANSFER MACHINE
D. LARGE ROTATING PLUG
E. INTERMEDIATE ROTATING PLUG
F. SMALL ROTATING PLUG
G. STATIONARY OUTER RING
H. SHIELDING
J. COVER GAS INLET
K. COVER GAS OUTLET
L. SODIUM LEVEL
M. SUPPRESSION PLATE
N. SODIUM OVERFLOW
O. SODIUM INLET
P. THERMAL LINER
Q. EX-VESSEL TRANSPORT GUIDE TUBE
R. IN-VESSEL TRANSFER GUIDE TUBE
S. SODIUM OUTLET TO PRIMARY PUMP
T. FUEL TRANSFER STORAGE
$U$. FUEL ASSEMBLIES
V. CORE
W. INLET MODULES
$X$. SODIUM INLET FROM INTERMEDIATE HEAT EXCHANGER
Y. GUARD VESSEL

FIGURE 1 CLINCH RIVER BREEDER REACTOR VESSEL 
Test Reactor (FTR) to simulated 150-MW-sec accidents. ${ }^{*}$ These experiments were designed to measure the structural response of the prototypic reactor but they were not designed to verify REXCO's modeling techniques. Code validation is best done by performing experiments in vessels with precision tolerances, simple well-defined boundary conditions, and simple models of reactor components.

The results of these experiments verify REXCO in the following way. REXCO's input are the vessel dimensions and boundary conditions, the stress-strain relationships for the vessel materials, and the pressurevolume relationship for the loading source. REXCO's calculations are then compared with the experimentally measured pressure-time loading in the core and on the platform, walls, and cover; the strain-time response of the core barrel and walls; and the posttest core barrel and wall deformations.

This report presents the loadings in the models and their response to these loadings; it does not present any of the REXCO predictions.

\section{B. Objective}

The objective of this program is to measure the loading, strain, and deformation in simple models of an LMFBR having well-defined material properties, dimensions, and simple boundary conditions for verification of modeling techniques used in REXCO.

\section{Approach}

Our overall approach is to conduct benchmark experiments on the dynamic response of simplified, small-scale models of an LMFBR vessel to an HCDA. The dimensions of these models are approximately $1 / 30$ of those of the Clinch River Breeder Reactor (CRBR). Water is used to

*A. L. Florence and G. R. Abrahamson, "Simulation of a Hypothetical Core Disruptive Accident in a Fast Flux Facility," SRI Final Report on Project PYU-1109, HEDL-SRI-1 (May 1973). 
simulate the liquid sodium coolant. The program is divided into three tasks: energy source calibration, rigid vessel experiments, and flexible vessel experiment $s$.

Energy Source Calibration--Calibration consists of measuring the pressure- and gas work- volume change relationships for the HCDA energy source in a thick-walled (rigid) vessel containing a thick-walled (rigid) core barrel and no cover, as shown in Figure 2(a). The energy source consists of a low-density $\left(0.33 \mathrm{~g} / \mathrm{cm}^{3}\right)$ explosive mixture of PETN $^{*}$ and hollow-glass microballoons ${ }^{\dagger}(65 / 35$ by weight) in a vented steel-ringed canister. The canister is bolted in the lower core barrel and is surrounded by air. Above the canister a Mylar diaphragm keeps the water from entering the lower core barrel.

After detonation of the explosive, high-pressure detonation products expand out of the canister, fill the lower core barrel, and expand against the water, forming a high-pressure bubble that accelerates the water upward. The pressure transducers in the core measure the bubble pressure, $p(t)$, and a light detection setup measures the displacement of the water surface as a function of time, $x(t)$. The light detection setup consists of a light source, a light ladder (a split, hollow, aluminum tube with horizontal slits), and a Lucite light rod connected to a photomultiplier. As the light ladder moves up with the water surface and each slit passes the light rod, light from the light source passes through the slits and into the light pipe and triggers the photomultiplier. For a known distribution of slits in the light ladder, the output of the photomultiplier produces a record of the displacement of the water surface as a function of time, $x(t)$. Knowing $x(t)$ and the area of the water surface and accounting for the compressibility of the water, we measure the volume

\footnotetext{
${ }_{\text {PETN }}^{*}\left(\mathrm{C}_{5} \mathrm{H}_{8} \mathrm{O}_{12} \mathrm{~N}_{4}\right)$ pentaerythritol tetranitrate.

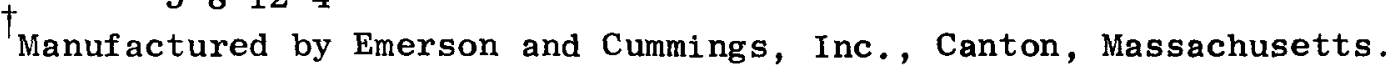




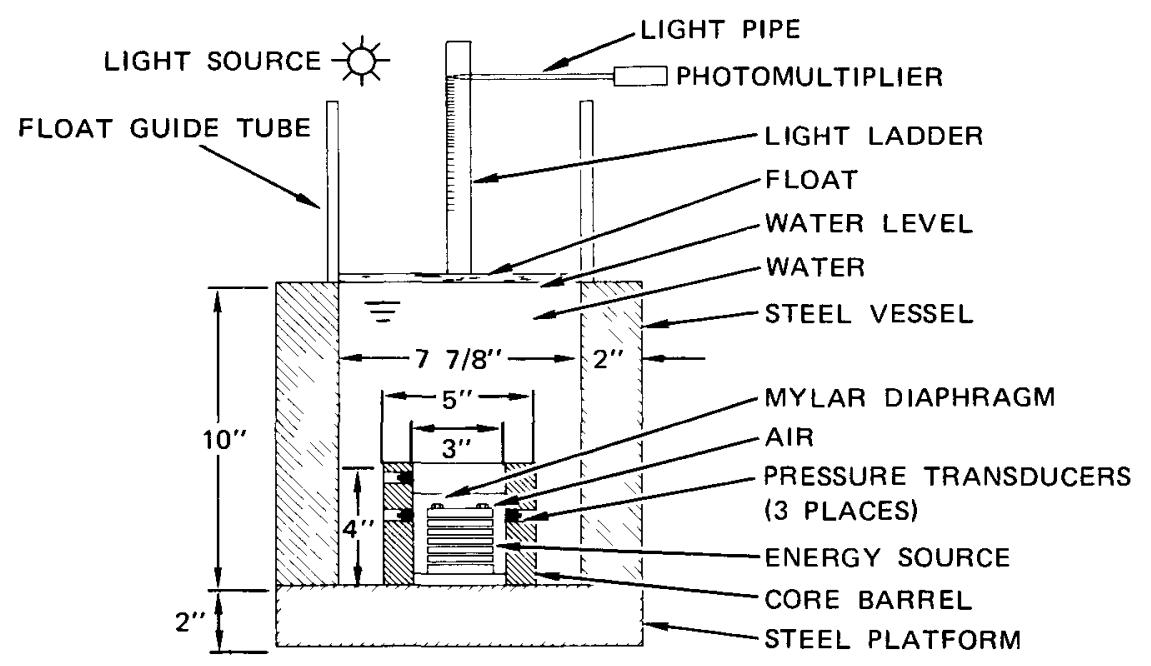

(a) ENERGY SOURCE CALIBRATION VESSEL AND INSTRUMENTATION

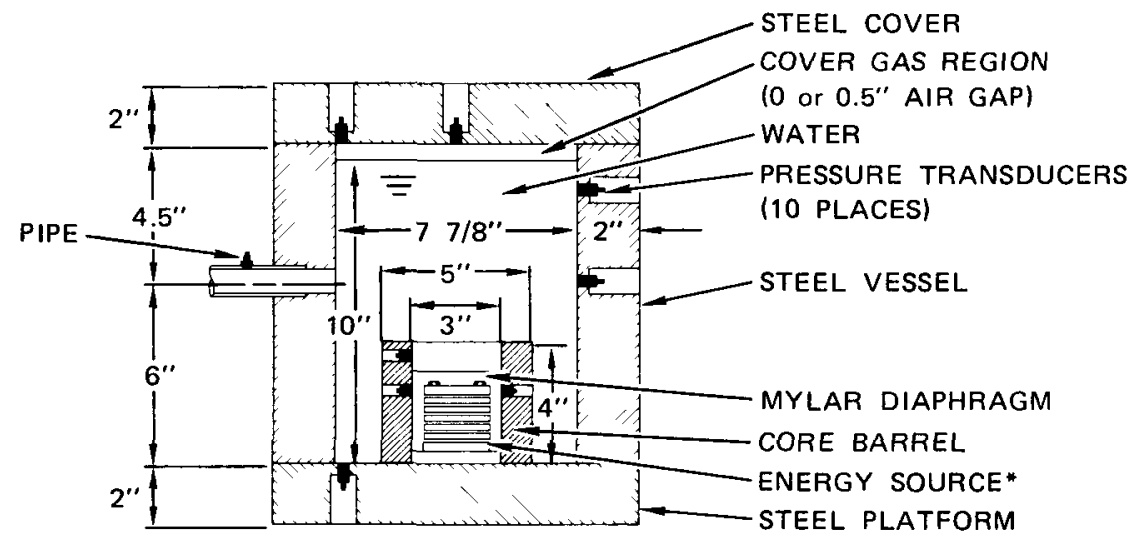

(b) RIGID VESSEL AND INSTRUMENTATION

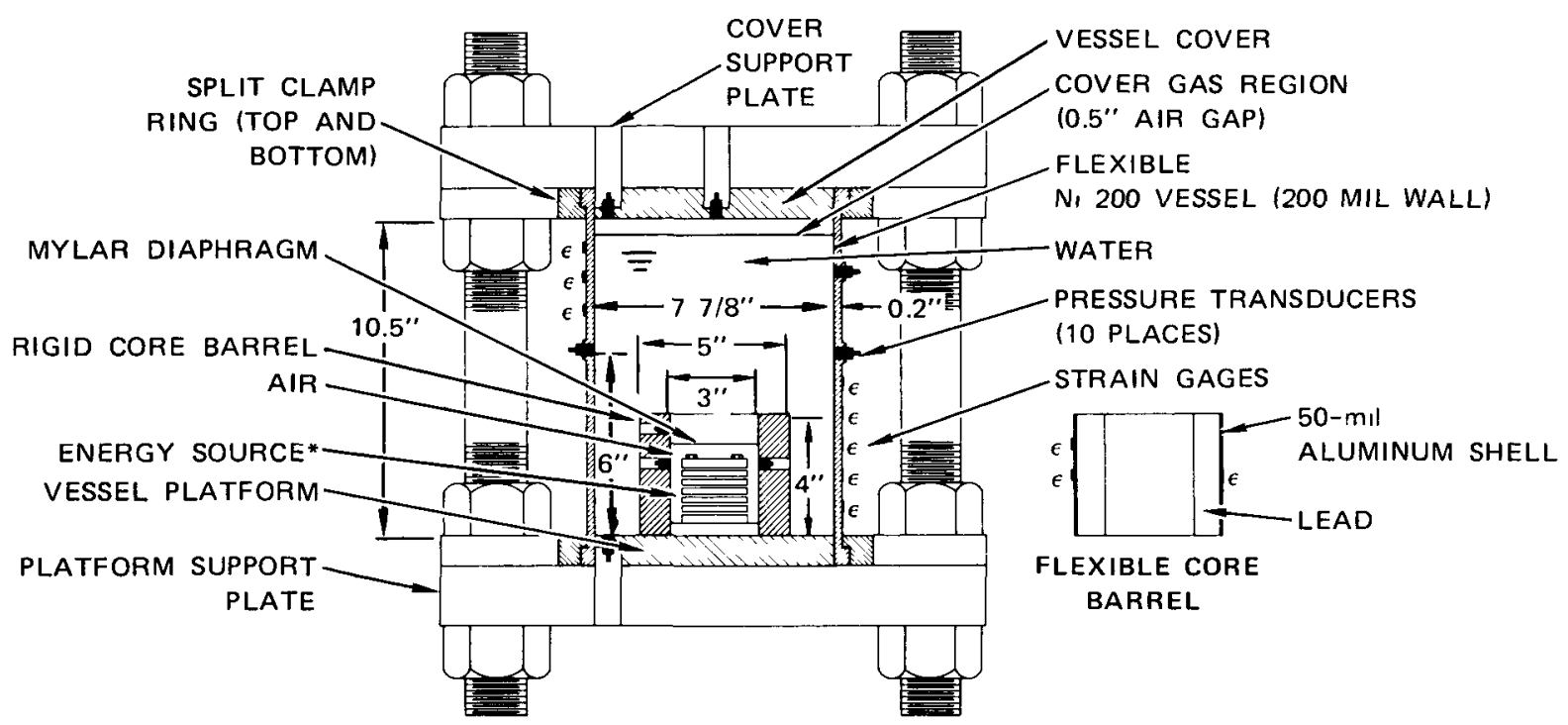

-PETN/Microballoon Mixture

(c) FLEXIBLE VESSEL AND INSTRUMENTATION

MA-1960-229 (65/35 by weight)

FIGURE 2 SCHEMATIC OF SOURCE CALIBRATION, RIGID, AND FLEXIBLE VESSELS 
change of the expanding detonation products as a function of time $\Delta V(t)$. Then from $p(t)$ and $\Delta V(t)$ we determine the pressure-volume change relationship $p(\Delta V)$ of the energy source. By integrating $p(\Delta V)$ over volume change, we calculate the gas work as a function of volume change $U_{g}(\Delta V)$.

Rigid Vessel Experiments--To determine the loading pressures in a vessel with only small elastic strains, the energy source was used in the thick-walled (rigid) vessel shown in Figure 2(b). The vessel consists of a steel cylinder sealed at the top and bottom by thick steel plates and contains a thick-walled core barrel. Pressures were measured in the rigid core barrel, on the core-support platform, on the vessel walls, and cover, and in a pipe attached to the vessel wall. The effects of a cover gas volume on these pressures were also determined.

Flexible Vessel Experiments--Two experiments were performed to investigate the effects of vessel wall flexibility and core barrel flexibility on the loading pressures and to determine the plastic response of a flexible vessel to the HCDA loads. The vessels, shown in Figure 2(c), had inside dimensions approximately equal to those of the rigid vessel shown in Figure $2(\mathrm{~b})$. The cover and platform were clamped and bolted to thick steel plates, which were connected to each other by steel studs to ensure simple, well-defined boundary conditions--zero axial and radial displacement and zero rotation at the vessel ends. The vessel wall was made from annealed $\mathrm{Ni} 200$ to approximately simulate at room temperature the stress-strain properties of 304 SS at reactor operating temperatures $\left(\sim 1000^{\circ} \mathrm{F}\right)$.

The first experiment was performed with a rigid steel core barrel and the second with a flexible core barrel consisting of a $0.950-i n c h-$ thick lead cylinder surrounded by a $0.050-i n c h-t h i c k$ aluminum cylinder. In each experiment we measured the pressure on the core platform, vessel walls, and cover at the same locations as in the rigid vessel, the strain of the vessel walls, the deflection of the cover, and the posttest 
deformation of the vessel wall. In the experiment with a rigid core barrel we measured the core pressure, and in the experiment with the flexible core barrel we measured the circumferential strain on the outside of the aluminum cylinder.

D. Summary of Results

Calibration of the energy source showed that:

- The pressure-volume change relationship for the energy source, an 8-g PETN/Microballoon mixture $(65 / 35$ by weight), has a peak pressure of 3700 psi and decreases to 360 psi as the detonation products expand out of the core from an initial volume of $226.5 \mathrm{~cm}$ and displace the water above the core to $\mathrm{fill}_{3}$ the cover gas region with a volume of $410 \mathrm{~cm}$.

- The gas work expended by the detonation products up to slug impact on the vessel cover is $2.87 \mathrm{~kW}-\mathrm{sec}$, corresponding to $77.5 \mathrm{MW}-\mathrm{sec}$ in a full-scale reactor.

The results of the rigid vessel experiments are summarized below.

- In the vessel with a cover gas volume the maximum pressure on the platform is 3000 psi, on the vessel walls 6000 psi, and on the cover 14,000 psi caused by compression of the cover gas and then down to 7000 psi caused by slug impact on the cover.

- The pressure pulse in a pipe attached to the vessel wall has a peak pressure of 6000 psi caused by the reflected slug-cover impact pressure wave and is the same as the pressure pulse measured at a similar location on the vessel wall without a pipe.

- In the vessel without a cover gas volume the duration of the loads is longer than in the vessel with a cover gas volume, but the magnitude of the loads is about the same.

The results of the flexible vessel experiments a re summarized below.

- The platform pressure is 50\% lower and the impact pressure on the cover is $7 \%$ lower than in the rigid vessel experiments.

- Peak strains of $3.5 \%$ in the vessel walls occur $1-1 / 4$ inches below the cover. 
- The effects of core barrel flexibility on the cover pressure and on the response of the upper half of the vessel are negligible for the loads applied here.

- The vessel absorbed $0.44 \mathrm{~kW}-\mathrm{sec}$ of strain energy before slug impact (15\% of the gas work to impact) and an additional $1.4 \mathrm{~kW}-\mathrm{sec}$ after slug impact (49\% of the slug kinetic energy at impact). The total strain energy absorbed, $1.84 \mathrm{~kW}-\mathrm{sec}$, is $57 \%$ of the total gas work $(3.25 \mathrm{~kW}-\mathrm{sec})$ done for a volume change equal to the cover gas volume plus the volume increase of the vessel.

- The posttest deformations of the vessels with a rigid core barrel and with a flexible core barrel are identical in the upper half of the vessels but are about twice as large in the lower half for the vessel with a rigid core barrel.

The accuracy of the instrumentation is $\pm 2 \%$ for pressure gages, $\pm 2 \%$ for strain gages, and $<0.1 \%$ for diameter measurements. Based on the six calibration and rigid vessel experiments, the pressures throughout the models are within $\pm 10 \%$ of the average. For the two flexible vessel experiments, therefore, pressures are assumed to be reproducible to within $\pm 10 \%$. Stress-strain curves for the two flexible vessels are within $\pm 4 \%$ of the average whereas scatter on an individual stress-strain test is $\pm 1 \%$.

Measurements of the posttest radial deflections are accurate to within \pm 0.5 mils, which corresponds to $\pm 0.4 \%$ in areas of large deflections to $\pm 2.5 \%$ in areas of small deflections. The variation in the radial deflections at a given axial location is $5 \mathrm{mils}$, which corresponds to $3.6 \%$ in areas of large deflections and to $26 \%$ in areas of small deflections.

E. Recommendations for Future Work

To further verify REXCO's modeling of reactor components, we recommend scale-modeled experiments that include

- Simple upper internal structures, and

- High density fluids modeling the fission gas region. 


\section{I EXPERIMENTAL PROGRAM}

\section{A. Energy Source Calibration Experiments}

Ten calibration experiments were performed in the apparatus shown in Figure 3. Two low-density explosive mixtures were tested over a range of charge masses to determine the appropriate energy source to be used in the rigid and flexible vessels. The two charge mixtures investigated were a 65/35 (by weight) mixture of PETN and Microballoons, hollow glass spheres, and a 90/10 (by weight) mixture of PETN and Microspheres, hollow plastic spheres. Table 1 lists the specifications of the experiments.

Detailed descriptions of the apparatus and instrumentation and the experimental reproducibility are given in Appendix A.

\section{B. Rigid Vesse1 Experiments}

In the apparatus shown in Figure 4, four experiments were performed to measure the pressure loading on the core support platform, the vessel walls, and the vessel cover with and without a cover gas volume. The energy source was the calibrated 8-g charge of PETN/Microballoon mixture, $65 / 35$ by weight. The first three experiments had a $0.5-i n c h$ air gap between the water surface and the cover and the fourth had no air gap. Table 2 lists the specifications of the experiments.

Detailed descriptions of the apparatus and instrumentation and the experimental reproducibility are given in Appendix $B$.

\section{Flexible Vessel Experiments}

In the flexible vessel apparatus shown in Figure 5, two experiments were performed with the calibrated energy source to measure the loading on the core support platform, the walls, and the cover and the strain and deformation of the walls. The effects of core barrel flexibility on vessel response were studied by performing the first experiment with the thick-walled steel core barrel used in the rigid vessel experiments 


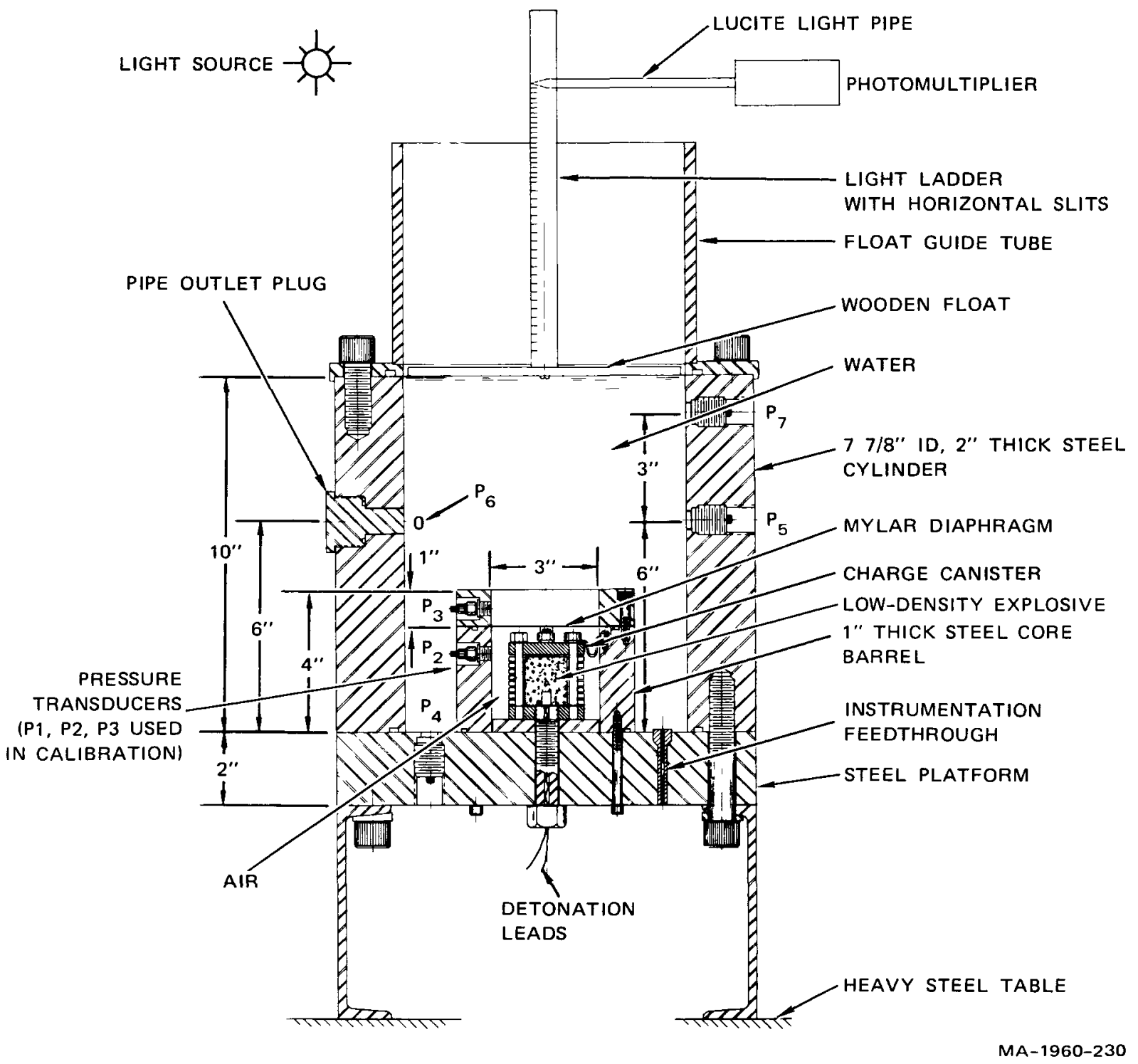

FIGURE 3 CALIBRATION VESSEL WITH INSTRUMENTATION 
Table 1

CALIBRATION EXPERIMENTS

\begin{tabular}{|c|c|c|c|c|c|}
\hline $\begin{array}{c}\text { Experiment } \\
\text { Number }\end{array}$ & $\begin{array}{c}\text { Charge Mass } \\
\text { (g) }\end{array}$ & $\begin{array}{c}\text { Mixture } \\
\text { (by weight) }\end{array}$ & $\begin{array}{c}\text { Water Height } \\
\text { Above Core } \\
\text { (in.) }\end{array}$ & $\begin{array}{c}\text { Peak Core } \\
\text { Pressure } \\
\text { (psi) }\end{array}$ & $\begin{array}{c}\text { Gas Work } \\
\text { (kW-sec) }\end{array}$ \\
\hline RV 101 & 8.0 & $65 / 35^{\mathrm{a}}$ & 6.0 & 3930 & 2.85 \\
RV 102 & 8.0 & $65 / 35^{\mathrm{b}}$ & 6.0 & 3605 & 2.88 \\
RV 103 & 5.8 & $90 / 10$ & 6.0 & 3800 & -- \\
RV 104 & 5.8 & $90 / 10$ & 6.0 & -- & - \\
RV 105 & 8.0 & $65 / 35$ & 9.0 & 3750 & 2.95 \\
RV 106 & 14.0 & $65 / 35$ & 6.0 & -- & - \\
RV 107 & 14.0 & $65 / 35$ & 6.0 & 5650 & 3.65 \\
RV 108 & 5.8 & $90 / 10$ & 6.0 & 3650 & -- \\
RV 109 & 5.8 & $90 / 10$ & 6.0 & 4000 & 2.85 \\
RV 110 & 10.1 & $90 / 10$ & 6.0 & -- & - \\
\hline
\end{tabular}

${ }^{a}$ PETN/Microballoons (hollow glass spheres).

${ }^{b}$ PETN/Microspheres (hollow plastic spheres).

Expansion from $226.5 \mathrm{~cm}^{3}$ to $635 \mathrm{~cm}^{3}\left(410 \mathrm{~cm}^{3}\right.$ expansion equals cover gas volume). 


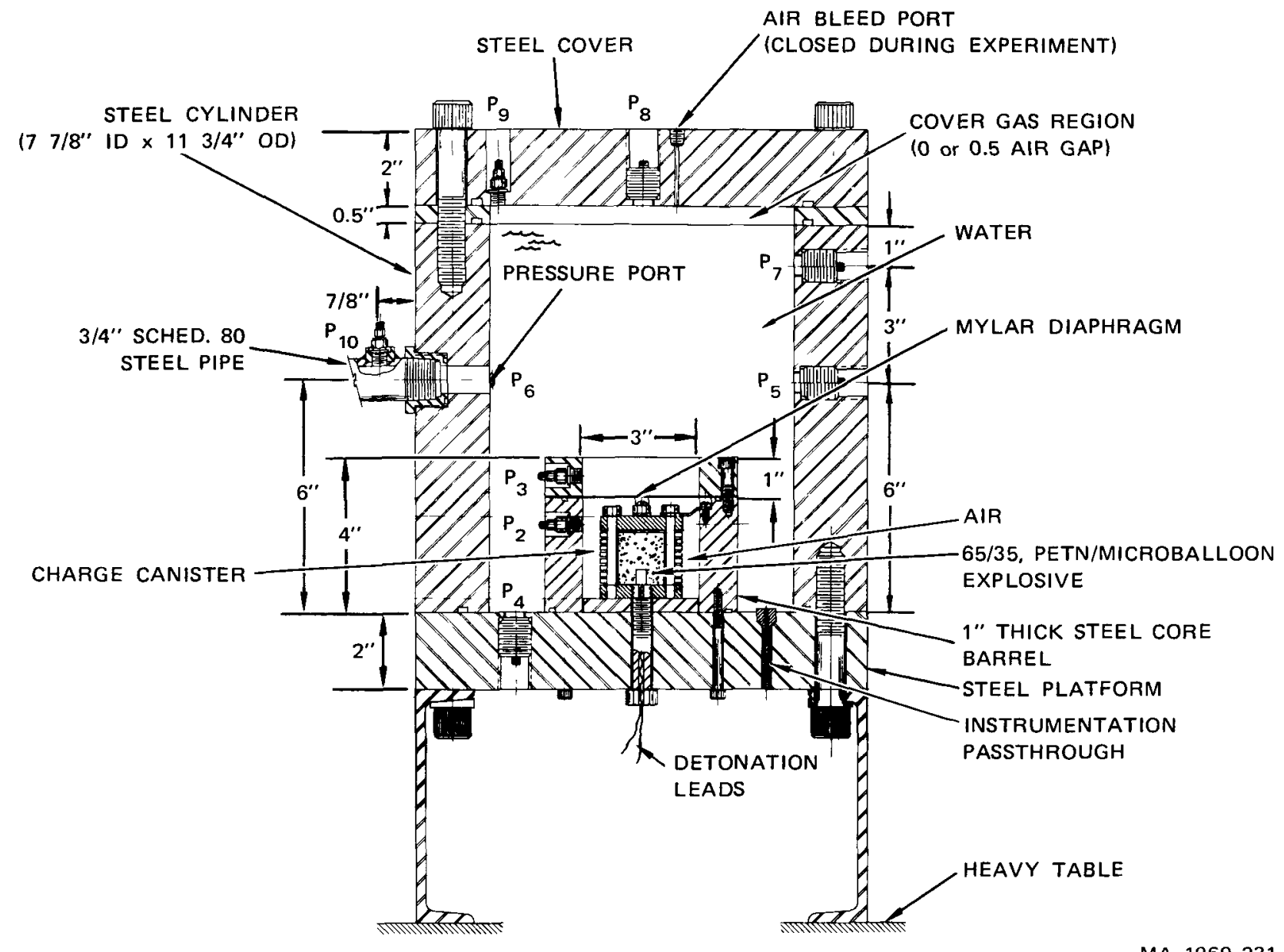

FIGURE 4 RIGID VESSEL WITH INSTRUMENTATION

Table 2

RIGID VESSEL EXPERIMENTS

\begin{tabular}{|c|c|c|c|c|c|c|}
\hline $\begin{array}{c}\text { Experiment } \\
\text { Number }\end{array}$ & $\begin{array}{l}\text { I.D. } \\
\text { (in.) }\end{array}$ & $\begin{array}{c}\text { Length } \\
\text { (in.) }\end{array}$ & $\begin{array}{c}\text { Charge Mass } \\
\text { (g) }\end{array}$ & $\begin{array}{c}\text { Mixture } \\
\text { (by weight) }\end{array}$ & $\begin{array}{c}\text { Cover Gas } \\
\text { Gap } \\
\text { (in.) }\end{array}$ & $\begin{array}{c}\text { Peak Core } \\
\text { Pressure } \\
\text { (psi) }\end{array}$ \\
\hline RV 111 & 7.875 & 10.5 & 8.0 & $65 / 35$ & 0.5 & 3650 \\
RV 112 & 7.875 & 10.5 & 8.0 & $65 / 35$ & 0.5 & 3650 \\
RV 113 & 7.875 & 10.5 & 8.0 & $65 / 35$ & 0.5 & 3900 \\
RV 114 & 7.875 & 10.5 & 8.0 & $65 / 35$ & 0.0 & 3600 \\
\hline
\end{tabular}

$*$

PETN/Microballoons. 


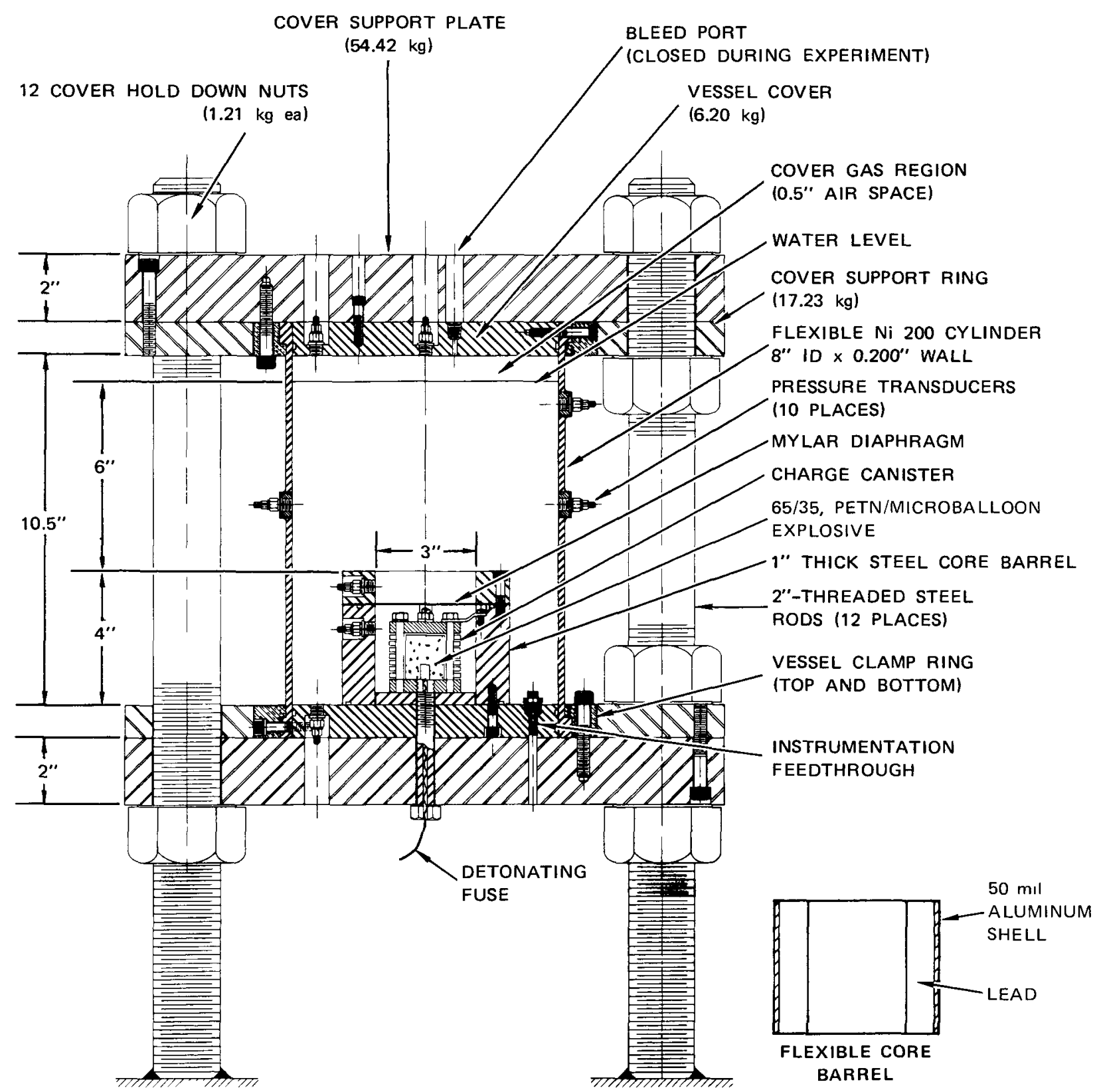

MA-1960-232

FIGURE 5 FLEXIBLE VESSEL ASSEMBLY 
and the second experiment with a flexible core barrel consisting of a 0.950-inch-thick lead barrel press-fitted into a 0.050-inch-thick aluminum 6061-T6 cylinder. Table 3 lists the specifications of the experiments.

The stress-strain relationships for the $\mathrm{Ni} 200$ material of the vessel wall were measured for each vessel (see Appendix C). The stressstrain relationships for the lead and aluminum used in the flexible core barrel were obtained from handbooks and are also given in Appendix $C$.

The instrumentation used in the experiments consisted of the following:

- Pressure transducers in the vessel platform, walls, and cover at the same locations as those in the rigid vessel.

- Pressure transducers in the rigid core barrel and strain gages on the aluminum cylinder of the flexible core barrel.

- Circumferential and axial strain gages on the outside of the vessel wall.

- Linear potentiometers for displacements on the vessel cover.

A detailed description of the vessel and its instrumentation is given in Appendix $D$.

Table 3

FLEXIBLE VESSEL EXPERIMENTS

\begin{tabular}{|c|c|c|c|c|c|c|c|}
\hline $\begin{array}{c}\text { Experiment } \\
\text { Number }\end{array}$ & $\begin{array}{c}\text { I.D. } \\
\text { (in.) }\end{array}$ & $\begin{array}{c}\text { Wal1 } \\
\text { Thickness } \\
\text { (in.) }\end{array}$ & $\begin{array}{c}\text { Length } \\
\text { (in.) }\end{array}$ & $\begin{array}{c}\text { Charge } \\
\text { Mass } \\
\text { (g) }\end{array}$ & $\begin{array}{c}\text { Mixture } \\
\text { (by weight) }\end{array}$ & Core Barrel & $\begin{array}{c}\text { Peak Core } \\
\text { Pressure } \\
\text { (psi) }\end{array}$ \\
\hline FV 101 & 8.0 & 0.2 & 10.5 & 8.0 & $65 / 35$ & Rigid & 3750 \\
FV 102 & 8.0 & 0.2 & 10.5 & 8.0 & $65 / 35$ & Flexible & - \\
\hline
\end{tabular}

${ }^{*}$ PETN/Microballoons. 


\section{I RESULTS}

This section presents the overall results from the energy source calibration experiments, the rigid vessel experiments, and the flexible vessel experiments. Tabulations and plots of the results discussed here appear in Appendices A, B, and D. The reduced data from all experiments listed in Tables 1,2 , and 3 were sent to Argonne National Laboratory.

\section{A. Energy Source Characteristics}

Figure 6 shows the pressure- and gas work-volume change relationships for the energy source used in the rigid and flexible vessels. The average $\mathrm{P}-\Delta \mathrm{V}$ relationship shows that the peak pressure in the lower core $\left(226.5 \mathrm{~cm}^{3}\right)$ is about 255 bars ( $3700 \mathrm{psi})$ and that the pressure decreases to about 25 bars (360 psi) as the detonation products expand to $\Delta V=410 \mathrm{~cm}^{3}$, the cover gas volume. The gas work expended by the detonation products expanding out of the core and displacing the water pool into the cover gas region increases from zero to about $2.87 \mathrm{~kW}-\mathrm{sec},{ }^{*}$ which corresponds to $77.5 \mathrm{MW}-\mathrm{sec}$ in full-scale.

The gas work-time relationship for the detonation products (Figure 7) shows that the pool displaces the cover gas volume in about $0.75 \mathrm{msec}$, which corresponds to $25 \mathrm{msec}$ in full-scale. Neglecting compression of the cover gas volume, this time is the time of slug impact on the vessel cover. From the surface displacement measurements the velocity of the slug at impact is $108 \mathrm{ft} / \mathrm{sec}$. The kinetic energy of the slug at impact equals the gas work expended by the detonation products at slug impact, $2.87 \mathrm{~kW}-\mathrm{sec}$.

\section{B. Pressure Loadings in the Rigid Vessel}

From three identical experiments (RV 111, 112, and 113), Figure 8 shows the pressures in the core, and on the platform, vessel wall, pipe, and cover and demonstrates the excellent experimental reproducibility $( \pm 10 \%)$.

${ }^{*}{ }_{1 \mathrm{~kW}-\mathrm{sec}}=10^{3}$ joules $=10^{4}$ bar $-\mathrm{cm}^{3}$. 


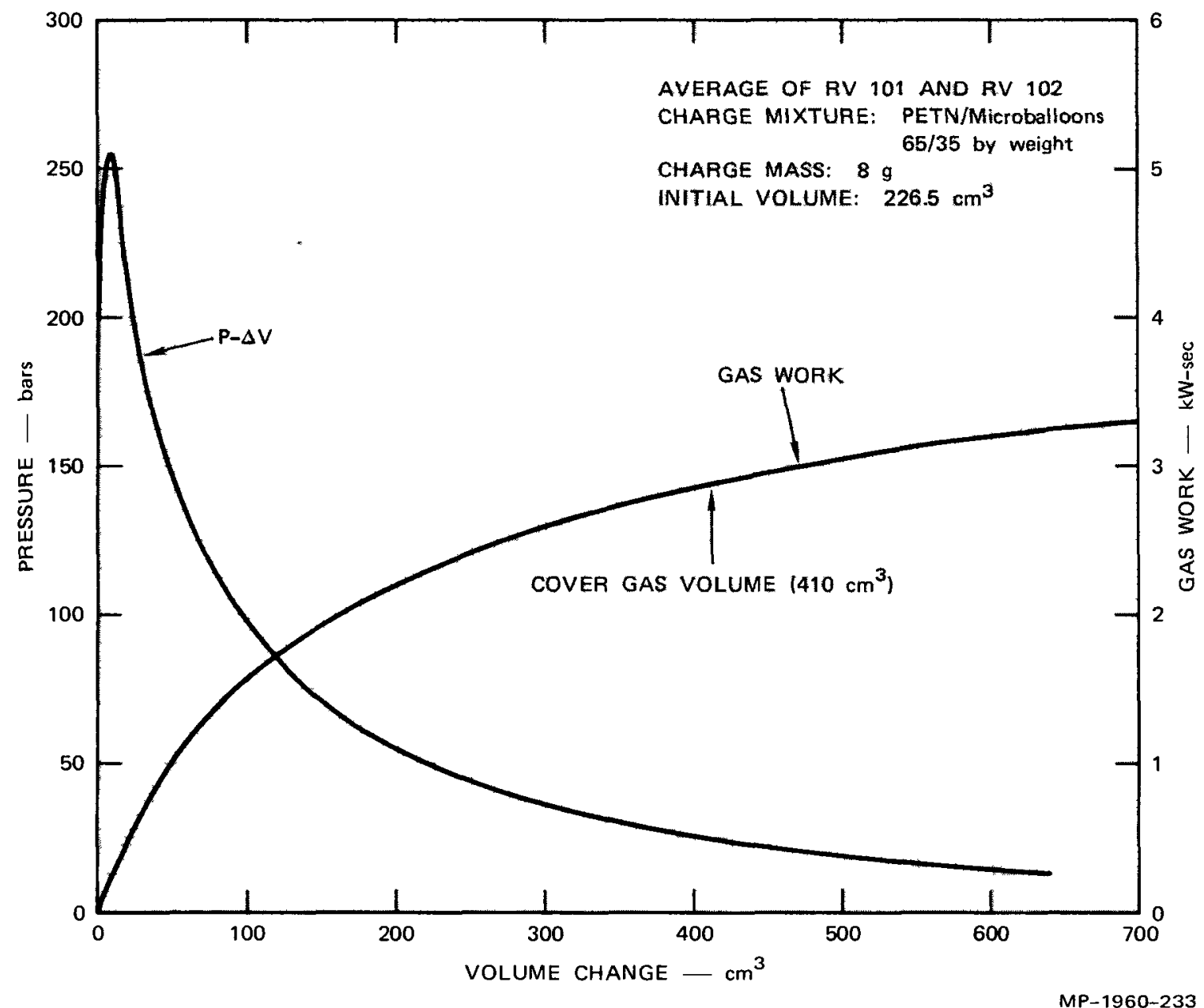

FIGURE 6 PRESSURE- AND GAS WORK-VOLUME CHANGE RELATIONSHIPS FOR ENERGY SOURCE 


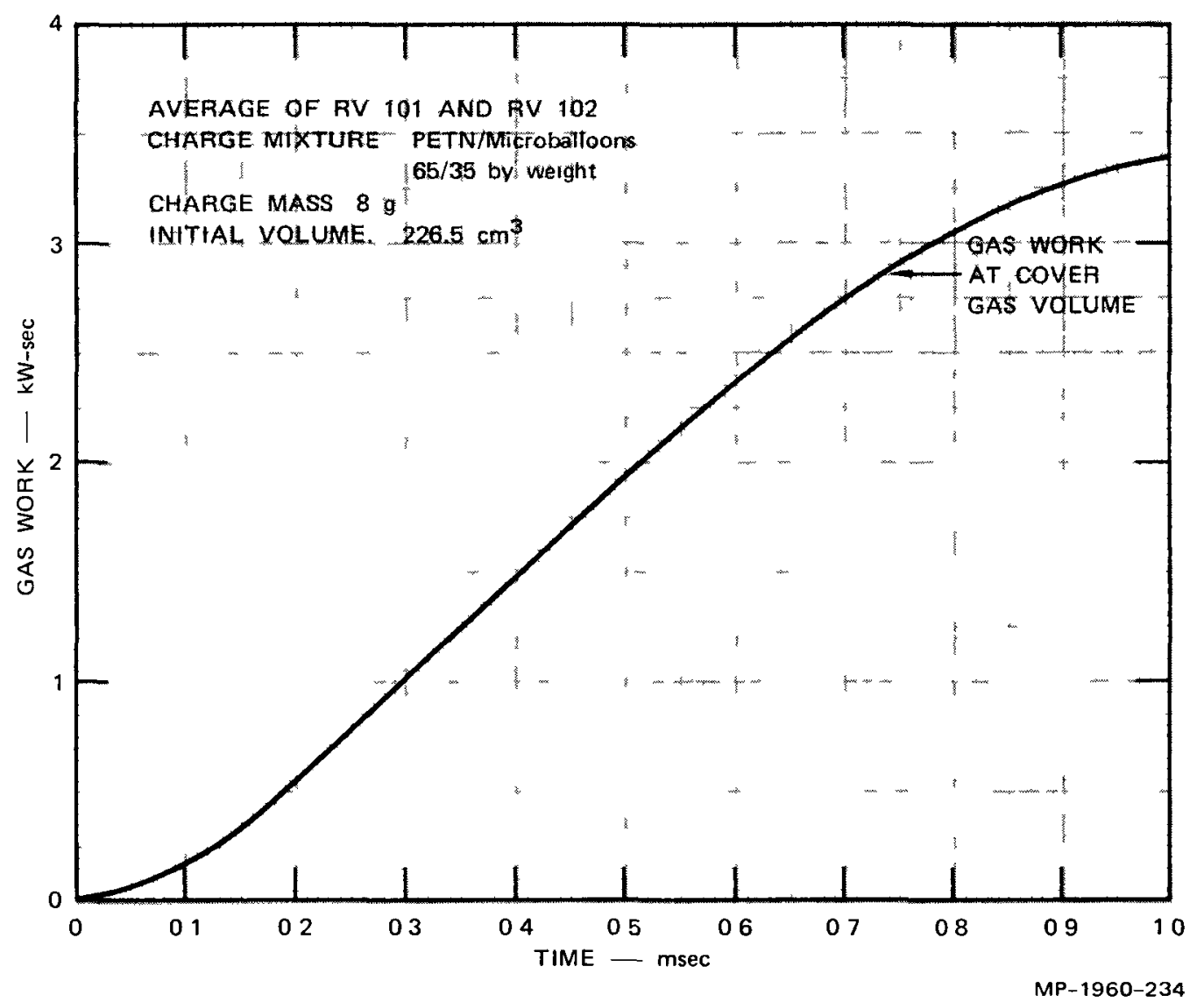

FIGURE 7 GAS WORK-TIME RELATIONSHIP FOR ENERGY SOURCE 

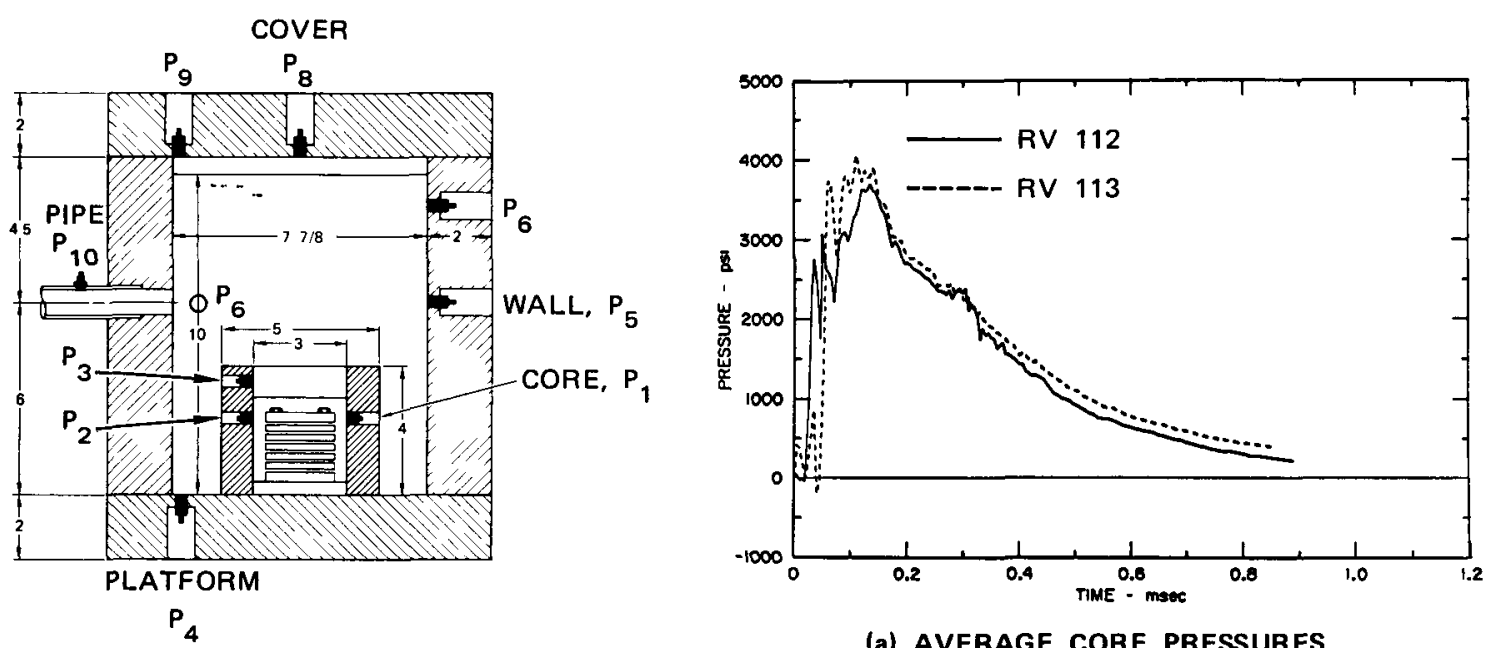

(a) AVerage core pressures

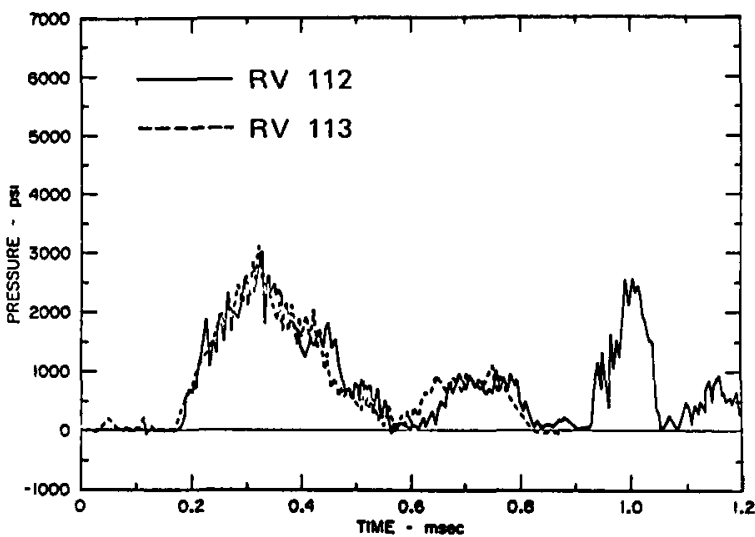

(b) PLATFORM PRESSURE $\left(\mathbf{P}_{4}\right)$

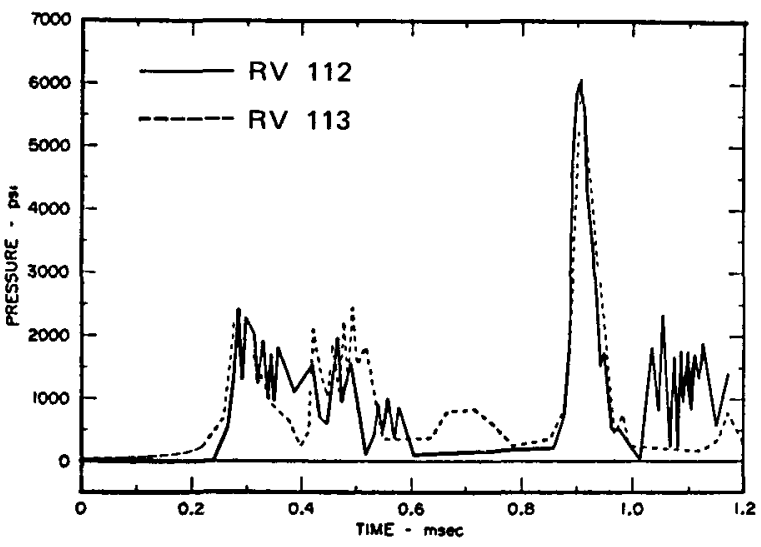

(d) PIPE PRESSURE $\left(\mathrm{P}_{10}\right)$

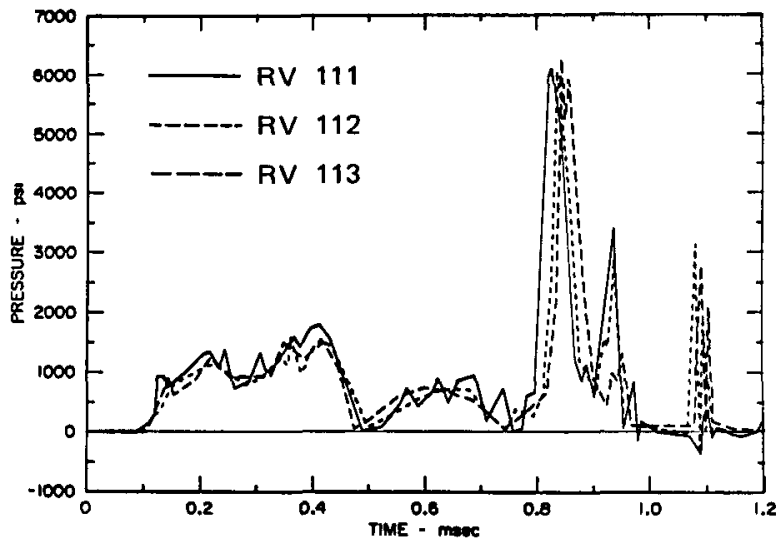

(c) WALL PRESSURE $\left(\mathbf{P}_{\mathbf{5}}\right)$

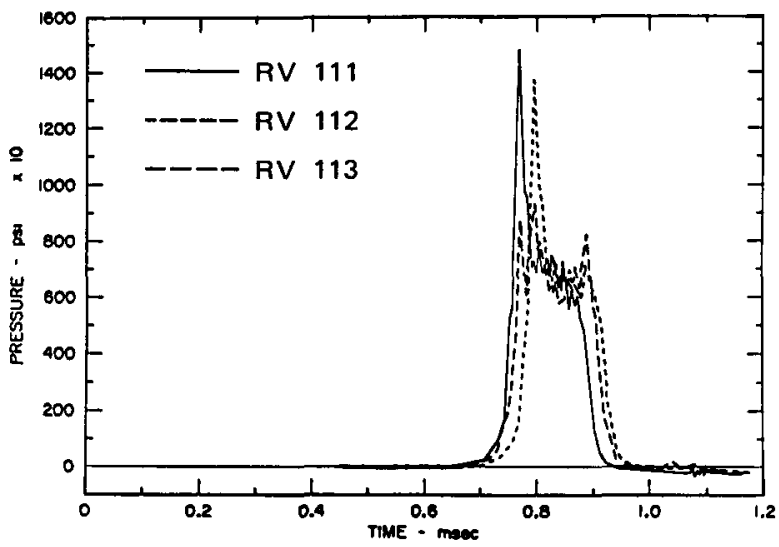

(e) COVER PRESSURE (CENTER) $\left(\mathbf{P}_{\mathbf{8}}\right)$

MA-1960-235

FIGURE 8 LOADING PRESSURES IN RIGID VESSEL WITH COVER GAS VOLUME 
The pressure in the core, Figure $8(a)$, increases to 3700 psi about $125 \mu \mathrm{sec}$ after detonation of the charge and decreases to about 360 psi in about $0.82 \mathrm{msec}$ as the detonation products expand against the water and accelerate it upward into the cover.

The pressure on the platform, Figure $8(\mathrm{~b})$, begins at about $t=0.18 \mathrm{msec}$, the time for pressure waves propagating at $4915 \mathrm{ft} / \mathrm{sec}^{*}$ through the water to reach the platform. The loading reaches a peak of about 3000 psi at $t=0.3 \mathrm{msec}$ and then decreases to zero at about $t=0.55 \mathrm{msec}$ as expansion waves reflected from the water surface arrive at the platform. At $t=1.0 \mathrm{msec}$ the pressure wave caused by slug impact on the cover and propagating at $4810 \mathrm{ft} / \mathrm{sec}^{\dagger}$ reaches the platform and increases the platform pressure from zero to about 2600 psi.

The pressure on the vessel wal1, Figure $8(\mathrm{c})$, six inches above the platform begins to increase to about $1500 \mathrm{psi}$ at $\mathrm{t}=0.1 \mathrm{msec}$. As expansion waves from the water surface propagate past the gage and reflect from the platform and again pass by the gage, the wall pressure decreases to zero at $t=0.4 \mathrm{msec}$. At $t=0.85 \mathrm{msec}$ the pressure wave caused by slug impact on the cover reaches the wall gage and increases the pressure there to about $6000 \mathrm{psi}$. The pressure then decreases as expansion waves from the bubble surface reach the wall. At $t=1.1 \mathrm{msec}$ the impact pressure wave reflected from the platform reaches the pressure gage and increases the pressure to 2500 psi.

The pressure in the pipe, Figure $8(d)$, connected to the vessel six inches above the platform is the same as the pressure on the wall directly across from the pipe, Figure $8(\mathrm{c})$ (peak pressure $=6000$ psi). This clearly demonstrates that the pressure pulse transmitted into an inlet or outlet pipe attached to the vessel wall is equal to the pressure pulse measured at a similar location on the wall where there is no pipe.

\footnotetext{
For water at $25^{\circ} \mathrm{C}$ with a bulk modulus of $325,000 \mathrm{psi}$.

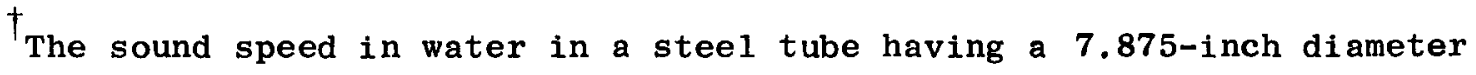
and a $1.94-$ inch wall.
} 
The pressure on the vessel cover is zero until $t=0.75 \mathrm{msec}$ when the slug accelerated to $108 \mathrm{ft} / \mathrm{sec}$ impacts the cover. The pressure increases to about 14,000 psi as the air in the cover gas region is compressed and the slug impacts the cover. The pressure drops sharply to about $7000 \mathrm{psi}$ and remains at this pressure until the impact pressure wave travels from the cover to the gas bubble where it is reflected as an expansion wave and returns to the cover, decreasing the cover pressure to zero at $t=0.95 \mathrm{msec}$. The impact pressure corresponding to a water slug impacting a rigid wall at $108 \mathrm{ft} / \mathrm{sec}$ is $p=\rho c u=1.92$ slugs $\times 4915$ $\mathrm{ft} / \mathrm{sec} \times 108 \mathrm{ft} / \mathrm{sec}, p=1.02 \times 10^{6} \mathrm{lb} / \mathrm{ft}^{2}=7080 \mathrm{psi}$. This is in excellent agreement with the measured impact pressure.

The effects of cover gas on the pressure in a thick-walled vessel are shown in Figure 9 by comparing the pressures in a vessel with a $410-\mathrm{cm}^{3}$ cover gas volume (0.5-inch air gap) with pressures in a vessel without a cover gas volume. The loading pressures in the core, Figure 9(a), are identical until about $t=0.35 \mathrm{msec}$ when the pressure in the vessel with a cover gas volume (and hence with a free surface) decreases more rapidly than the core pressure in the vessel without cover gas. This difference occurs because in a vessel with cover gas the detonation products can expand by an amount equal to the cover gas volume, $410 \mathrm{~cm}^{3}$, whereas in the vessel without cover gas the detonation products can expand only against the water, compressing it by about $71 \mathrm{~cm}^{3}$.

The pressure on the vessel platform, Figure $9(\mathrm{~b})$, is greater in the vessel without cover gas ( $4500 \mathrm{psi}$ ) than in the vessel with cover gas (3000 psi), because there is no free surface from which the pressure waves generated in the core can reflect as expansion waves that decrease the platform pressure. Instead, the pressure waves reflect as pressure waves from the cover and return to the platform, increasing the platform loading and its duration and resulting in a higher impulse on the platform. Note also that the loading caused by the reflected impact pressure wave is less than the maximum platform pressure in the vessel without cover gas. 

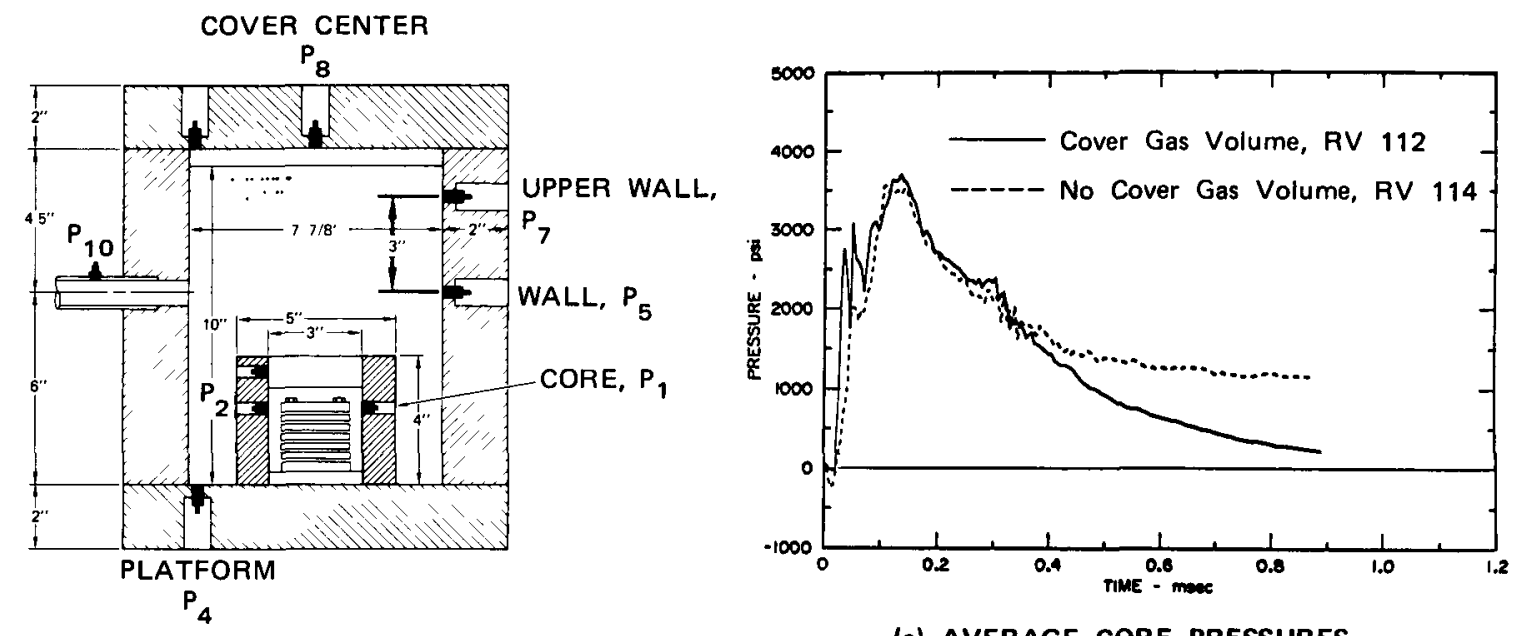

(a) AVerage core PRessures

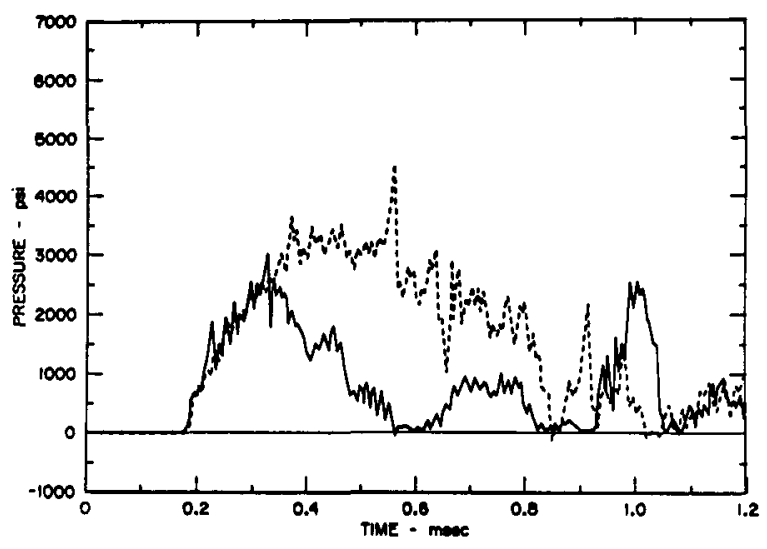

(b) PLATFORM PRESSURE $\left(P_{4}\right)$

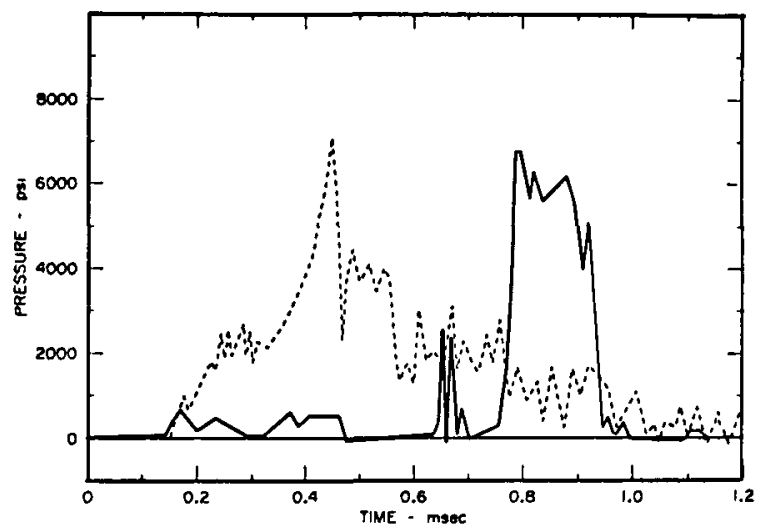

(d) UPPER WALL PRESSURE $\left(P_{\mathbf{7}}\right)$

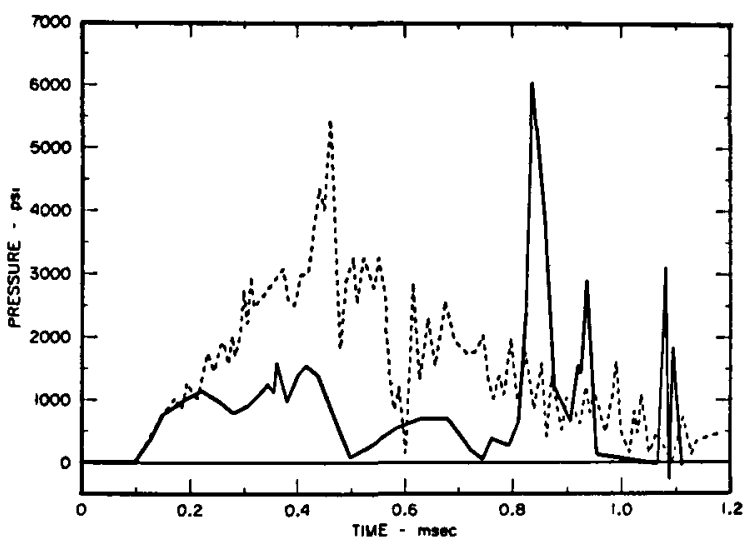

(c) WALL PRESSURE $\left(\mathbf{P}_{5}\right)$

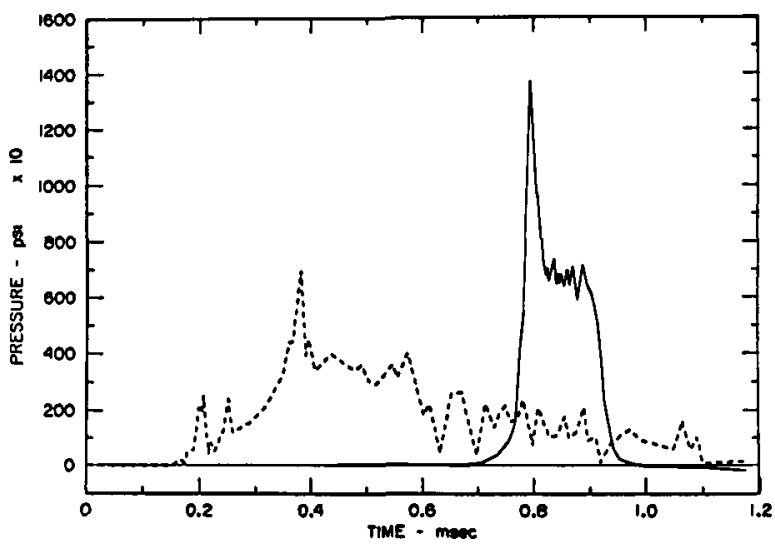

(e) COVER PRESSURE (CENTER) $\left(P_{8}\right)$

MA-1960-236

FIGURE 9 EFFECT OF COVER GAS VOLUME ON LOADING PRESSURES IN RIGID VESSEL 
Although the shapes are different, the peak pressures on the vessel wall at 6 and 9 inches above the platform, Figure $9(\mathrm{c})$ and $9(\mathrm{~d})$, are about 6000 and $7000 \mathrm{psi}$, respectively, in both vesse1s.

The cover loading begins much earlier in the vessel without cover gas $(t=0.18 \mathrm{msec})$ than in the vessel with cover gas $(t=0.75 \mathrm{msec})$ because the loading is transmitted directly from the core through the water and not by compression of the cover gas and impact of the slug on the cover. In the vessel with cover gas the initial peak load is much greater because of gas compression. Shortly after slug impact, however, the pressure on the cover decreases to about 7000 psi, about the same as the peak pressure occurring on the cover of the vessel without cover gas. The duration of cover loads, however, is greater in the vessel without cover gas than in the vessel with cover gas.

\section{Pressure Loadings and Deformations in Flexible Vessels}

1. Comparison of Pressure Loading in Rigid and Flexible Vessels Figure 10 compares the pressures in the core and on the core support platform, vessel walls, and cover of the rigid vessel (RV 112) and the flexible vessel (FV 101). The pressure in the rigid core barrel, Figure 10(a), of each vessel is the same, showing that the deforming vessel wall has no effect on these loads.

The pressure on the platform, however, is significantly higher in the rigid vessel than in the flexible vessel. The peak platform loading is about $3000 \mathrm{psi}$ in the rigid vessel and only $1500 \mathrm{psi}$ in the flexible vessel because the expansion of the flexible vessel wall relieves the pressurized water between the core and the vessel wall. Similarly, the reflected impact pressure wave reaching the platform is much lower in the flexible vessel than in the rigid vessel because the pressure wave is attenuated by the expansion of the vessel wall near the cover.

The wall pressures 6 inches above the platform, Figure 10(c), differ significantly when the impact pressure wave arrives. Then, the 

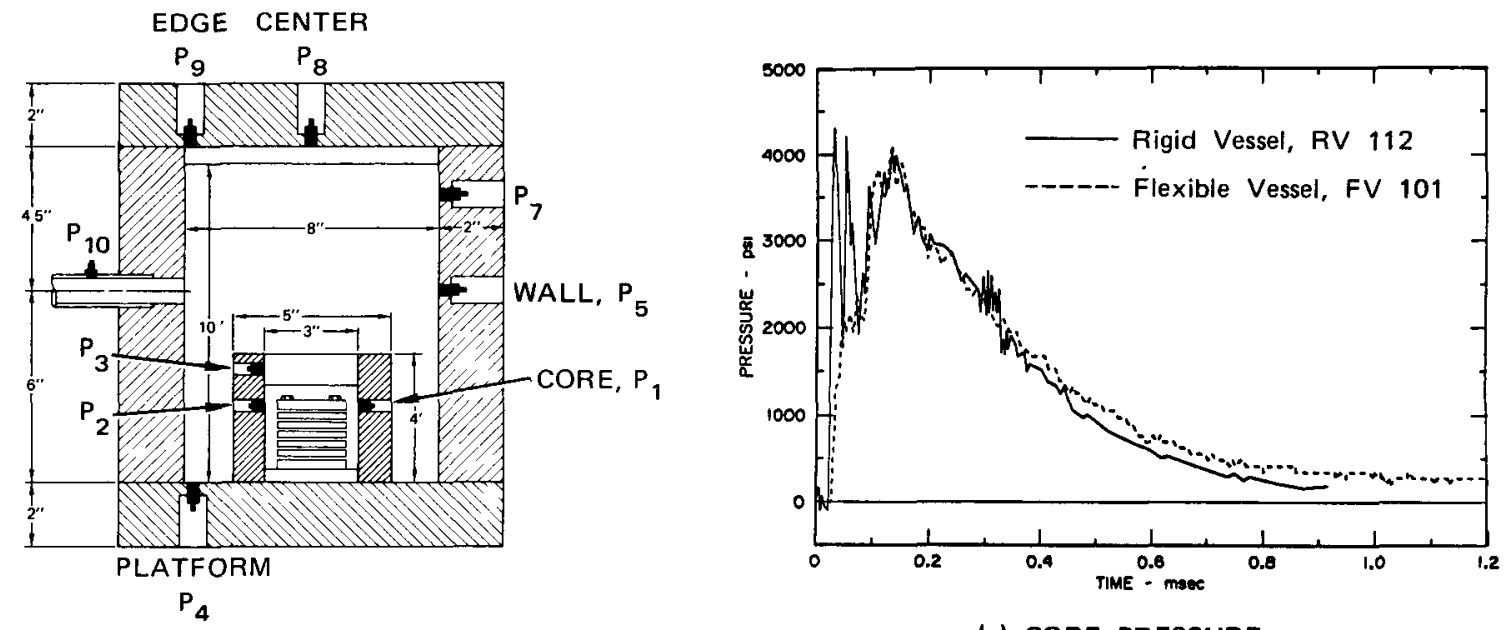

(a) CORE PRESSURE

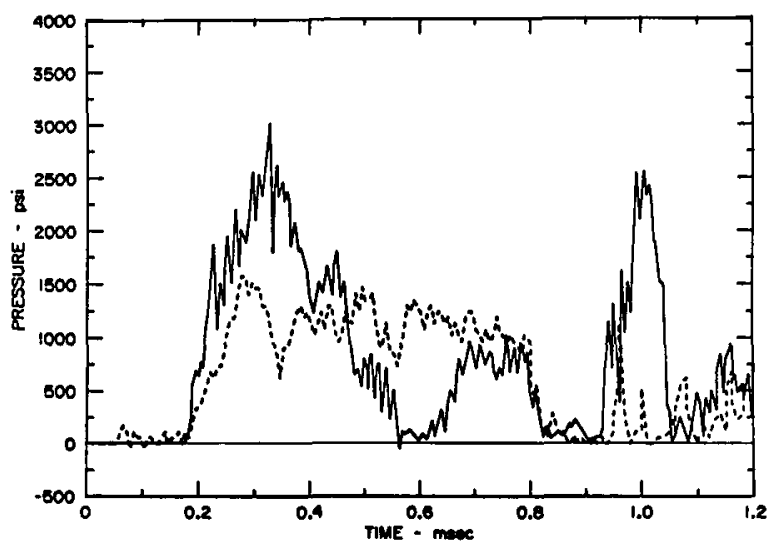

(b) PLATFORM PRESSURE $\left(\mathbf{P}_{\mathbf{4}}\right)$

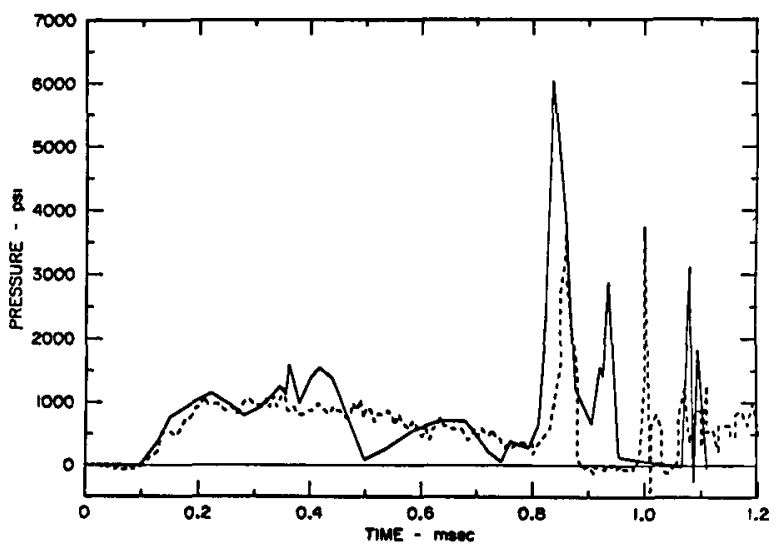

(c) WALL PRESSURE $\left(P_{5}\right)$

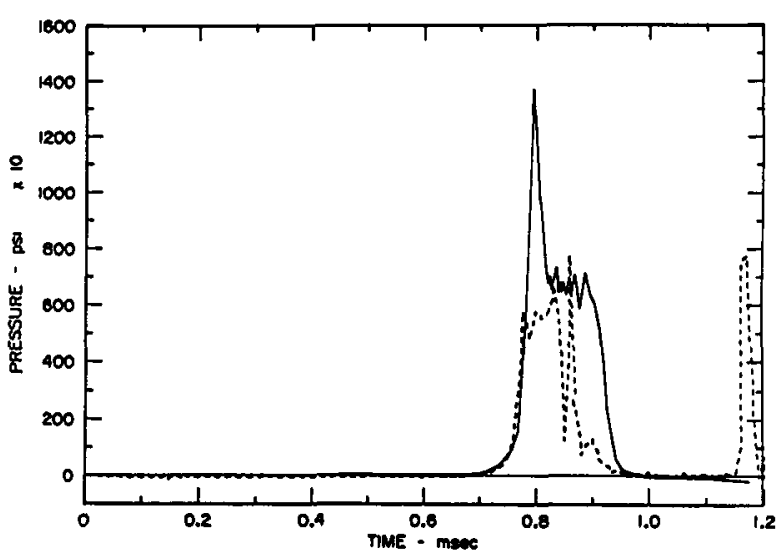

(d) COVER PRESSURE (CENTER) $\left(\mathbf{P}_{\mathbf{8}}\right)$

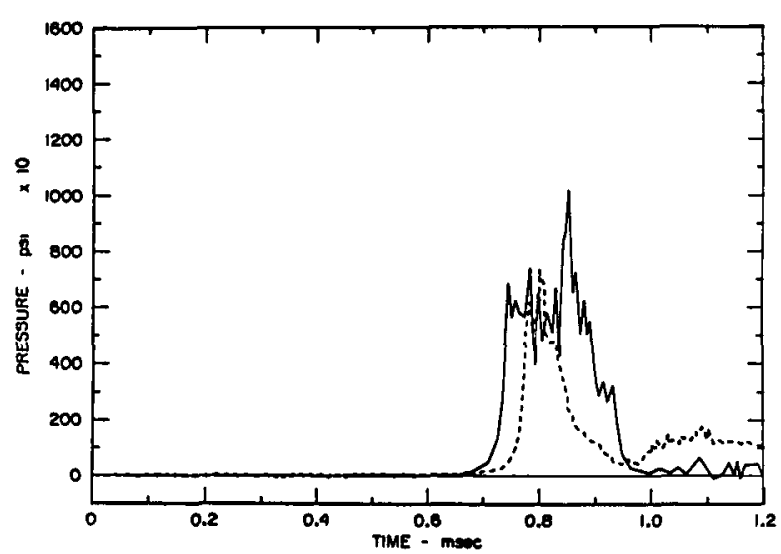

(e) COVER PRESSURE (EDGE) (P/9)

MA-1960-237

FIGURE 10

LOADING PRESSURES IN RIGID AND FLEXIBLE VESSELS WITH RIGID CORE BARRELS 
wall pressure increases to $8000 \mathrm{psi}$ in the rigid vessel and to on $1 \mathrm{y} 3500$ psi in the flexible vessel. Again, the much lower pressure in the flexible vessel is due to the attenuation of the impact pressure wave by the expanding wall between the cover and the wall location.

Except for the relatively high sharp peak that occurs in compressing the cover gas in the rigid vessel, the peak load on the cover, Figure $10(\mathrm{~d})$ and $10(\mathrm{e})$, is $7000 \mathrm{psi}$ in the rigid vessel and 6500 psi in the flexible vessel. This $7 \%$ difference means that the impact velocity of the slug differs by on $1 y 7 \%$ and that the gas work gone into plastically deforming the vessel before impact is $14 \%$ of the gas work gone into the kinetic energy of the slug. The strain energy measurements, discussed below in Section 3, show that the strain energy absorbed by the flexible vessels before slug impact is $0.44 \mathrm{~kW}-\mathrm{sec}$, about $15 \%$ of the kinetic energy of the slug at impact in the rigid vessels. The duration of the slug impact is much shorter in the flexible vessel than in the rigid vessel because the deforming wall near the cover generates expansion waves in the water and these waves relieve the impact pressure sooner than those from the gas bubble.

\section{Effects of Core Barrel Flexibility on Vessel Loading}

As shown in Figure 11, the effects of a flexible core barrel on the pressures in the flexible vessel are relatively small. The only place a significant difference occurs is on the vessel platform where the loading begins about $150 \mathrm{\mu sec}$ earlier and is slightly less than in the vessel with a rigid core. The loading occurs earlier because the platform pressure is transmitted to the platform by the expansion of the flexible core, which pressurizes the water between the core and the vessel wall before the pressure waves traveling out of the top of the core reach the platform. The magnitude of the loading is about $10 \% 1$ ess in the vessel with a flexible core because of the energy loss in expanding the core and the presence of expansion waves caused by the wall expansion. 

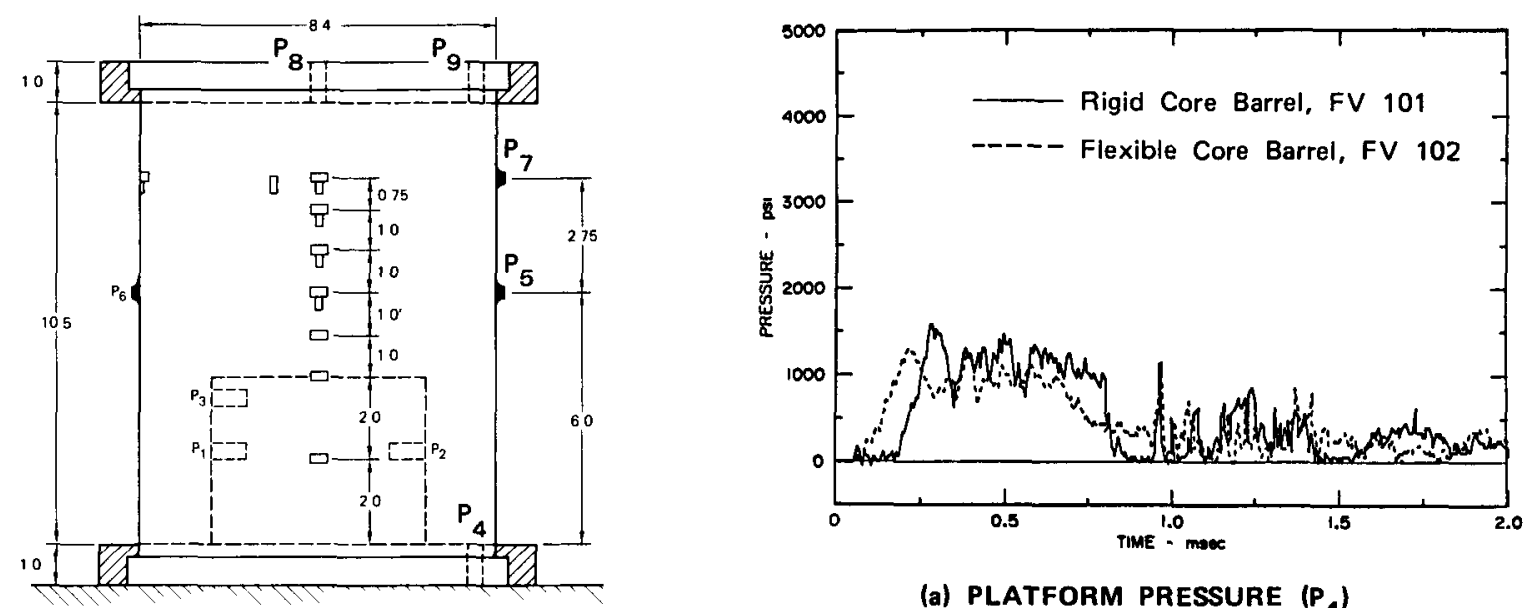

(a) PLATFORM PRESSURE $\left(P_{4}\right)$

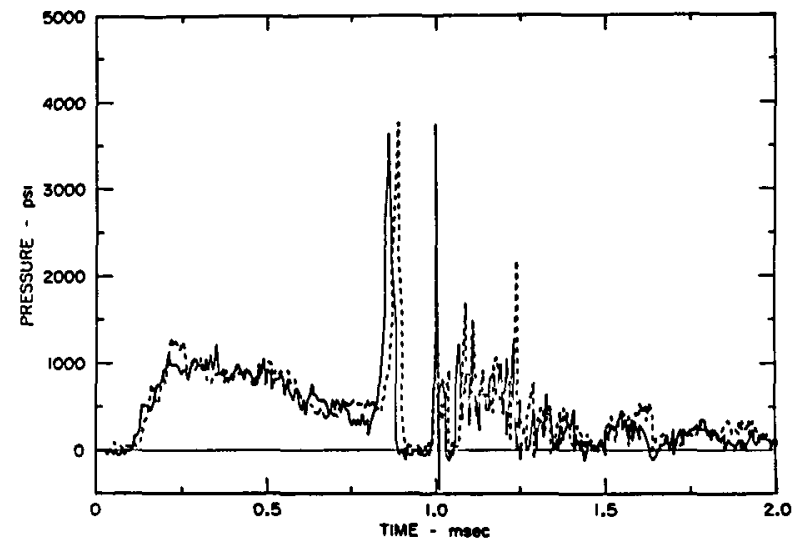

(b) WALL PRESSURE $\left(\mathbf{P}_{5}\right)$

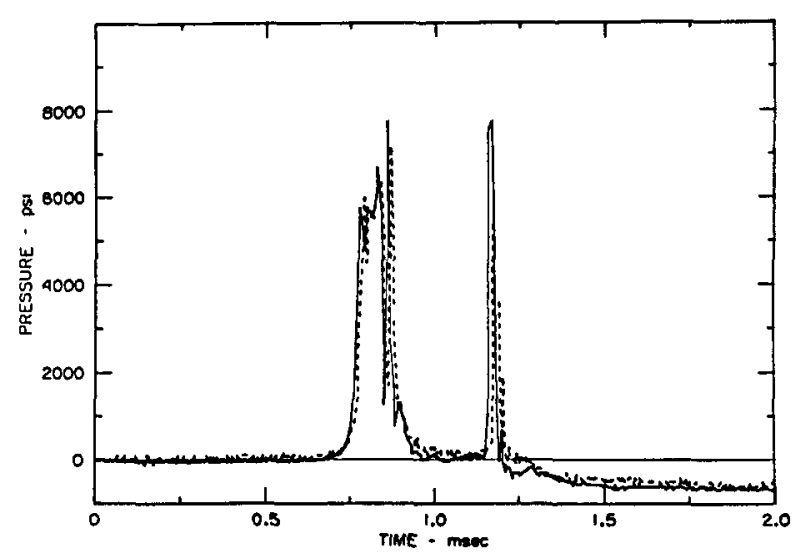

(d) COVER PRESSURE (CENTER) $\left(P_{8}\right)$

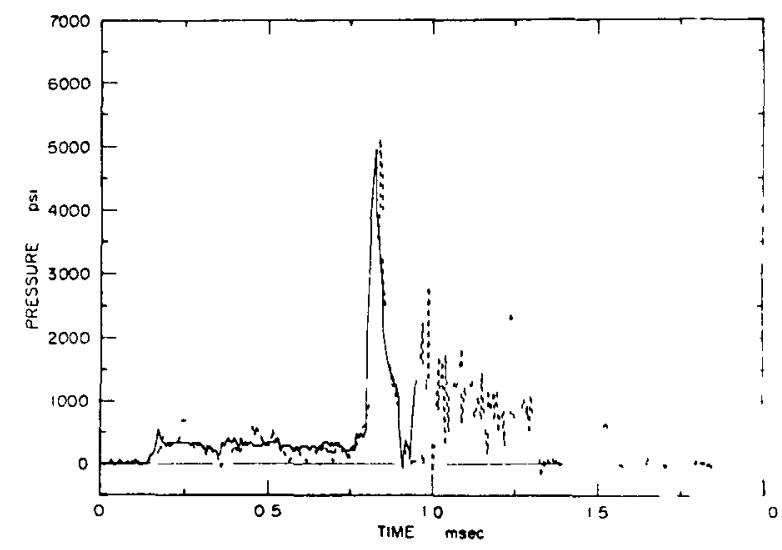

(c) UPPER WALL PRESSURE $\left(\mathbf{P}_{7}\right)$

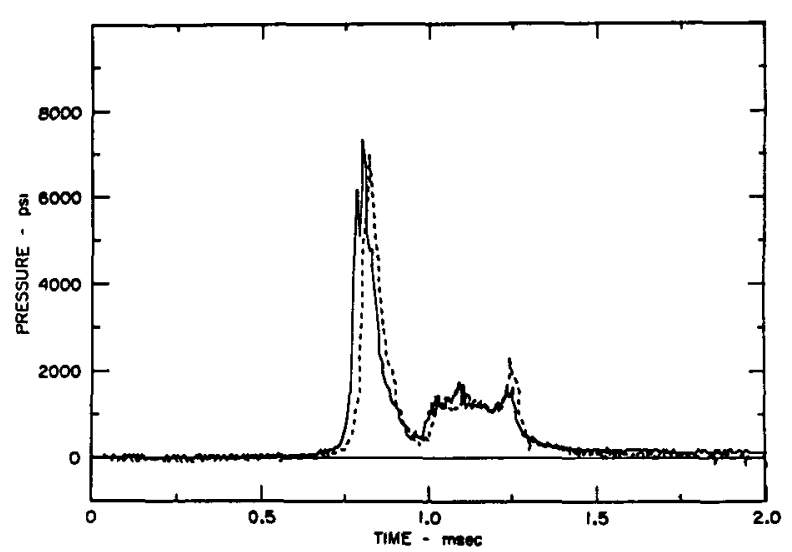

(a) COVER PRESSURe (EDGE) (Pי)

FIGURE 11 EFFECT OF CORE BARREL FLEXIBILITY ON LOADING PRESSURES IN FLEXIBLE VESSELS 


\section{Effects of Core Barrel Flexibility on Vessel Strain and Deformation}

As shown in Figure 12, core barrel flexibility affects the wall strains only near the core barrel. The strain histories in the upper half of the vessels, Figures $12(a),(b)$, and (c), are about the same in shape and magnitude, whereas the strain histories in the lower half of the vessels, Figure $12(\mathrm{~d})$ and (e), show two distinct response phases--the first before slug impact and the second after slug impact. Before slug impact the vessel walls respond to the loads transmitted through the water by the expansion of the core barrel and by the high-pressure detonation products accelerating the water upward. After slug impact the vessel walls respond to the slug impact pressure wave in the water. As the impact pressure wave moves down the vessel, it expands the vessel walls and attenuates. The attenuating pressure wave causes the decreasing magnitude of strains recorded in strain records 1,2 , and 3 located 3.4 , 4.5 , and 5.5 inches from the cover.

The effect of the flexible core barrel on the strain in the lower half of the vessel is shown in Figures $12(d)$ and (e). At location 4 , which is 4 inches above the platform at the level of the top of the core, the wall strain in the vessel with a flexible core is about $10 \%$ less than in the vessel with a rigid core. At location 5 (2 inches above the vessel platform), the difference in vessel response is greater; the maximum strain in the vessel with a flexible core is about half of that in the vessel with a rigid core. Although these results were not expected, they are in line with the comparison of vessel loadings discussed earlier. The effect of core barrel flexibility is shown in a different way in Figure 13 by comparing the vessel deformation profiles before slug impact, after slug impact, and the posttest profiles of the vessel. Before slug impact $(t=0.75 \mathrm{msec})$ deformations occur mainly in the vicinity of the core barrel and are about twice as large in the vessel 

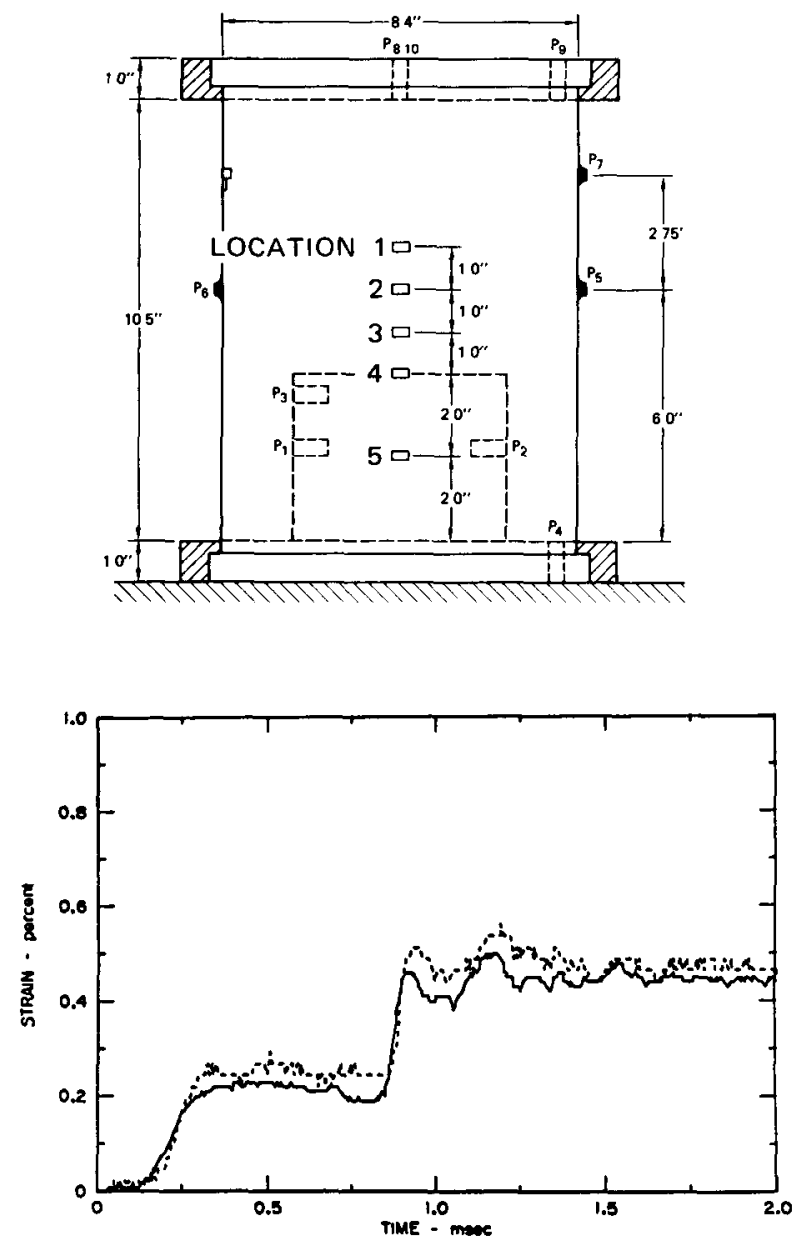

(b) LOCATION 2

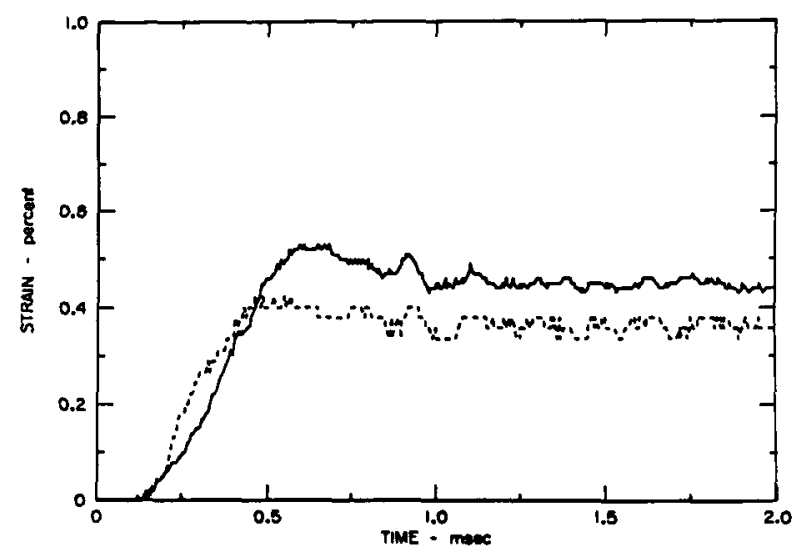

(d) LOCATION 4

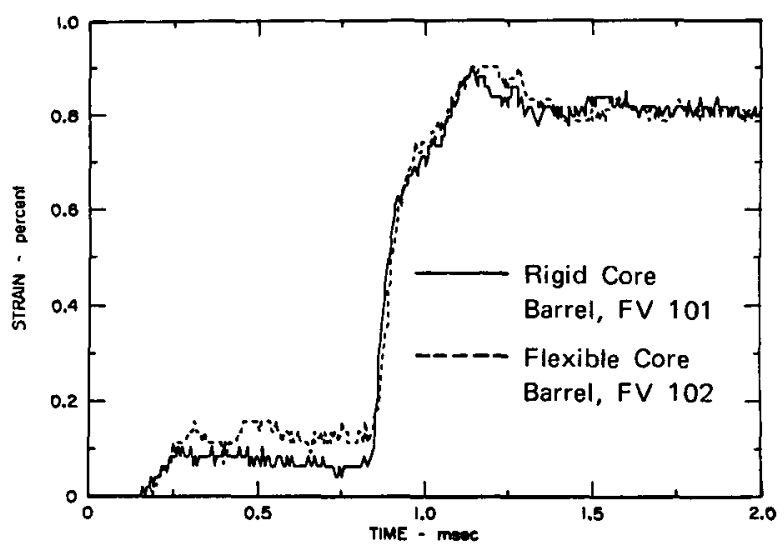

(a) LOCATION 1

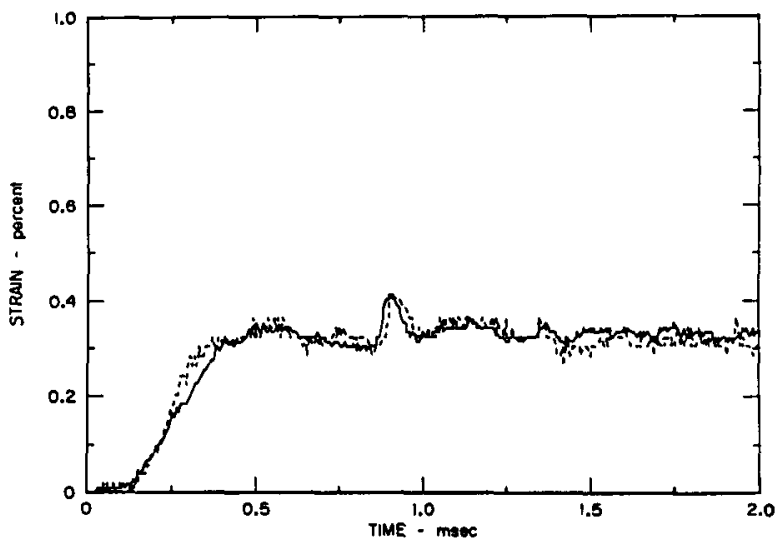

(c) LOCATION 3

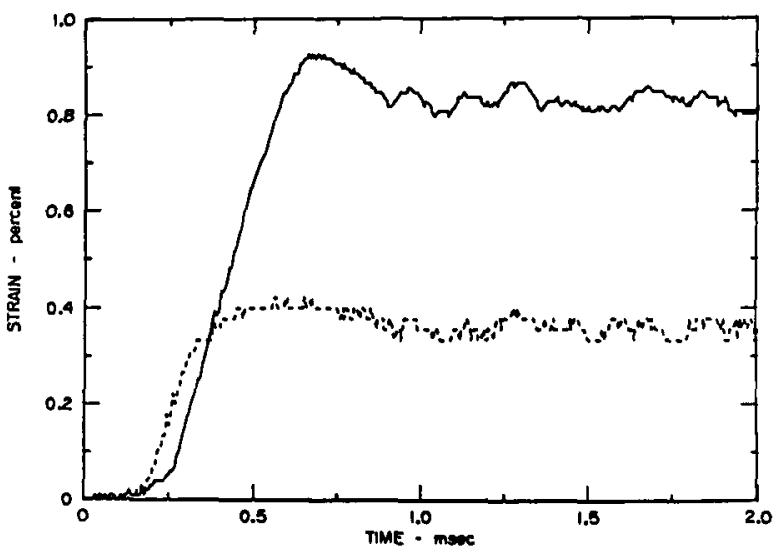

(e) LOCATION 5

FIGURE 12 EFFECT OF CORE BARREL FLEXIBILITY ON STRAIN-TIME RESPONSE OF FLEXIBLE VESSELS 


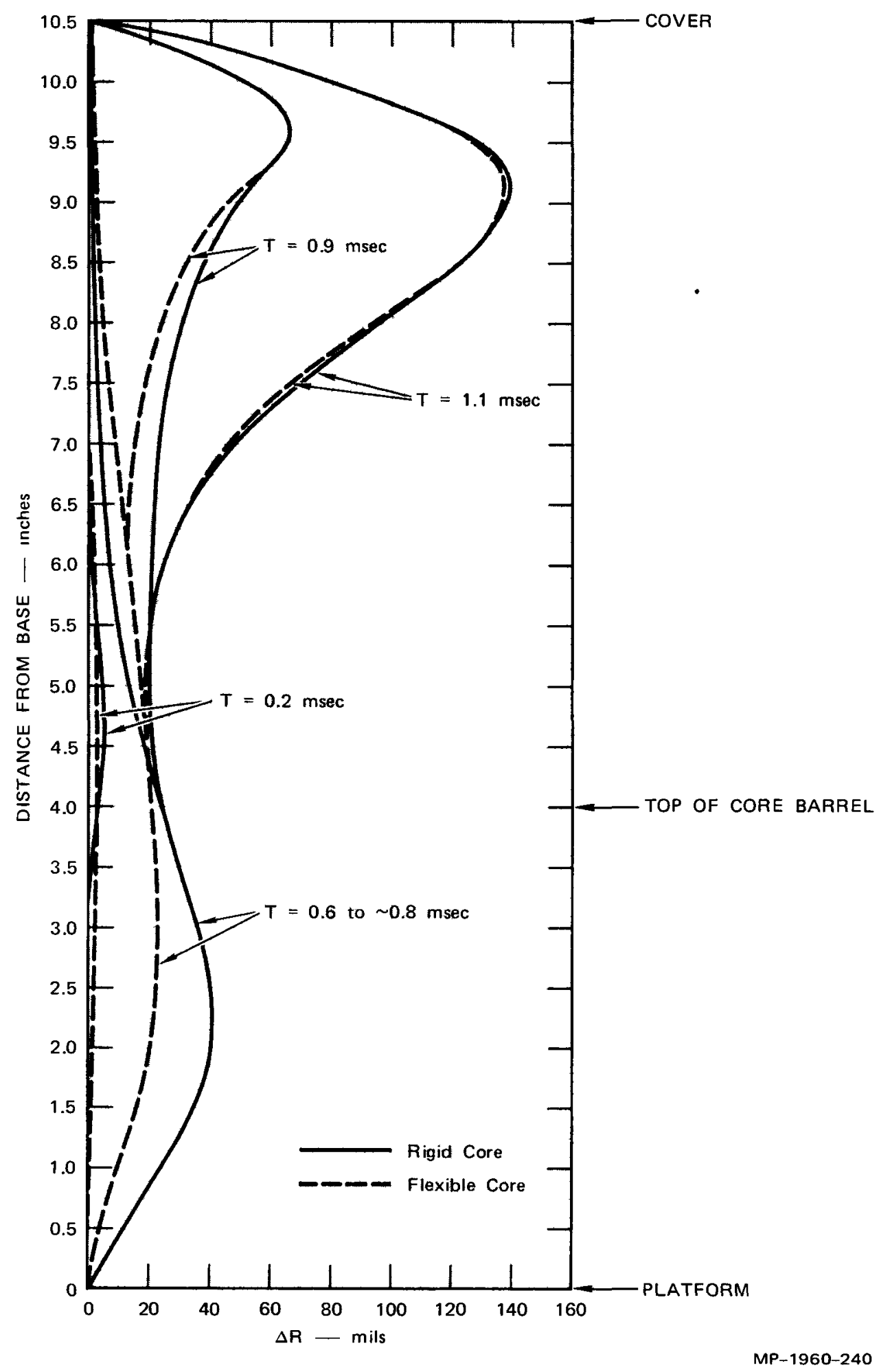

FIGURE 13 EFFECT OF CORE BARREL FLEXIBILITY ON DEFORMATION-TIME PROFILES OF FLEXIBLE VESSELS 
with a rigid core barrel than in the vessel with a flexible core barrel. In the upper half of the vessel, the wall deformations are relatively small until after slug impact. Then they increase to a peak of about 140 mils ( $3.5 \%$ strain) at 1.25 inches below the cover with the deformations in both vessels the same. The deformations are the same in both vessels because the impact velocities in both vessels have been affected little by the differences in vessel strain energies absorbed before slug impact $(0.44 \mathrm{~kW}-\mathrm{sec}$ with the rigid core barrel and $0.45 \mathrm{~kW}-\mathrm{sec}$ with the flexible core barrel).

The strain energy of both vessel and of the flexible core barrel as functions of time are shown in Figure 14 and tabulated in Table 4. Before slug impact the strain energy in the vessel with a rigid core barrel equals the strain energy in the vessel with a flexible core barrel. Therefore, the kinetic energy and thus the impact velocity of the slug in each vessel is the same. This results in the impact pressures on the cover being equal as shown in Figure 12 and in the final deformations near the cover being equal as shown in Figure 13. 


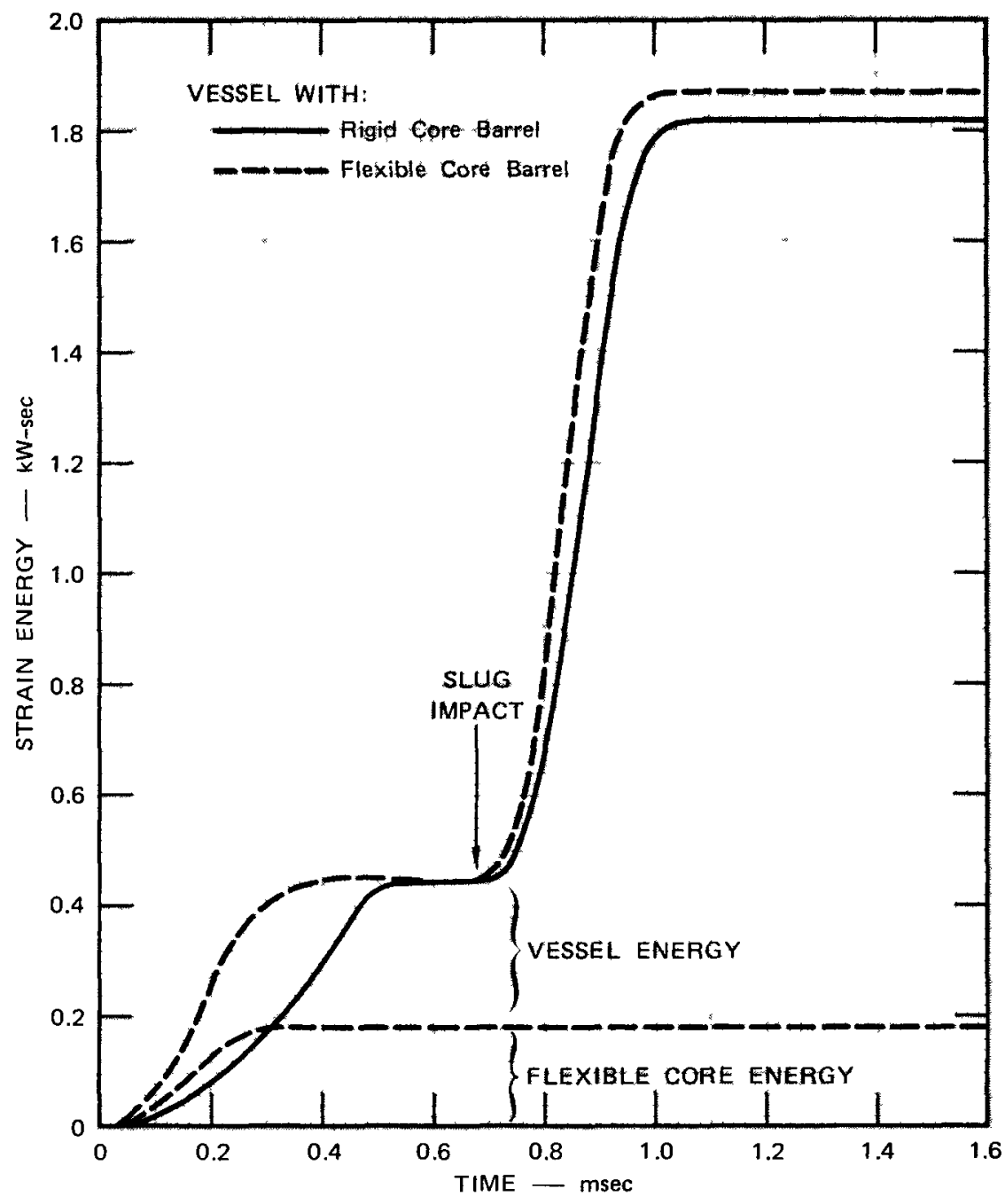

FIGURE 14 EFFECT OF CORE BARREL FLEXIBILITY ON STRAIN ENERGY ABSORBED DURING FLEXIBLE VESSEL EXPERIMENTS 
Table 4

ENERGY PARTITIONING IN FLEXIBLE VESSEL EXPERIMENTS

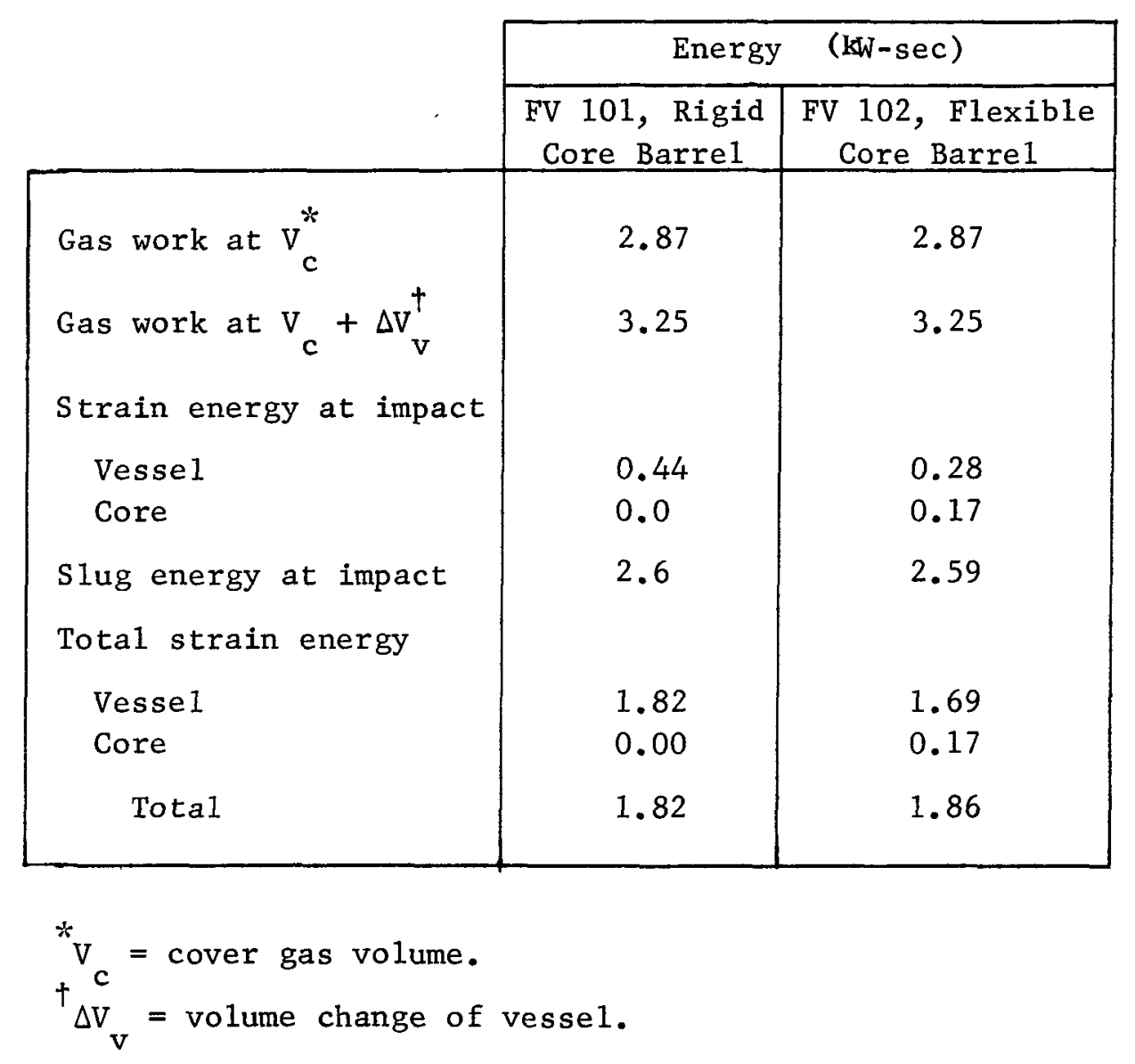


Appendix A

DETAILS OF THE ENERGY SOURCE CALIBRATION

\section{Apparatus}

\section{Rigid Vesse1}

The apparatus shown in Figure A.l was used to calibrate the energy source for the rigid and flexible vessel experiments. This rigid vessel consists of a thick steel vessel $\left(E=3 \times 10^{7}\right.$ psi), a thick steel platform, a thick steel core barrel, and a light ladder setup. The vessel has an inside diameter of 7.875 inches, is 10 inches long, and has a 2-inch-thick wa11. The vessel is bolted to a 2 -inch-thick steel platform, which is supported by four steel channel members, which in $t$ urn are welded to a massive steel table. The rigid core barrel (inside diameter of 3 inches, 1-inch-thick wall, and 4-inches long) is bolted to the platform at the center of the vessel. A Mylar diaphragm is clamped to the core barrel 3 inches above the base to prevent water from intruding into the initial air space volume of the energy source. Pressure gages a re located in the core barrel near the energy source and in the upper core structure above the Mylar diaphragm. The vessel is filled with water to a depth of 10 inches above the platforn (6 inches above the top of the core) and a light ladder setup is placed on the surface of the water to measure the displacement of the water surface.

\section{Charge Canister and Charge}

The charge canister consists of a stack of steel rings spaced at even intervals, two end plates, eight axial studs, and a threaded plug to hold the canister in place. The canister rings are made of heattreated, high-strength steel, each ring having an inside diameter of 1.75 inches, an outside diameter of 2.15 inches, and a thickness of 0.125 inch. Eight rings are spaced 0.050 -inch apart by aluminum straps that are woven between the rings. The explosive charge is placed inside 


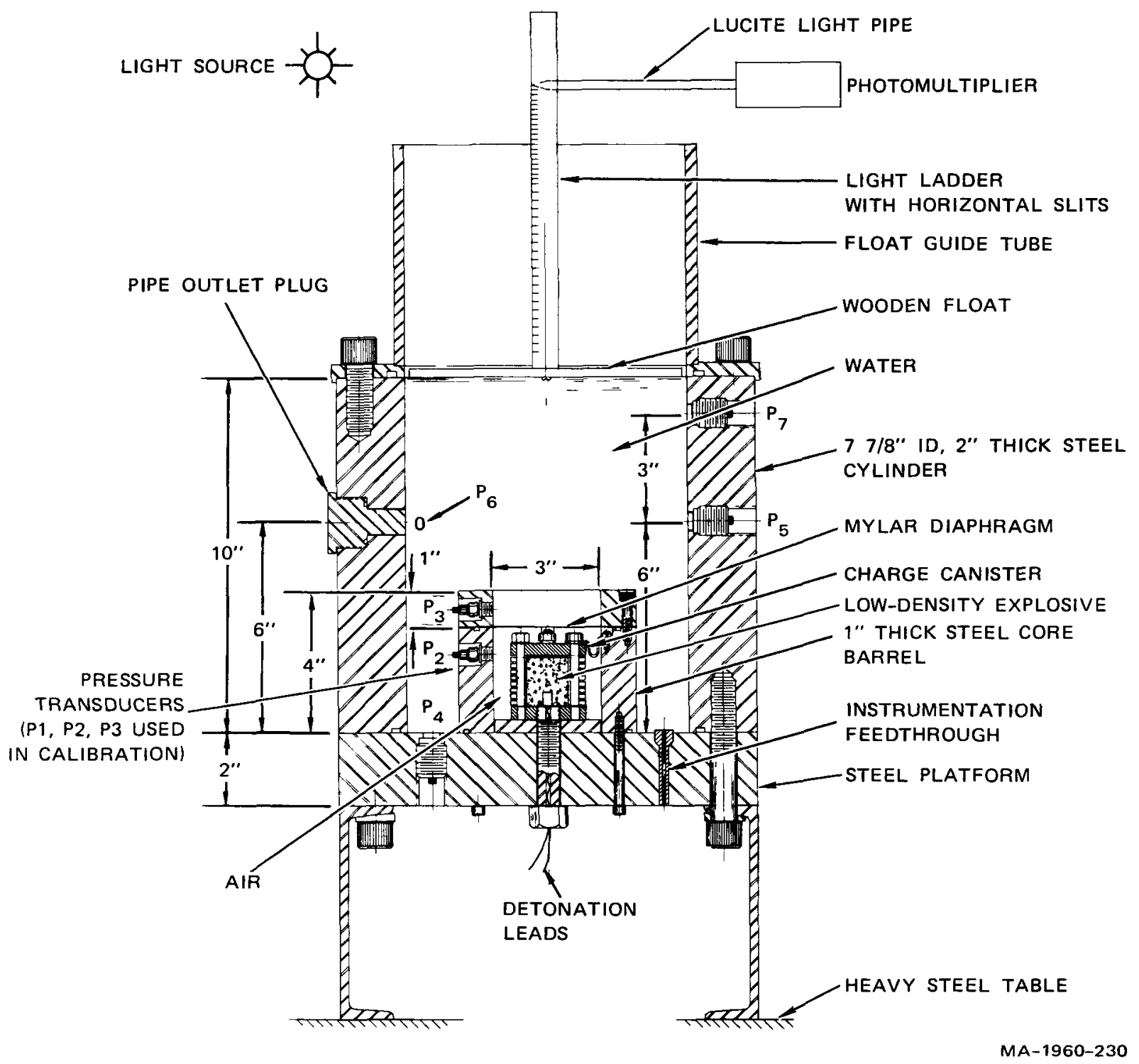

FIGURE A.1 CALIBRATION VESSEL WITH INSTRUMENTATION 
the canister rings, and the steel end plates (0.375-ich thick, 2.15-inchdiameter) are placed at either end of the stack of rings; eight highstrength studs hold the canister together. Detonator leads are fed out through the threaded plug that holds the canister in place.

The explosive charge consists of a paper cylinder filled with a lowdensity explosive powder. For these experiments two explosive mixtures were calibrated: one 65\% PETN and 35\% Microballoons (by weight) and the other 90\% PETN and 10\% Microspheres (by weight). The powder is packed into the paper canister, and an exploding bridgewire detonator filled with 0.15 of pure PETN is placed in one end of the charge. The bridgewire is detonated by an electronic detonating unit (EDU) that dumps about $20 \mathrm{~kJ}$ through the bridgeplug in $5 \mu \mathrm{sec}$.

Upon detonation, the explosive gases vent through the canister gaps, which control the rise time of the pulse in the core. The gas fills the initial volume of the core barrel $\left(226.5 \mathrm{~cm}^{3}\right)$ and then pushes on the water driving it upward. The motion of the slug of water controls the decay time of the pulse in the core.

Instrumentation

\section{Pressure Transducers}

Seven pressure transducers were used to measure loading pressures at important locations in the rigid vessel calibration model. The transducers were piezoelectric pressure gages (PCB Model 113A03/61) with a natural frequency of $450 \mathrm{kHz}$ and a rise time of $1 \mathrm{Hsec}$. Two pressure gages were located in the core to measure source pressure. One gage was placed in the core barrel above the Mylar diaphragm to measure initial water pressure. Another gage was placed in the platform to measure platform pressure, and two pressure gages were placed in the vessel wa11 6 inches above the platform to measure vessel wall loading pressures. A single pressure gage was placed in the upper wall 9 inches from the platform. The five pressure gages exclusive of the two core pressure 
gages were used to establish the reliability of the instrumentation and to obtain bounds on the loading pressures in the subsequent rigid vessel experiments.

\section{Light Detection Apparatus}

The light ladder apparatus was used to measure slug motion. The apparatus consists of a split, hollow aluminum tube (the ladder) attached to a 1/4-inch-thick, 8-inch-diameter wooden float. Thin (0.010 inch) slits are precisely cut into the metal tube, and a light source behind the light ladderilluminates the slits. A Lucite light guide tube connected to a photomultiplier is positioned near the light ladder so that it can distinguish the light from only one slit at a time. As the ladder moves, successive slits pass the Lucite light sensing tube. The alternate light and dark intervals produce distinct voltage peaks when sensed by the photomultiplier. Knowing the distances between slits and the time interval between voltage peaks, we can calculate a displacementtime record of slug motion. For these calibration experiments, the slit spacings were: 3 slits on $0.050-i n c h$ centers, followed by 20 slits on 0.1 -inch centers, followed by 20 slits on $0.2-i n c h$ centers. The light sensing element (Lucite tube) is centered initially on one of the first three slits by adjusting it to produce maximum photomultiplier voltage output. During early motion, the first 20 closely spaced slits give high displacement-time resolution. It is possible to follow a total of 6 inches of motion with this slit arrangement.

\section{Trigger System}

The explosive charge is detonated by triggering an electronic detonating unit (EDU), which dumps a 2000-volt charge (20 kJ) through the exploding bridgewire embedded in the charge. The EDU is triggered by a signal from a delay generator that allows precise (microsecond) timing of a sequence of events during an explosive experiment. For these calibration experiments the delay generator was used to trigger two sets 
of oscilloscopes; one set was triggered $50 \mu \mathrm{sec}$ before detonation and the other set was triggered $450 \mu s e c$ after detonation.

\section{Recording System}

Data from each experiment were recorded on oscilloscopes and on high speed magnetic tape. The oscilloscopes were Tektronix 543B models with a frequency response of $33 \mathrm{MHz}$. The tape records were made on two Bell and Howell 3700B tape recorders, which record at 120 inches per second and are set up for an $80-\mathrm{kHz}$ frequency response. A visual record was made from the magnetic tape record by playing the tapes back through a recording oscillograph (Visicorder Model 5-124), which reproduces the tape recorder signals on light-sensitive paper.

\section{Experiment Specifications}

Altogether, ten calibration experiments were performed. Table A.1 lists the important dimensions and characteristics of each experiment. The primary objective of these experiments was to obtain pressure-volume change data for the $8-\mathrm{g} 65 / 35$ explosive powder mix to be used in the rigid and flexible vessel experiments. Tests RV 101, 102, and 105 were designed to meet this objective. A secondary objective was to calibrate an equivalent source that used the $90 / 10$ explosive powder mix. Tests RV 103, 104, 108, and 109 were designed to meet this objective. Noise problems caused by breakage of grounding straps in the core and breakage of some of the steel canister rings were encountered during many of these secondary tests, but at least one clean set of records (RV 109) was obtained. Calibration experiments using both explosive mixes were also performed at higher charge levels to develop a higher energy source for possible future use.

\section{Measureme nts}

\section{Sample Records}

Figure A.2 shows four sample oscilloscope records from experiment RV 102. The pulse shape of the pressure in the core $\left(\mathrm{P}_{2}\right)$ is characterized by a rise to a peak pressure of about $3800 \mathrm{psi}$ in about $150 \mu \mathrm{sec}$, followed 
Table A.1

SPECIFICATIONS OF CALIBRATION EXPERIMENTS

\begin{tabular}{|c|c|c|c|c|c|c|c|c|c|}
\hline $\begin{array}{c}\text { Experiment } \\
\text { Number }\end{array}$ & $\begin{array}{c}\text { Vesse } 1 \\
\text { I.D. } \\
\text { (in.) }\end{array}$ & $\begin{array}{c}\text { Vesse1 } \\
\text { Height } \\
\text { (in.) }\end{array}$ & $\begin{array}{c}\begin{array}{c}\text { Initial Core } \\
\text { Volume } \\
\left(\mathrm{cm}^{2}\right)\end{array} \\
\end{array}$ & $\begin{array}{c}\text { Water } \\
\text { Height } \\
\text { Above Core } \\
\text { (in.) }\end{array}$ & $\begin{array}{c}\text { Charge } \\
\text { Mass } \\
(g)\end{array}$ & $\begin{array}{c}\text { Charge } \\
\text { Mixture } \\
\text { (by wt) } \\
\end{array}$ & $\begin{array}{c}\text { Canister Rings } \\
\text { I.D. } \times \mathrm{t} \times \mathrm{W} \\
\text { (in.) }\end{array}$ & $\begin{array}{l}\text { Ring } \\
\text { Gap } \\
\text { (in.) } \\
\end{array}$ & Remarks \\
\hline RV 101 & 8.0 & 10.0 & 226.5 & 6.0 & 8.0 & $65 / 35^{*}$ & $1-3 / 4 \times 1 / 8 \times 3 / 16$ & 0.050 & Good records \\
\hline RV 102 & 8.0 & 10.0 & 226.5 & 6.0 & 8.0 & $65 / 35$ & $1-3 / 4 \times 1 / 8 \times 3 / 16$ & 0.050 & Good records \\
\hline RV 103 & 8.0 & 10.0 & 226.5 & 6.0 & 5.8 & $90 / 10^{\dagger}$ & $1-3 / 4 \times 1 / 8 \times 3 / 16$ & 0.050 & $\begin{array}{l}\text { Noise on records, ring broken } \\
\text { in canister }\end{array}$ \\
\hline RV 104 & 8.0 & 10.0 & 226.5 & 6.0 & 5.8 & $90 / 10$ & $1-3 / 4 \times 1 / 8 \times 3 / 16$ & 0.050 & $\begin{array}{l}\text { Noise on records, } 2 \text { rings } \\
\text { broken }\end{array}$ \\
\hline RV 105 & 8.0 & 10.0 & 226.5 & 9.0 & 8.0 & $65 / 35$ & $1-3 / 4 \times 1 / 8 \times 3 / 16$ & 0.050 & Good records \\
\hline RV 106 & 8.0 & 10.0 & 225.9 & 6.0 & 14.0 & $65 / 35$ & $2 \times 1 / 8 \times 3 / 16$ & 0.050 & $\begin{array}{l}\text { Ground straps broken, noise } \\
\text { on all records }\end{array}$ \\
\hline RV 107 & 8.0 & 10.0 & 225.9 & 6.0 & 14.0 & $65 / 35$ & $2 \times 1 / 8 \times 3 / 16$ & 0.050 & $\begin{array}{l}\text { Good records, ground straps } \\
\text { intact }\end{array}$ \\
\hline $\mathrm{RV} 108$ & 8.0 & 10.0 & 226.5 & 6.0 & 5.8 & $90 / 10$ & $1-3 / 4 \times 1 / 8 \times 3 / 16$ & 0.050 & $\begin{array}{l}\text { Noise on records, } 2 \text { rings } \\
\text { broken, ground strap intact }\end{array}$ \\
\hline RV 109 & 8.0 & 10.0 & 226.5 & 6.0 & 5.8 & $90 / 10$ & $1-3 / 4 \times 1 / 8 \times 3 / 16$ & 0.050 & Good records \\
\hline RV 110 & 8.0 & 10.0 & 225.9 & 6.0 & 10.1 & $90 / 10$ & $2 \times 1 / 8 \times 3 / 16$ & 0.050 & Good records \\
\hline
\end{tabular}

* PETN/Microballoons.

$\dagger_{\text {PETN/Microspheres. }}$ 

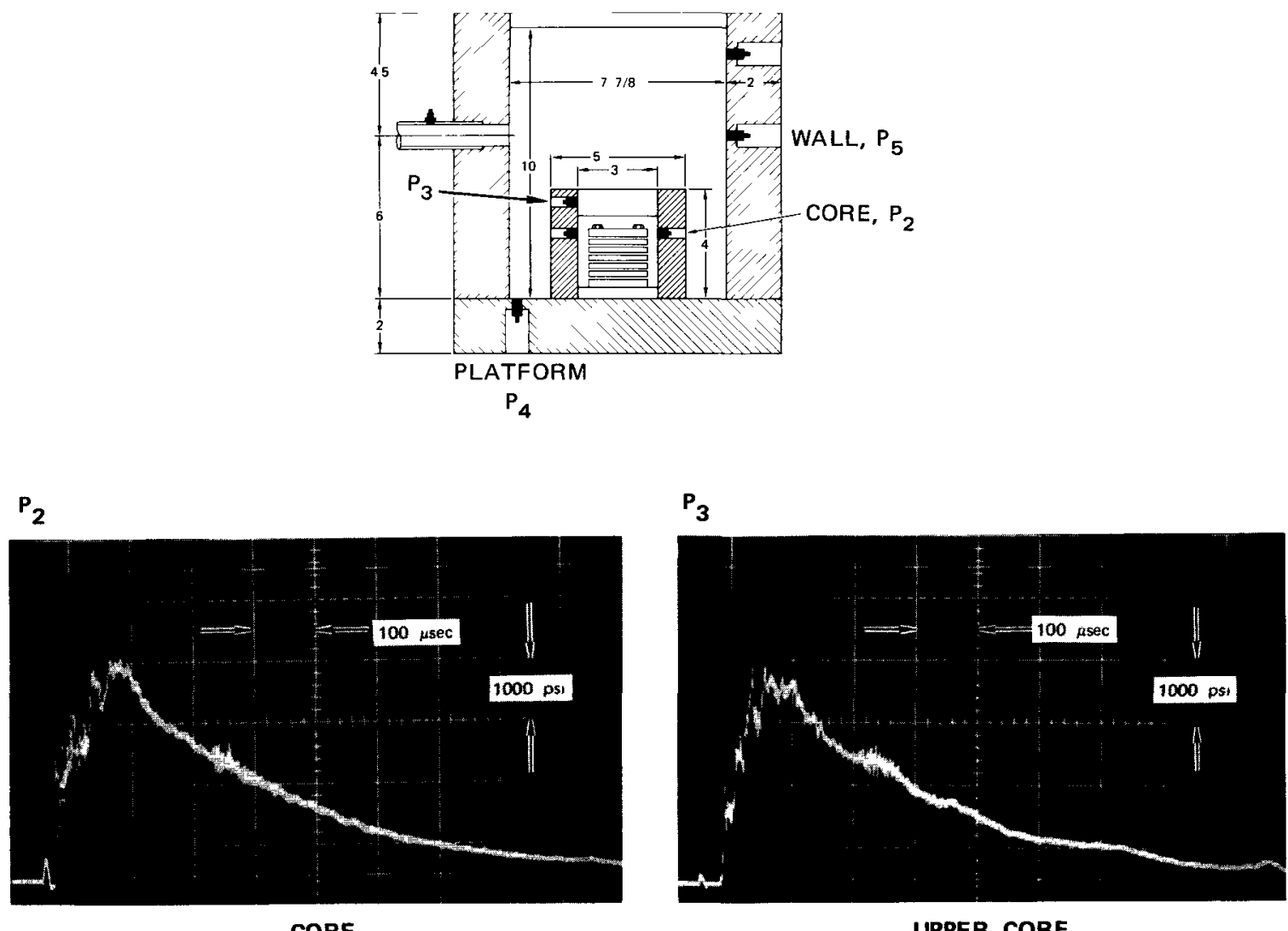

UPPER CORE

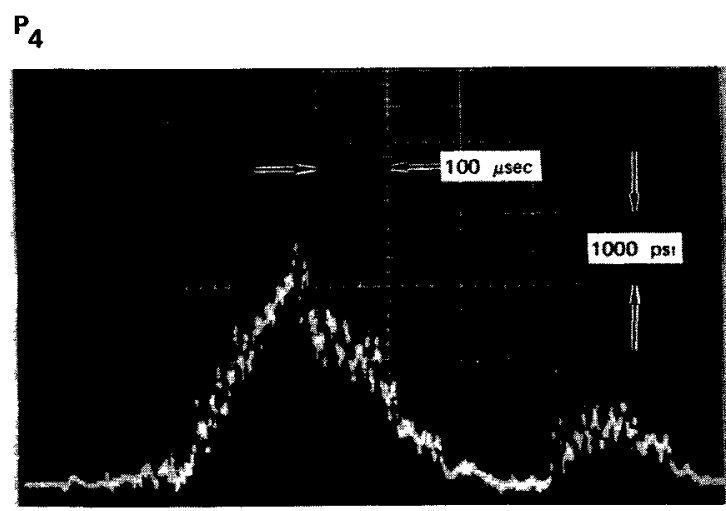

PLATFORM

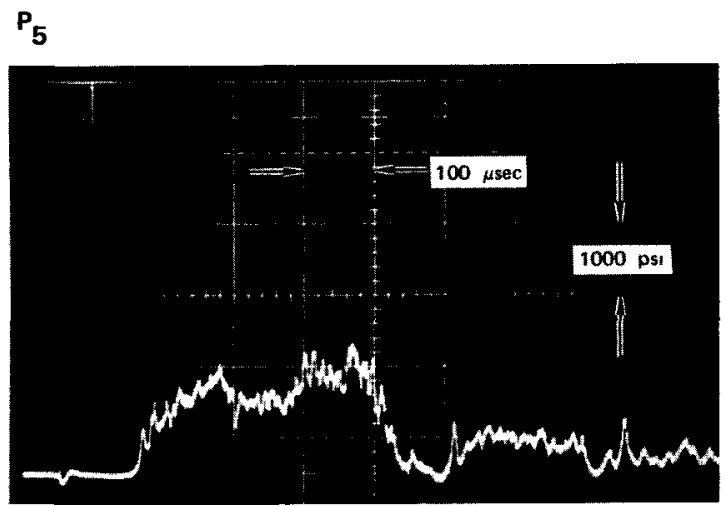

WALL OPPOSITE PIPE OUTLET

NOTE All records begin $50 \mu \mathrm{sec}$ before detonation of charge.

MP-1960-242

FIGURE A.2 SAMPLE PRESSURE OSCILLOGRAMS FROM CALIBRATION EXPERIMENT RV 102 
by a gradual decay to atmospheric pressure in about $1 \mathrm{msec}$. These records are typical of those obtained on noise-free experiments.

\section{Data Analysis}

The primary objective of the calibration experiments was to obtain pressure-volume change relationships for the energy source used in the rigid and flexible vessel experiments. The data analysis technique involves combining the core pressure data with the gas volume increase as measured by the upward motion of the water slug.

The gas volume change at any time is the sum of the volume of water displaced upwards, the increase in volume of the vessel, and the compression of the water. The volume of water displaced upwards is determined from the light ladder data, while the increase in volume of the vessel is negligible because of its relatively thick walls.

The contribution of the compression of the water is calculated by using a two-stage analytical model. In stage 1 , the fluid mot ion is described by a conical wave emanating from the core upward to the free surface. Approximating the motion of this conical mass of fluid by the spherical flow of aninfinite compressible fluid caused by an expanding spherical gas bubble, the gas-water interface displacement is

$$
y(t)=\frac{1}{\rho c} \int_{0}^{t} p(\tau) d \tau+\frac{1}{\rho a} \int_{0}^{t} I(\tau) d \tau
$$

where $y(t)=$ interface radial displacement

$$
\begin{aligned}
& p \quad=\text { density of fluid } \\
& p(\tau)=\text { pressure history in core } \\
& c \quad=\text { sound speed in fluid } \\
& a \quad=\text { bubble radius } \\
& I \quad=\text { impulse at the interface; } I(\tau)=\int_{0}^{t} p(\tau) d \tau
\end{aligned}
$$


An approximation to the volume change due to compression is therefore

$$
\Delta \mathrm{v}_{\mathrm{c}}=\mathrm{Ay}
$$

Where $A$ is the cross-sectional area of the core.

The expansion of the bubble is terminated in this analytical model at a time $t_{1}$, the time required for a wave in the water to travel from the source to the surface and back to the source.

Stage 2 commences at a time $t_{2}$ greater than $t_{1}$. Time $t_{2}$ is taken to be the time at which the pressure at the vessel wall just above the core $\left(\mathrm{P}_{5}\right)$ becomes approximately equal to the core pressure and is obtained from the experimental records. These two pressures stay equal so that for $t>t_{2}$, a quasi-static analytical model suggests itself in which the pressure outside the core and the pressure below the core top behave similarly. Above the core top, the pressure distribution is approximated by a linear drop to atmospheric pressure at the free surface. With this pressure distribution, the gas volume increase due to compressibility per unit volume of fluid is $\Delta V_{c}=P / K$, where $K$ is the fluid bulk modulus. During the transition time from $t_{1}$ to $t_{2}, \Delta v_{c}$ is approximated by a linear relationship. Figure A.3 shows a schematic description of the technique for obtaining the pressure-volume change relationship. Figure A.3(a) shows the pressure-time history in the core. Figure A.3(b) shows the gas volume increase-time history. Note the two components of gas volume increase: $\Delta \mathrm{V}_{\mathrm{c}}$, the volume increase due to compressibility, and $\Delta \mathrm{V}_{\mathrm{s}}$, the volume increase due to upward slug motion $\left(\Delta V_{v}\right.$ - vessel volume increase $\left.=0\right)$.

The two records, Figure $A .3(\mathrm{a})$ and $A .3(\mathrm{~b})$, are combined to obtain Figure A.3(c), the desired pressure-volume change relationship. 


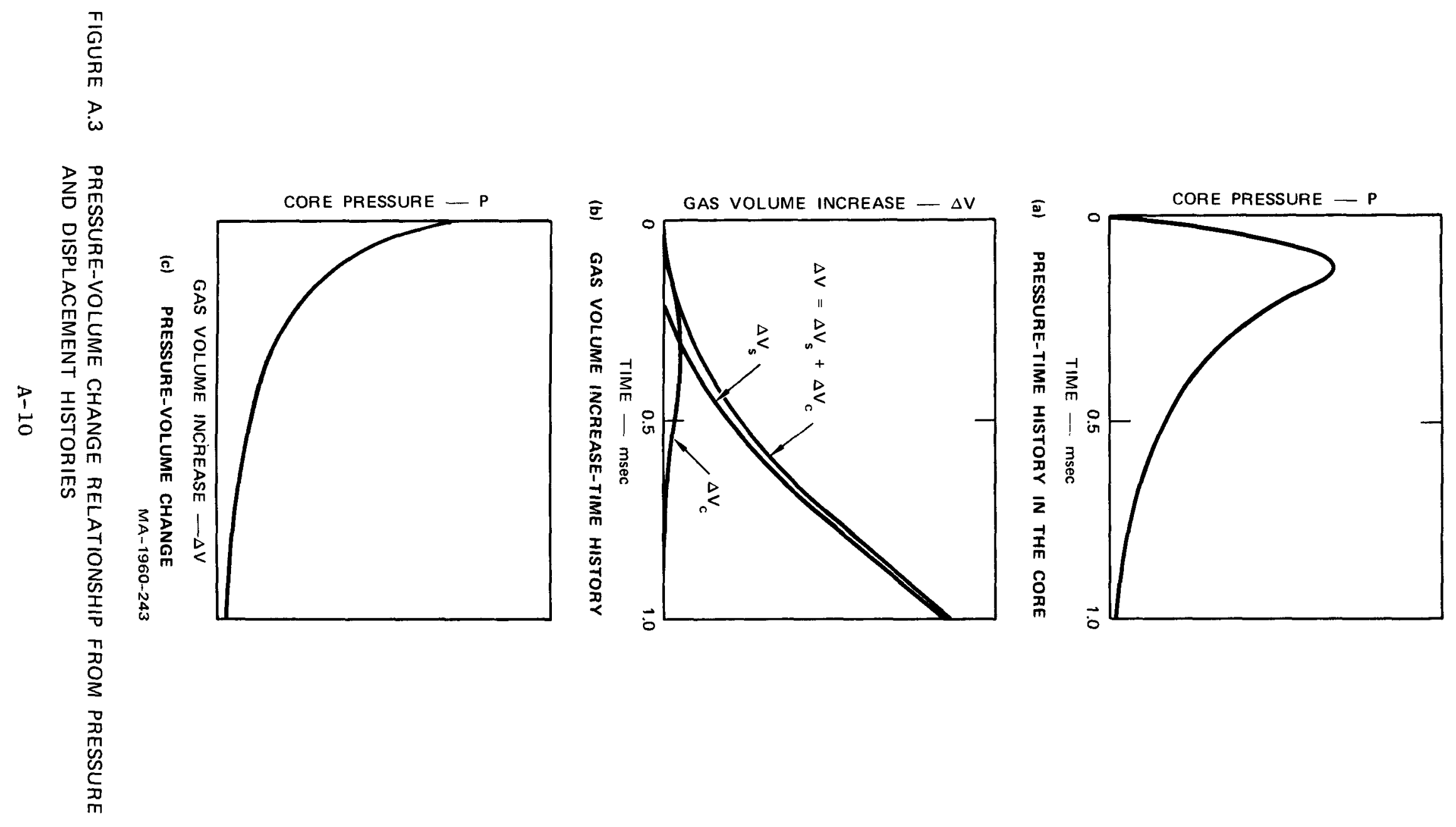




\section{Experiment Reproducibility}

To demonstrate experiment reproducibility, Figure A.4 compares the pressure-volume change relationships obtained from two repeat experiments, RV 101 and 102. The $P-\Delta V$ curves are virtually the same at small volume change and show only slight differences for large volume changes. The area under the two curves (total energy) is the same. This result demonstrates the excellent reproducibility that could be expected of the ensuing rigid vessel experiments.

\section{Pressure-Volume Change Curves}

Figure A.5 shows the pressure-volume change relationship for an 8-g charge of 65/35 explosive powder mix (PETN/Microballoons). The curve was obtained by averaging the results of $R V 101$ and RV 102. Also shown in Figure A.5 is the cumulative gas work done by the source out to a volume increase of $600 \mathrm{~cm}^{3}$.

Figure A.6 shows the pressure-volume change relationship for a $14-\mathrm{g}$ charge of $65 / 35$ explosive powder mix. As expected both the $P-\Delta V$ and gas work curves are higher than those for the 8-g charge.

Figure A.7 shows the pressure-volume change relationship for a 5.8-g charge of 90/10 explosive powder mix (PETN/Microspheres). This charge is supposed to be equivalent in energy to the 8-g charge of $65 / 35$ mix. Comparison of Figures A.5 and A.7 shows that the $5.8-g$ charge of $90 / 10 \mathrm{mix}$ is slightly more energetic than the equivalent $8-\mathrm{g}$ charge of $65 / 35 \mathrm{mix}$. However, differences are small enough that an equivalent charge of the $90 / 10 \mathrm{mix}$ could be substituted successfully for the $65 / 35$ mix in future experiments. 


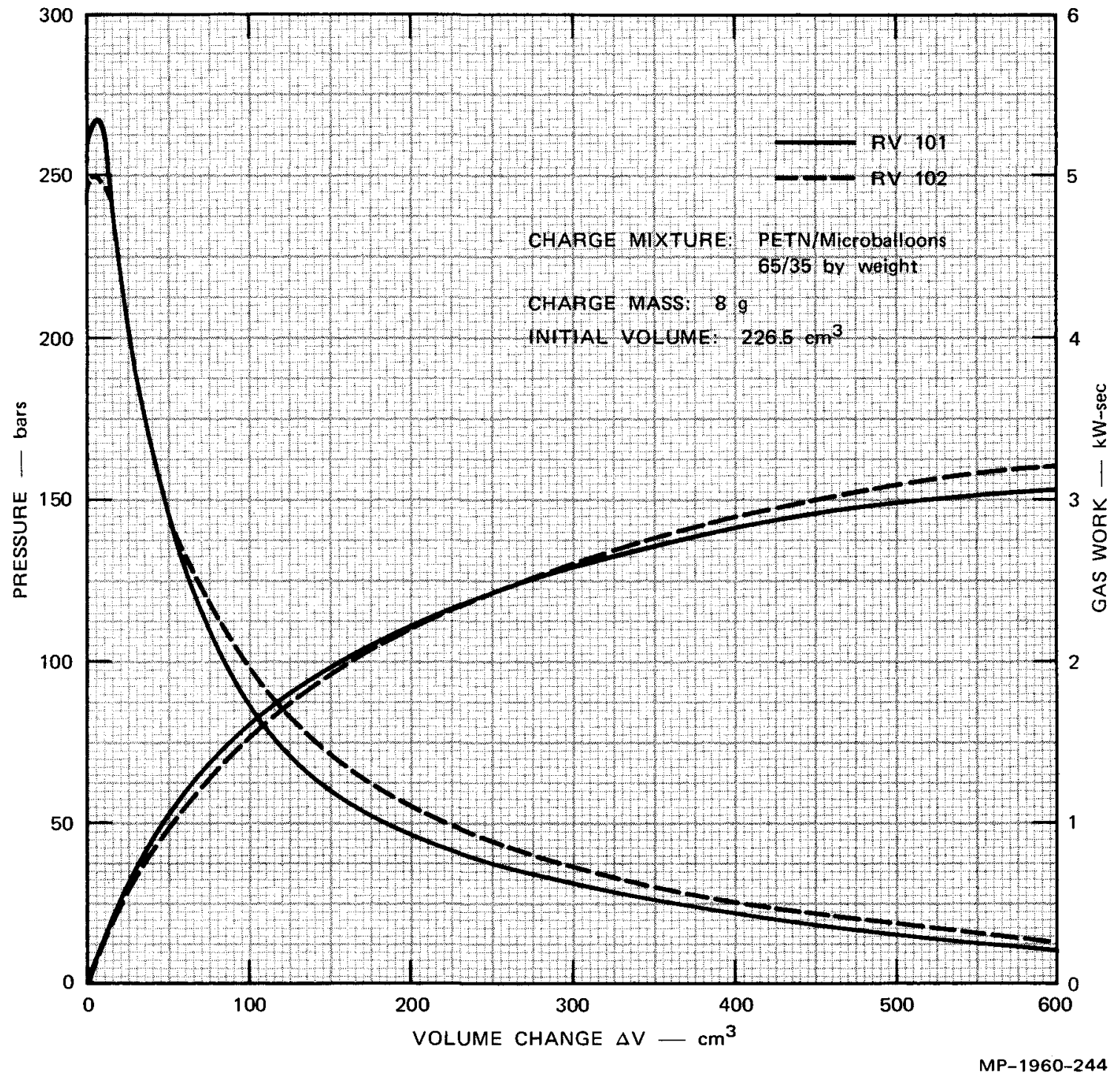

FIGURE A.4 REPRODUCIBILITY OF PRESSURE-VOLUME CHANGE AND GAS WORK MEASUREMENTS FOR ENERGY SOURCE 


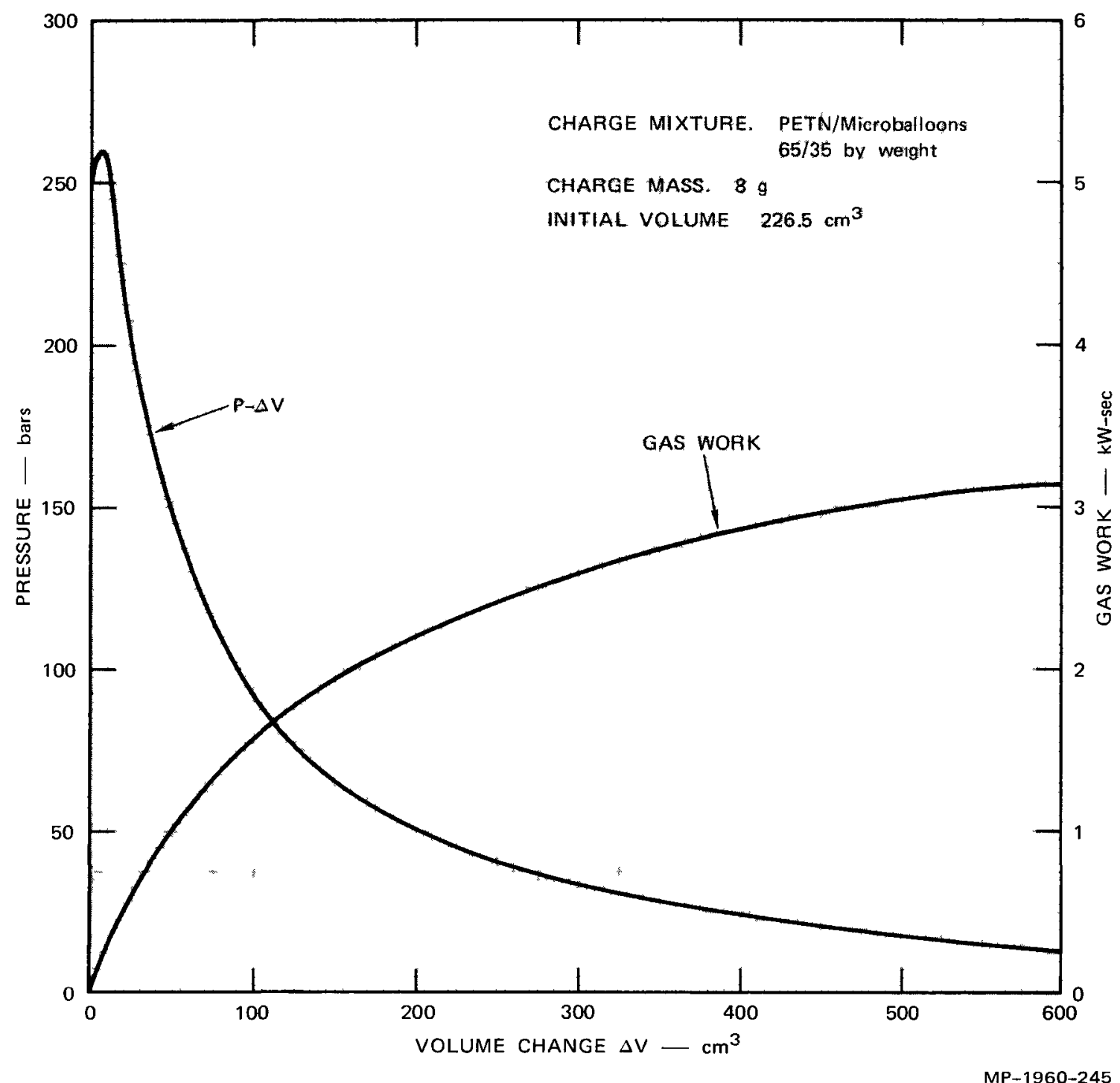

FIGURE A.5 PRESSURE-VOLUME CHANGE AND GAS WORK-VOLUME CHANGE RELATIONSHIPS FOR ENERGY SOURCE 


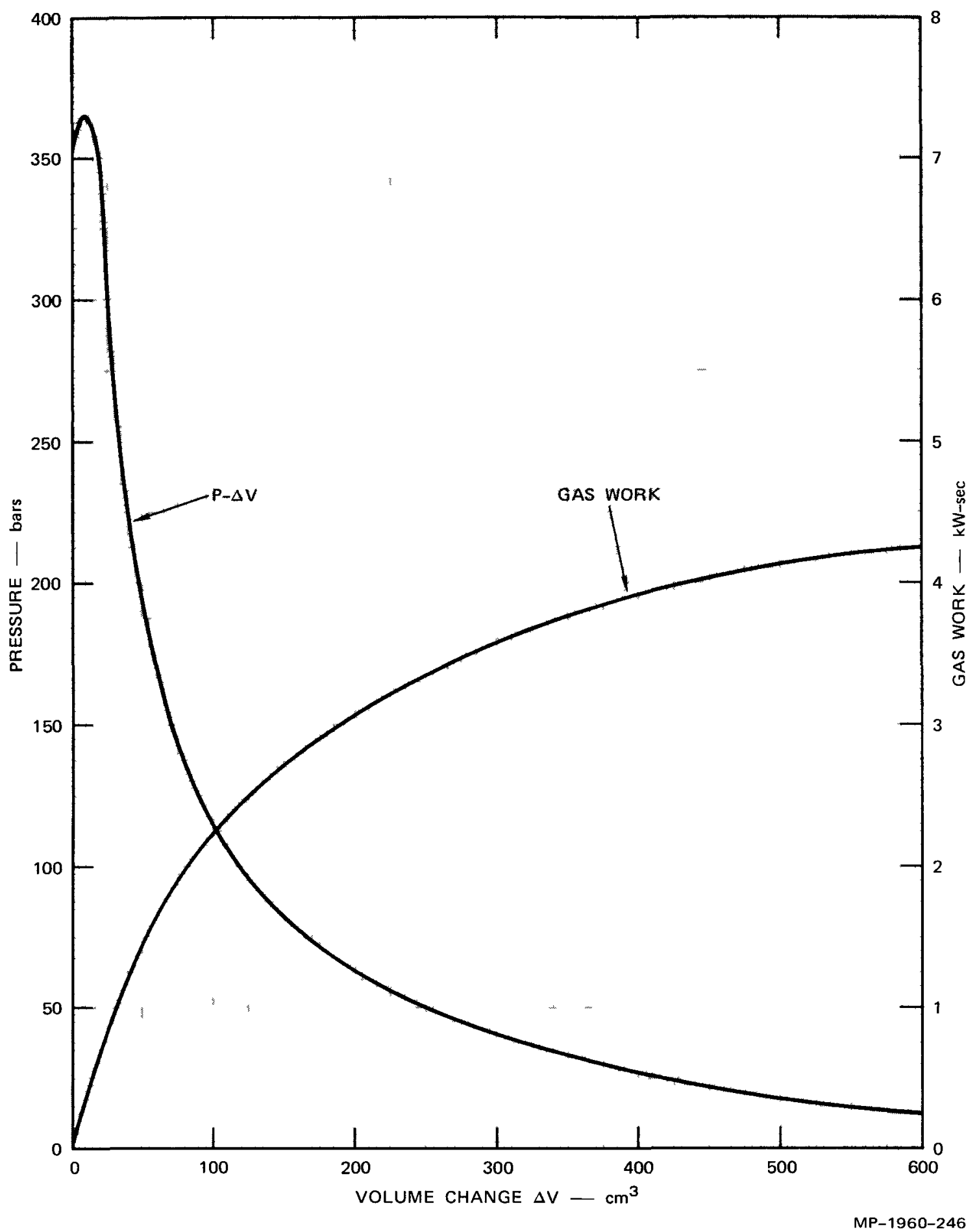

FIGURE A.6 PRESSURE-VOLUME CHANGE AND GAS WORK-VOLUME CHANGE RELATIONSHIPS FOR A 14-g CHARGE OF PETN-MICROBALLOON MIXTURE $(65 / 35$ BY WT) 


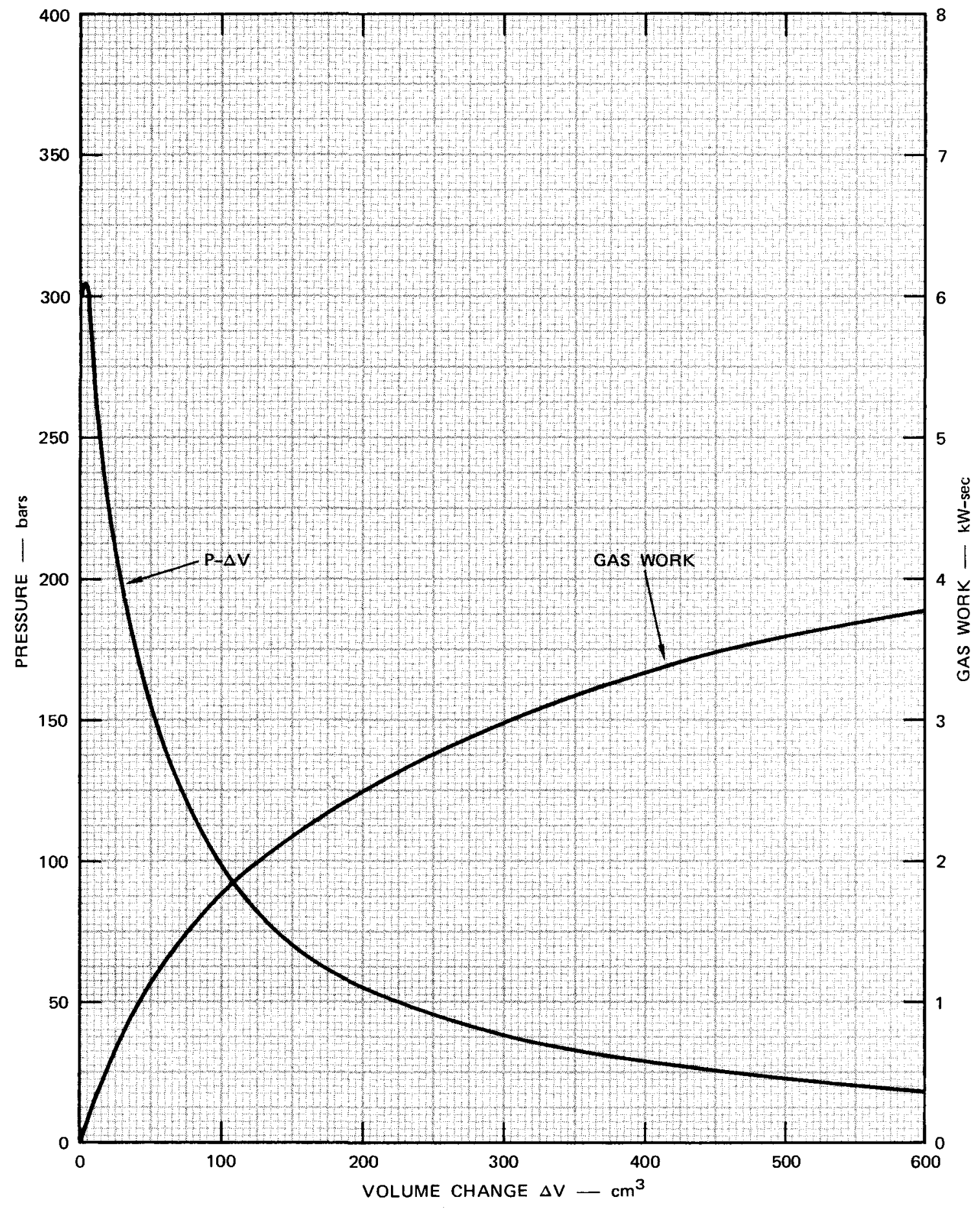

$M P-1960-247$

FIGURE A.7 PRESSURE-VOLUME CHANGE AND GAS WORK-VOLUME CHANGE RELATIONSHIPS FOR A 5.8-g CHARGE OF PETN-MICROSPHERE MIXTURE (90/10 BY WT) 


\section{Appendix B \\ DETAILS OF THE RIGID VESSEL EXPERIMENTS}

Apparatus

Rigid Vessel

Rigid vessel experiments were carried out in the apparatus shown in Figure B.1. The main components of this apparatus (the vessel, core, and base plate) are the same as those used in calibration experiments described in Appendix A. The vessel is a steel cylinder with 7.875-inch inside diameter, a 2-inch-thick wall, and a length of 10 inches.

One feature of this vessel that distinguishes it from the calibration vessel is the addition of a pipe outlet 6 inches above the base of the vessel. The pipe outlet is designed to accept a $0.75-i n c h$, schedule 80 , steel pipe (0.742-inch I.D. $x$ 1.050-inch O.D.). An 8-foot-long pipe terminated by a free surface was used in the experiments. The length of the pipe was chosen so that wave reflection times in the pipe ( $\sim 3 \mathrm{msec}$ ) were greater than loading times in the vessel itself. The vessel is filled with water to a depth of 10 inches from the base. The second feature that distinguishes the rigid vessel experiments from the calibration experiments is a 2-inch-thick steel cover plate, which is bolted to the top of the vessel. The effects of a cover gas region on vessel head pressure were investigated by providing a 0.5 -inchthick air space above the water. This air space was created by placing a steel ring between the cover and the rigid vessel. Three experiments were performed on the vessel with a cover gas region. In a fourth experiment, the 0.5 -inch-thick ring was removed to eliminate the cover gas region. Pressure gages mounted at the center and the edge of the cover measured slug impact pressures during the cover gas experiments or vessel head pressures caused by wave reflections during the experiment without a cover gas region. 


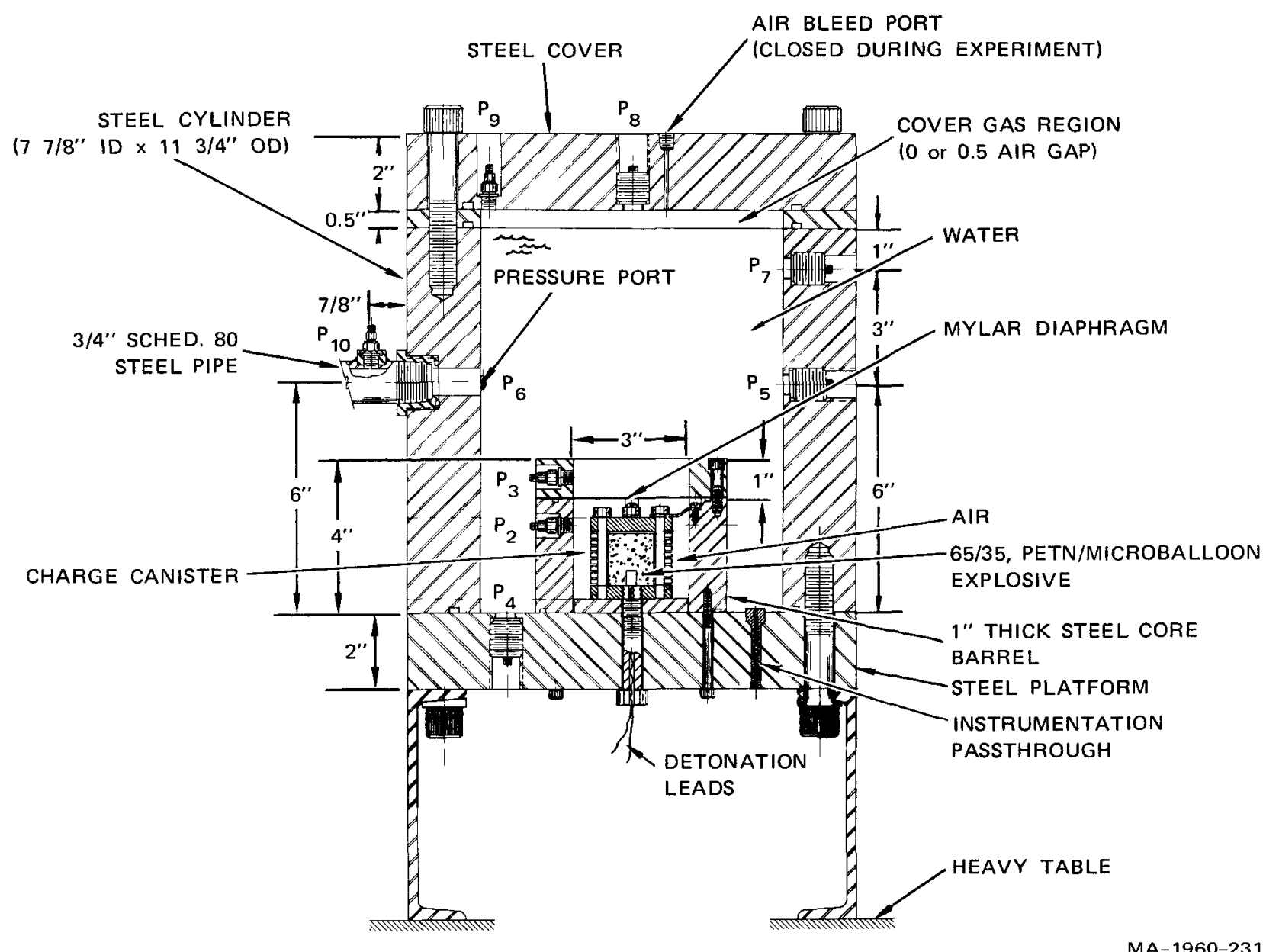

FIGURE B.1 RIGID VESSEL WITH INSTRUMENTATION 


\section{Charge and Canister}

An 8-g charge of $65 \%$ PETN and 35\% Microballoons (by weight) was used in all four rigid vessel experiments. The charge was packed in a paper container, which included an exploding bridgewire detonator filled with $0.15-g$ of pure PETN. The charge was placed inside the steel ring canister described in Appendix A. The completed assembly was placed in the core and held down by a steel plug that has a hole in it to allow passage of the lead wires to the detonator. The charge is detonated by dumping a 2000-volt charge from the EDU through the exploding bridgewire.

Instrumentation

Instrumentation on the rigid vessel experiments was restricted to the same pressure transducers used on the calibration tests (PCB Model $113 \mathrm{A03} / 61,450 \mathrm{kHz}, 1 \mu \mathrm{sec}$ rise time). Ten pressure transducers were mounted on the model in the locations shown in Figure B.1. Two of the gages $\left(\mathrm{P}_{1}\right.$ and $\left.\mathrm{P}_{2}\right)$ were mounted in the core to measure core gas pressure. A single gage $\left(\mathrm{P}_{3}\right)$ was placed in the core barrel above the Mylar diaphragm to measure initial water pressure. A single gage $\left(\mathrm{P}_{4}\right)$ was mounted in the base plate to measure platform pressure. Two pressure gages $\left(\mathrm{P}_{5}\right.$ and $\left.\mathrm{P}_{6}\right)$ were mounted in the vessel wall 6 inches above the base to measure wall loading pressure. One of these two wall gages $\left(\mathrm{P}_{6}\right)$ was located 15 degrees away from the pipe outlet and the other was diametrically opposite to the pipe outlet. Another pressure gage $\left(\mathrm{P}_{7}\right)$ was mounted in the upper wall 9 inches above the base ( 1 inch below the water surface). Two pressure gages were mounted in the cover to measure slug impact pressure; one of these gages $\left(\mathrm{P}_{8}\right)$ was mounted at the center of the cover and the other $\left(\mathrm{P}_{9}\right)$ was mounted in the cover near the edge of the vessel. This cover gage layout allowed measurement of the planarity of slug impact. The tenth pressure gage was mounted in the pipe leading from the model 2.875 inches from the pipe outlet. 
Data were recorded on oscilloscopes and on a high-speed tape recorder for later evaluation.

Experiment Specifications

Table B.1 lists the specifications for the four rigid vessel experiments. Tests RV 111, 112, and 113 are repeat tests on a mode1 that included a $0.5-i n c h$ cover gas region. The threaded plug holding the charge canister in the core was blown out of the model on Test RV 111, resulting in a large noise burst on the pressure records. Test RV 114 was performed on a model with no cover gas region.

Measurements

Sample Pressure Measurements

Figure B.2 shows five sample oscilloscope pressure records for Experiment RV 112. Pressure $\mathrm{P}_{2}$ was measured in the core, pressure $\mathrm{P}_{4}$ was measured on the platform, pressures $P_{5}$ and $P_{6}$ were measured in the wall 6 inches above the platform, and pressure $P_{8}$ was measured at the lid center.

Experimental Reproducibility

Figure B.3 shows comparison plots of pressure records from the three rigid vessel experiments that included a cover gas region. These plots were generated by digitizing the oscillogram or oscillograph records and then processing the digital data on a computer. It can be seen that but for a few exceptions, the experimental reproducibility is excellent, within $\pm 10 \%$

Data from Rigid Vesse1 Experiments

Figures B.4 to B.7 show the pressure histories for each pressure gage on each of the four rigid vessel experiments. The schematic drawing in the upper left-hand corner of each figure shows the location of each pressure gage. 
Table B.1

SPECIFICATIONS OF RIGID VESSEL EXPERIMENTS

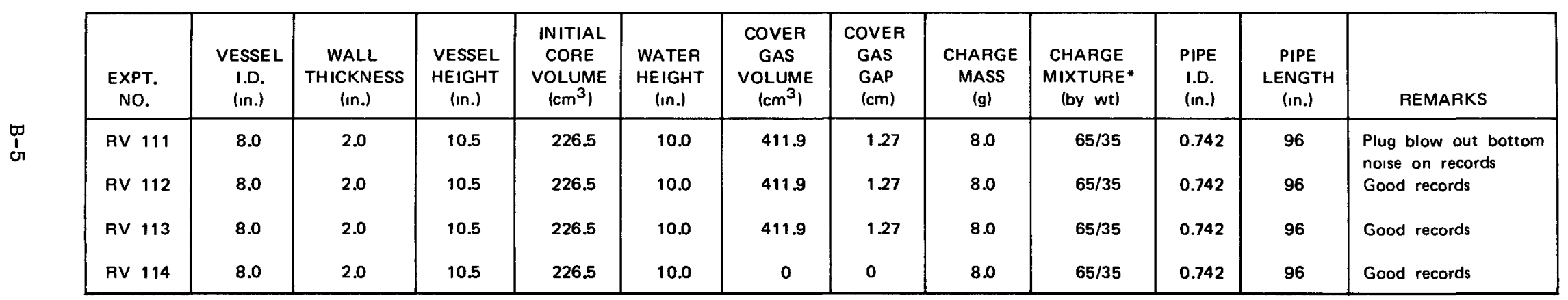

*PETN/Microbalion. 


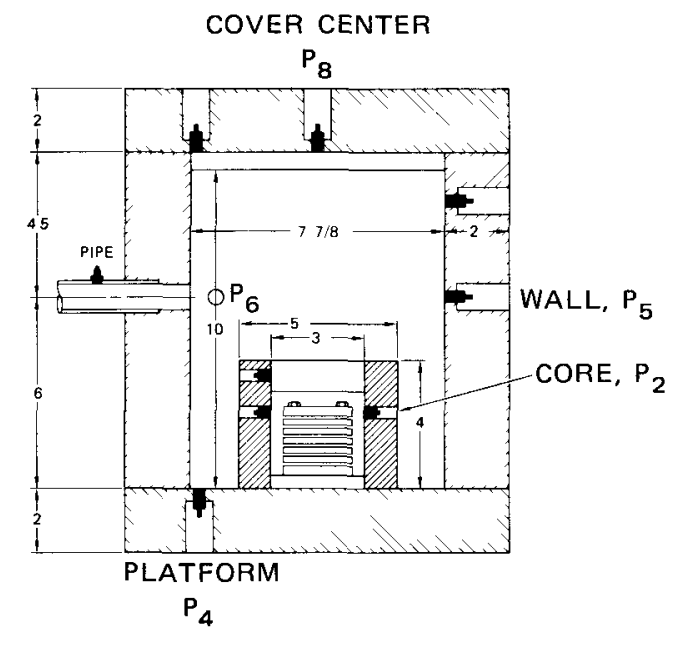

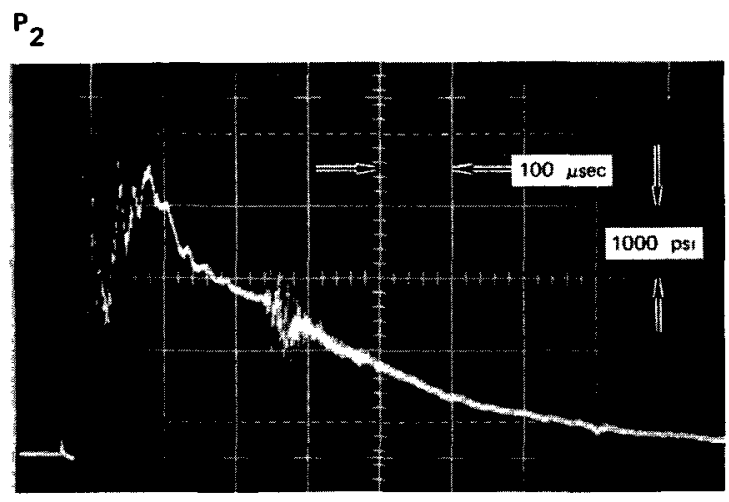

CORE

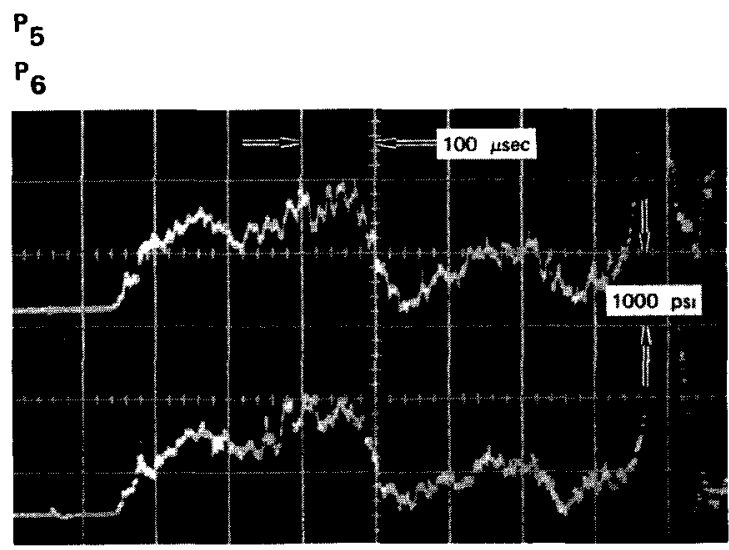

WALL AT PIPE OUTLET HEIGHT

NOTE All records begin $50 \mu \mathrm{sec}$ before detonation in core except $\mathrm{P}_{8}$

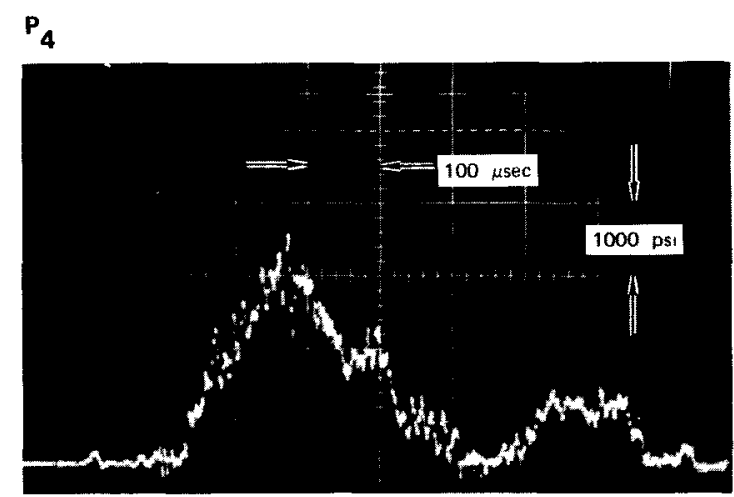

PLATFORM

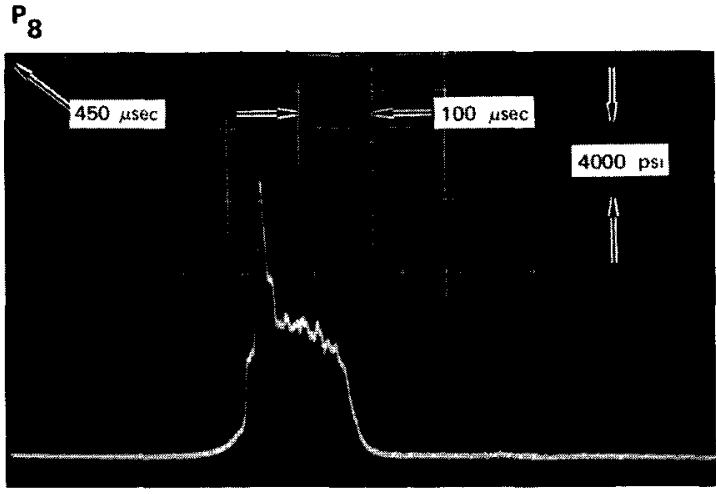

COVER CENTER

MP-1960-248

FIGURE B.2 SAMPLE PRESSURE OSCILLOGRAMS FROM RIGID VESSEL EXPERIMENT RV 112 

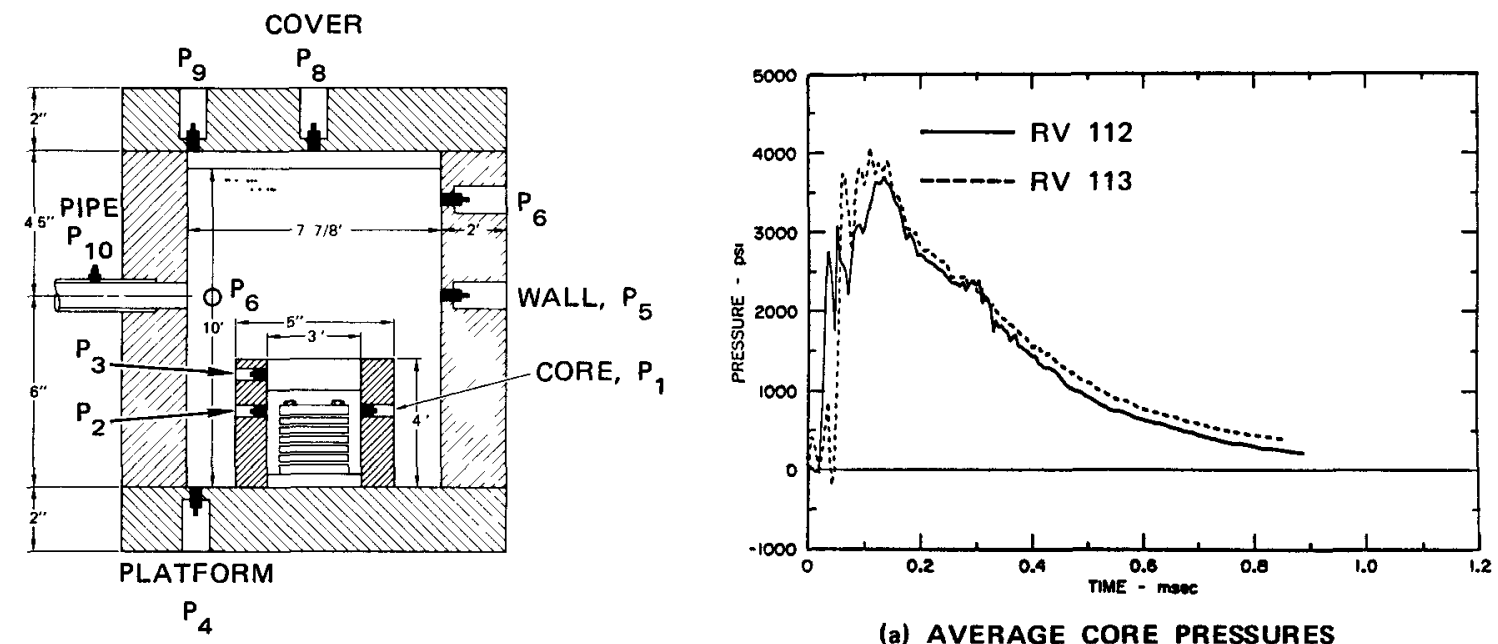

(a) AVERAge core pressures

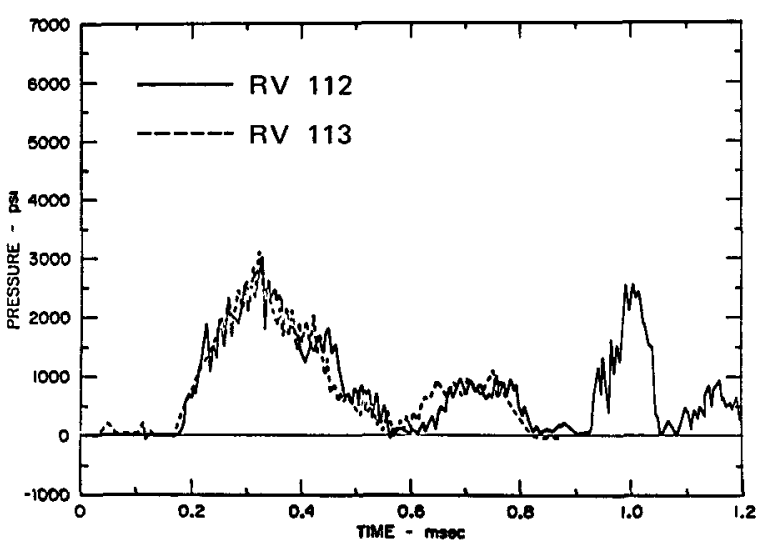

(b) PLATFORM PRESSURE $\left(P_{4}\right)$

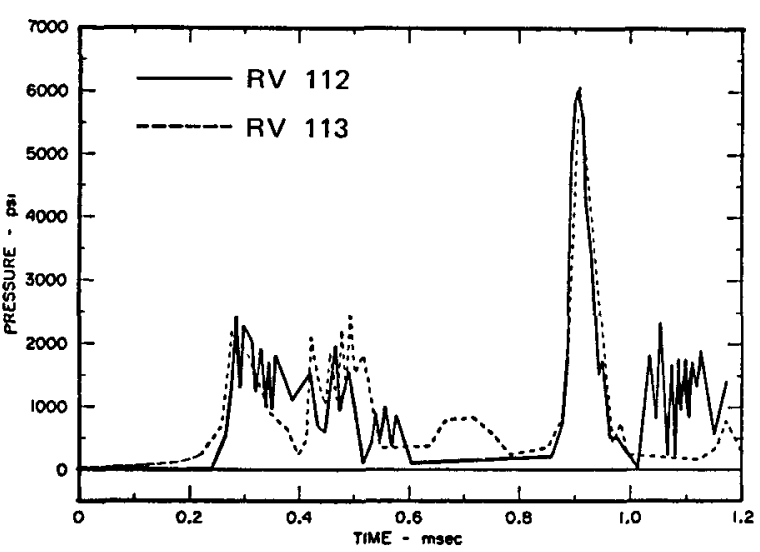

(d) PIPE PRESSURE $\left(P_{10}\right)$

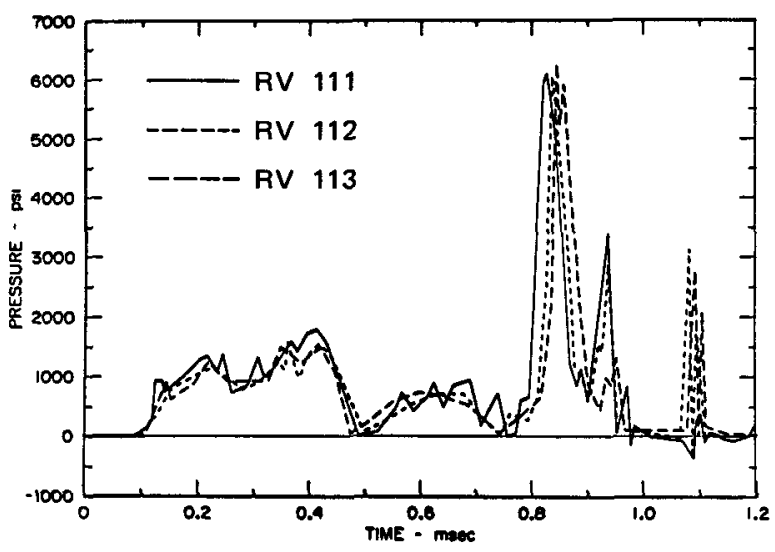

(c) WALL PRESSURE $\left(P_{5}\right)$

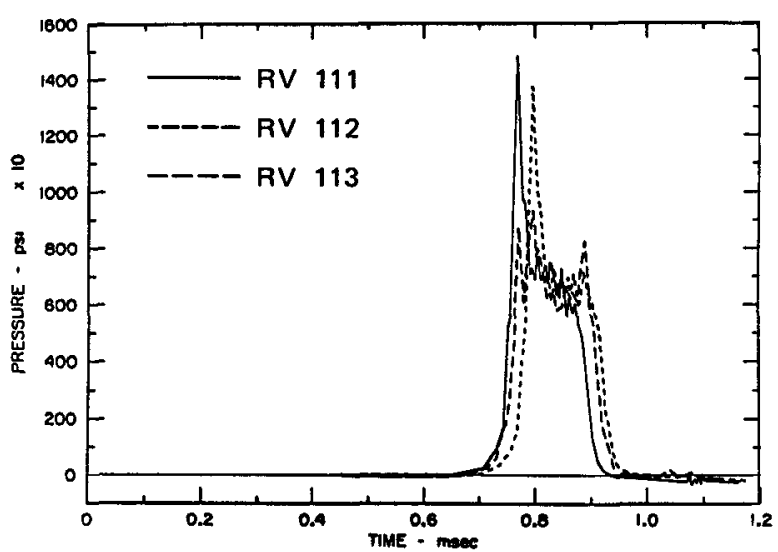

(e) COVER PRESSURE (CENTER) (P $)$

MA-1960-235

FIGURE B.3 REPRODUCIBILITY OF PRESSURE-TIME LOADINGS FROM RIGID VESSEL EXPERIMENTS 


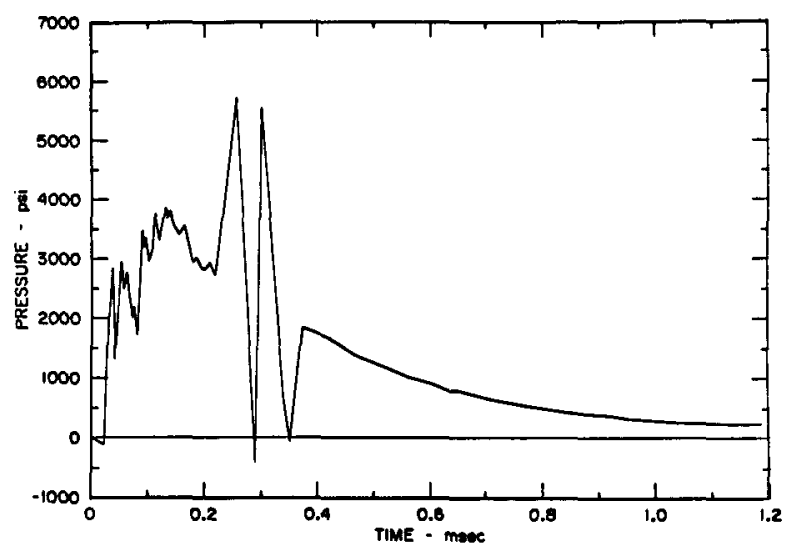

PRESSURE 1

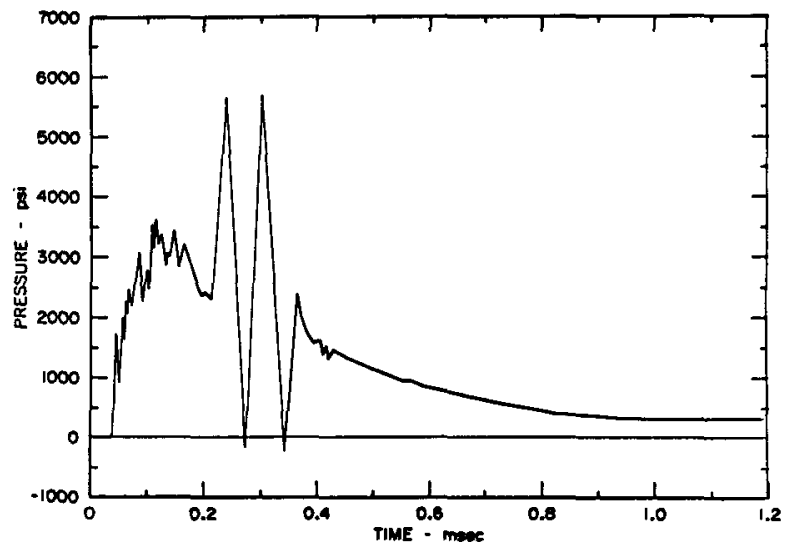

PRESSURE 3

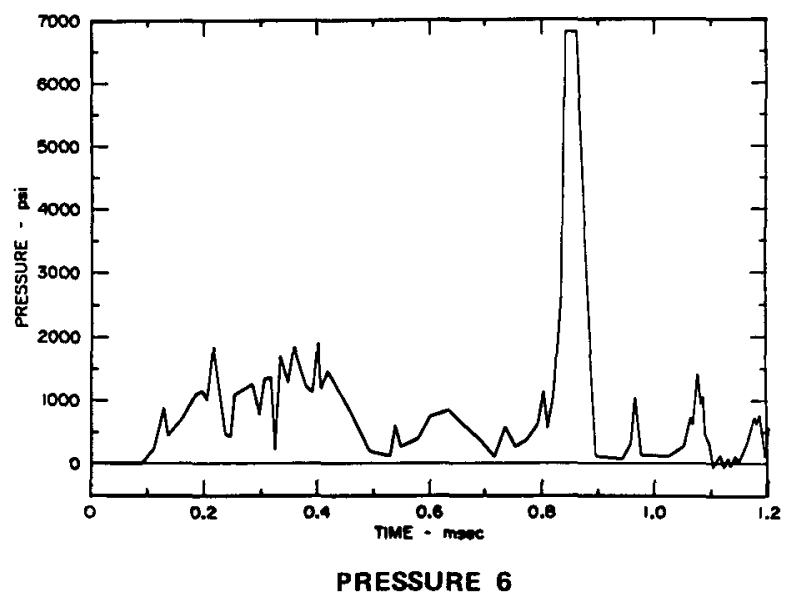

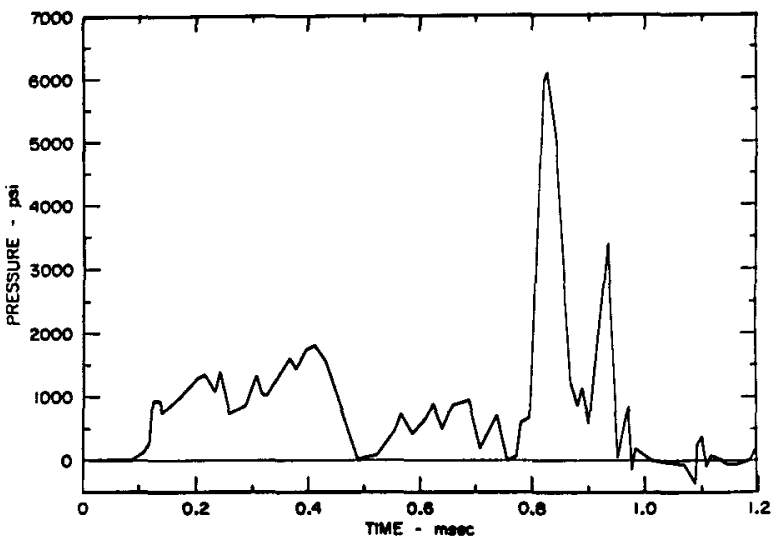

PRESSURE 5

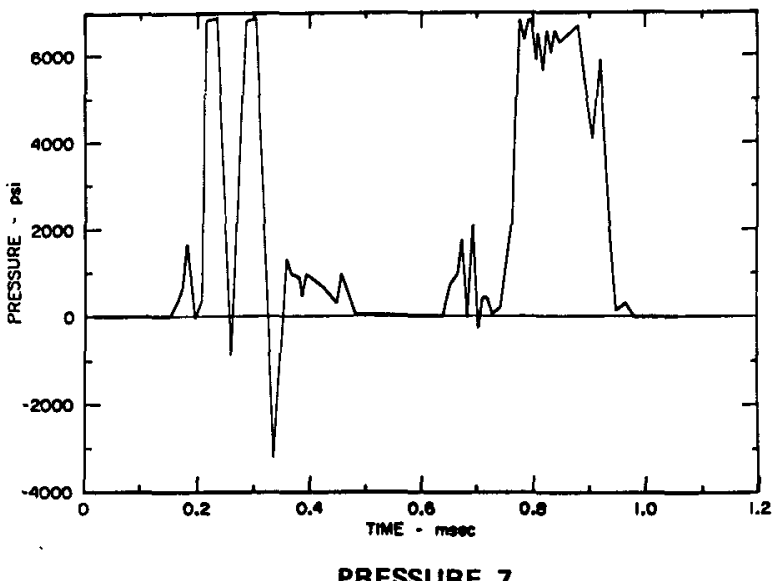

MA-1960-249

FIGURE B.4 PRESSURE-TIME LOADING: EXPERIMENT RV 111 

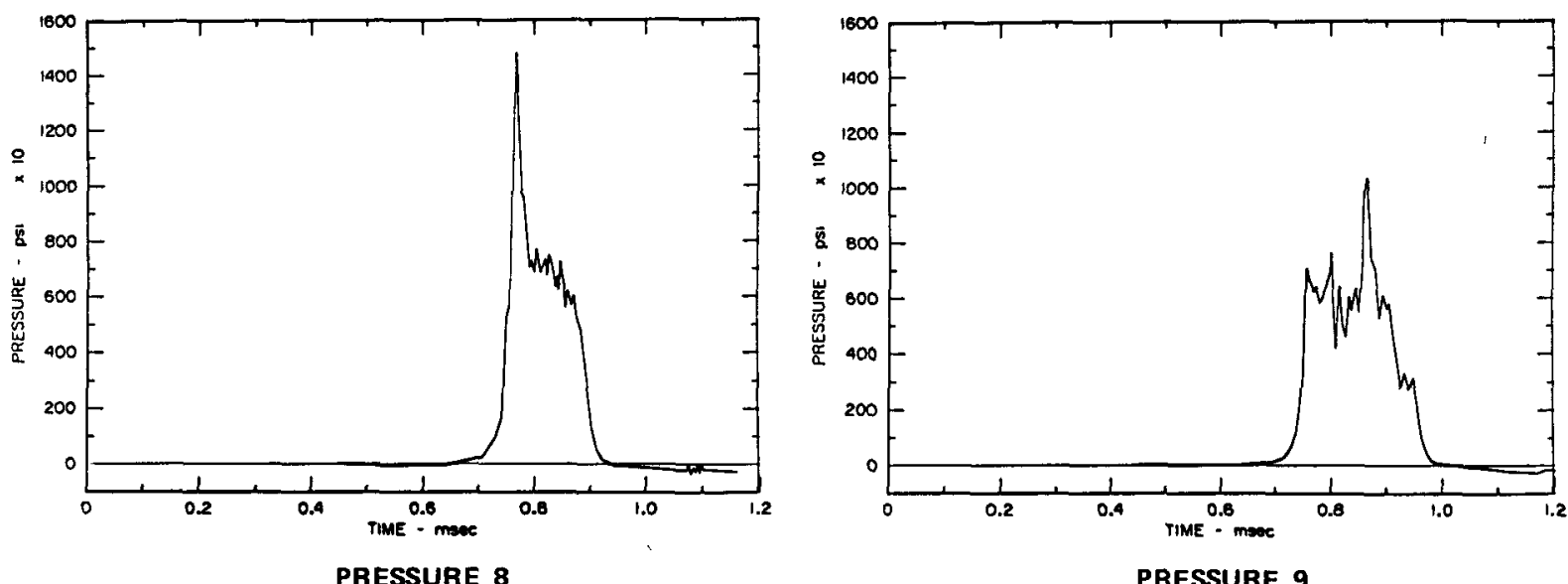

MA-1960-250

FIGURE B.4 PRESSURE-TIME LOADING: EXPERIMENT RV 111 (Concluded) 


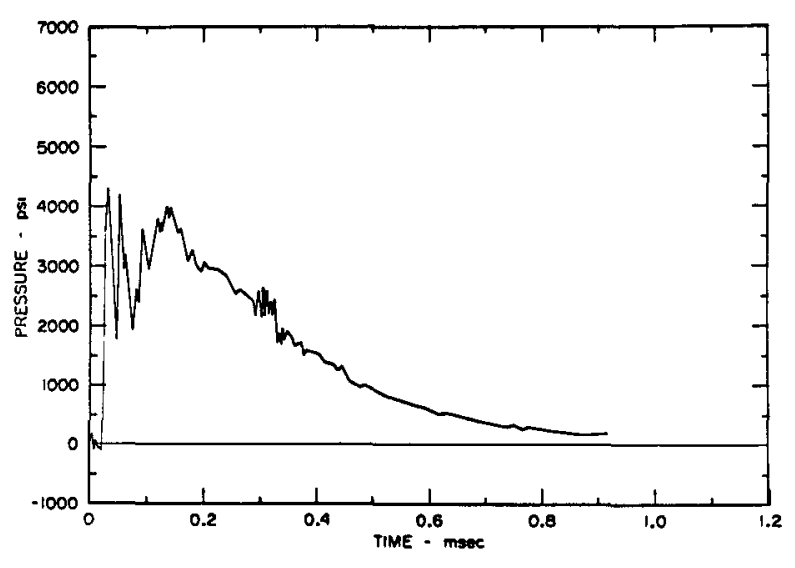

PRESSURE 1

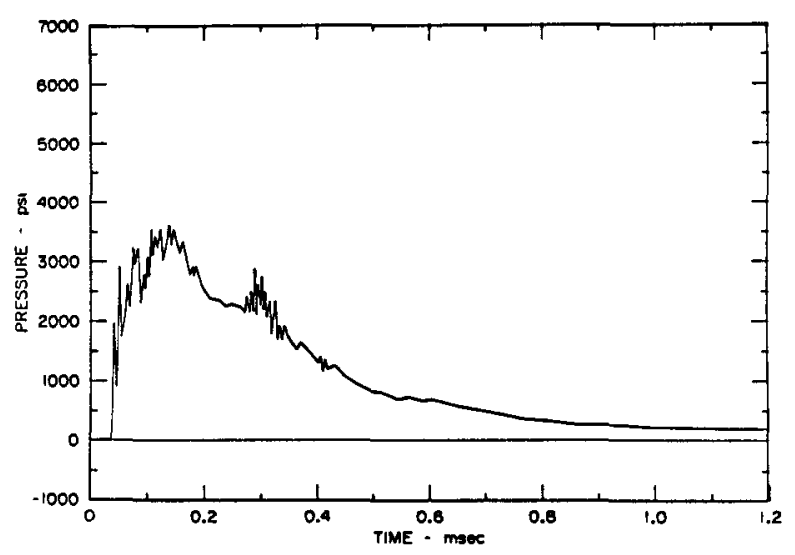

PRESSURE 3

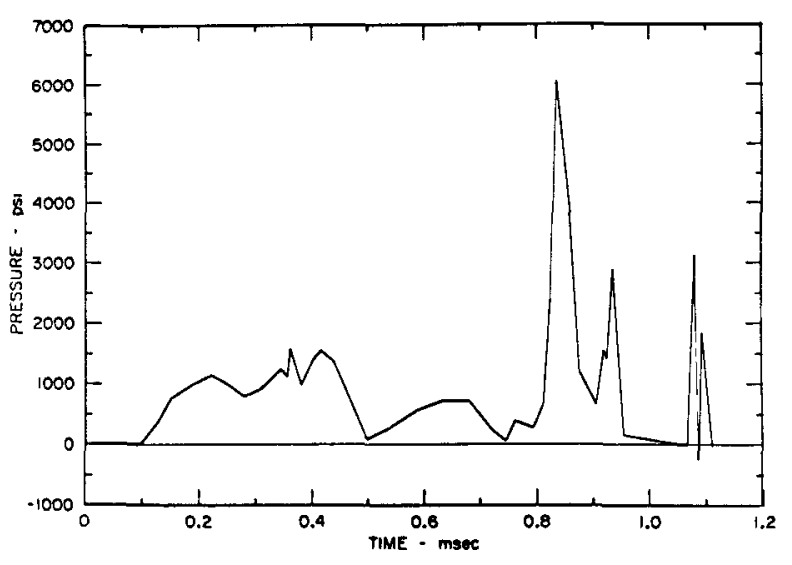

PRESSURE 5

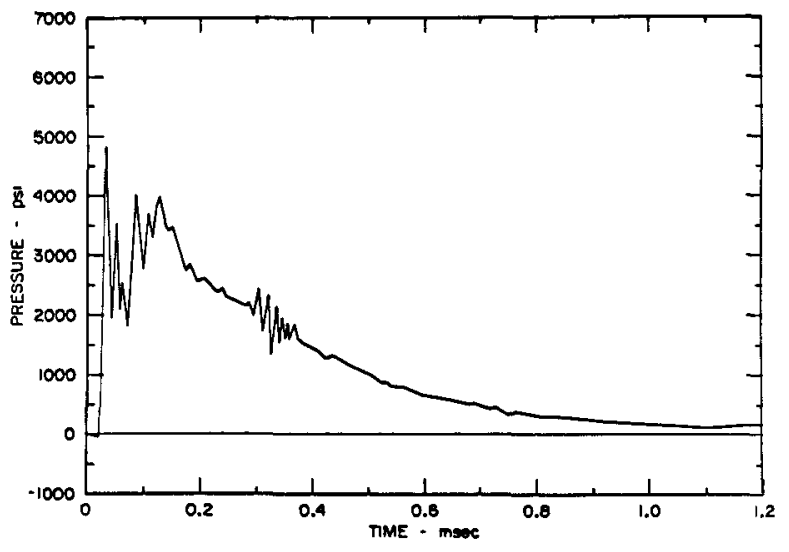

PRESSURE 2

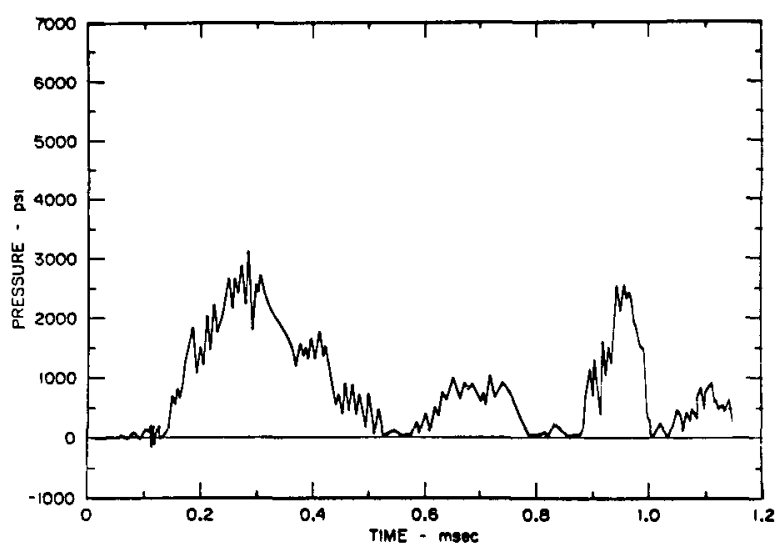

PRESSURE 4

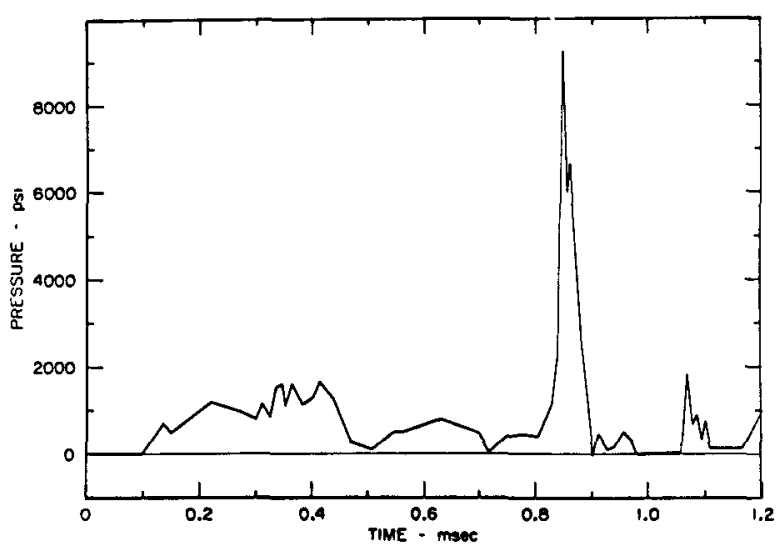

PRESSURE 6

FIGURE B.5 PRESSURE-TIME LOADING: EXPERIMENT RV 112 


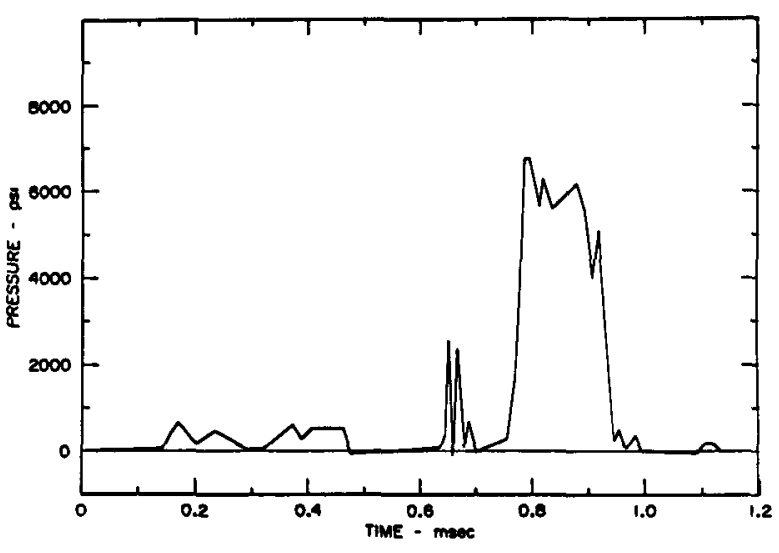

PRESSURE 7

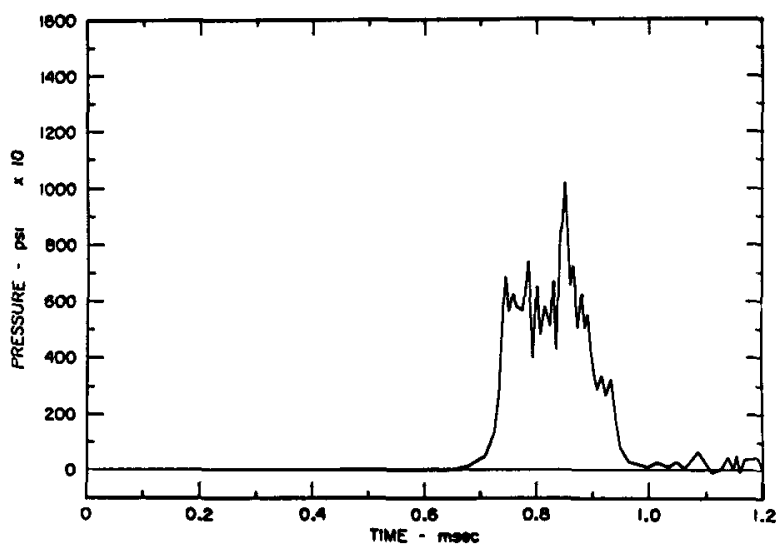

PRESSURE 9

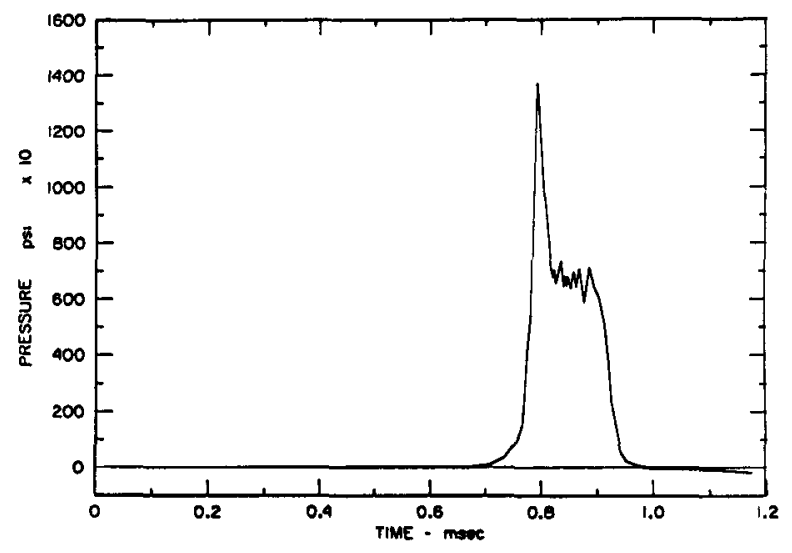

PRESSURE 8

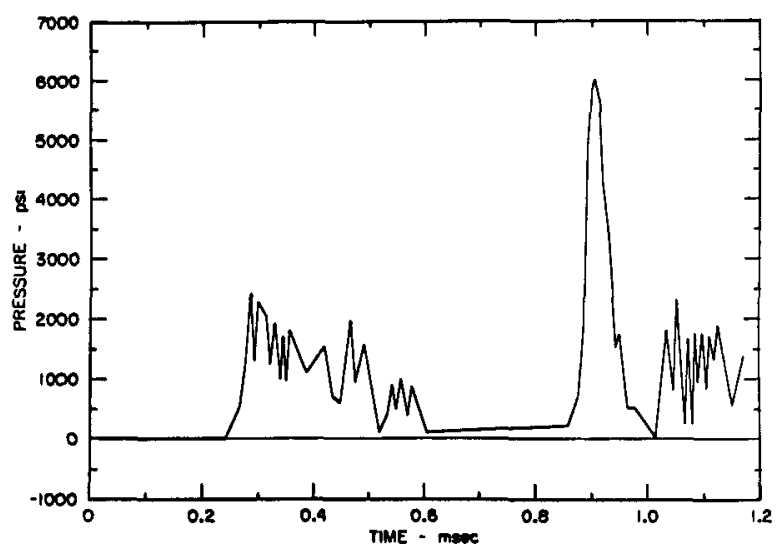

PRESSURE 10

FIGURE B.5 PRESSURE-TIME LOADING: EXPERIMENT RV 112 (Concluded) 


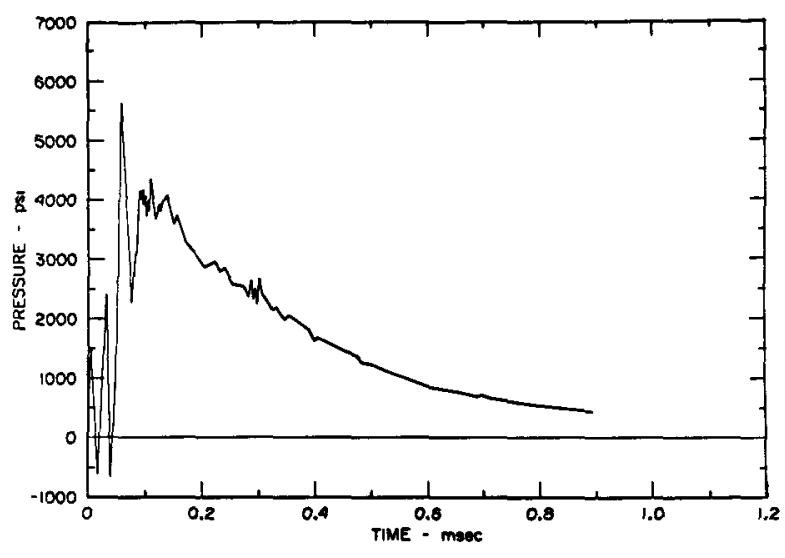

PRESSURE 1

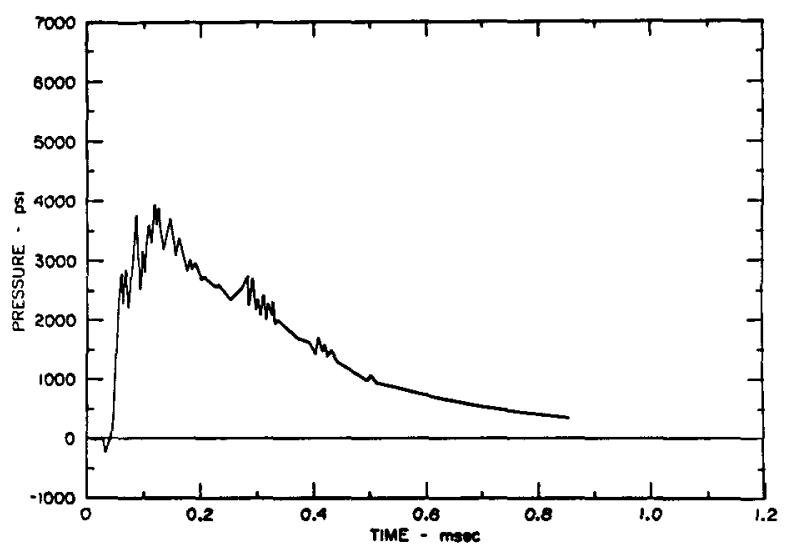

PRESSURE 3

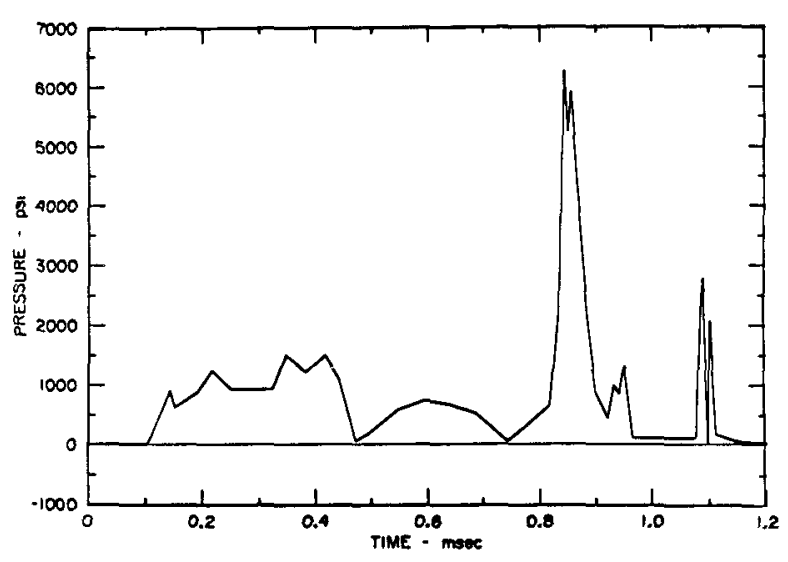

PRESSURE 5

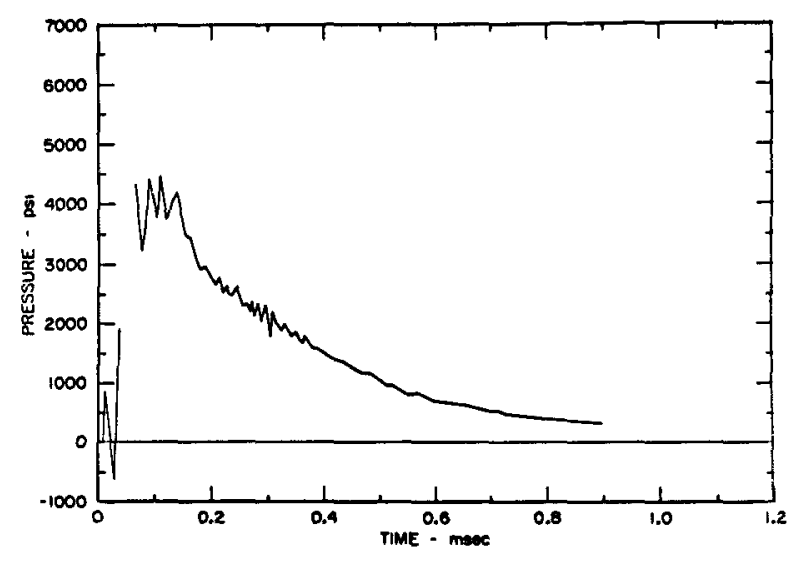

PRESSURE 2

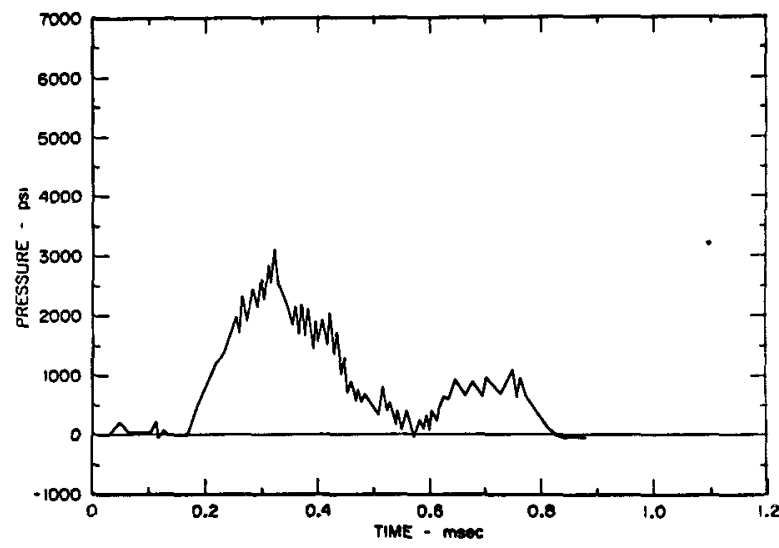

PRESSURE 4

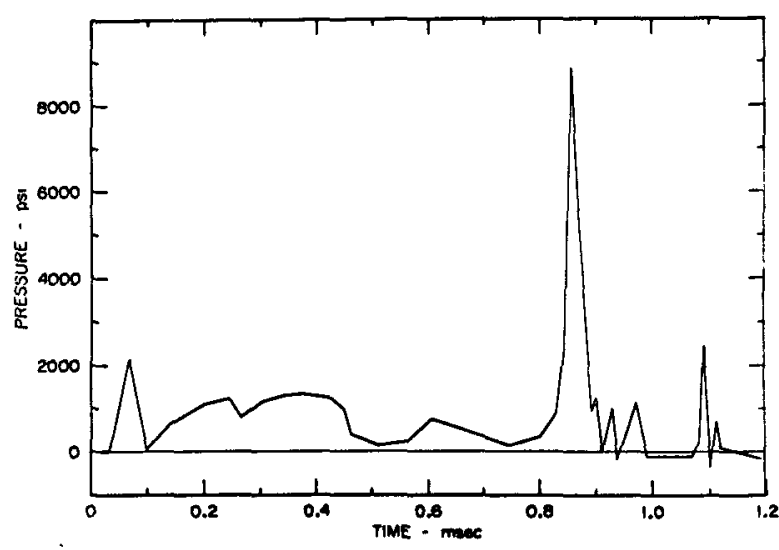

PRESSURE 6

FIGURE B.6 PRESSURE-TIME LOADING: EXPERIMENT RV 113 

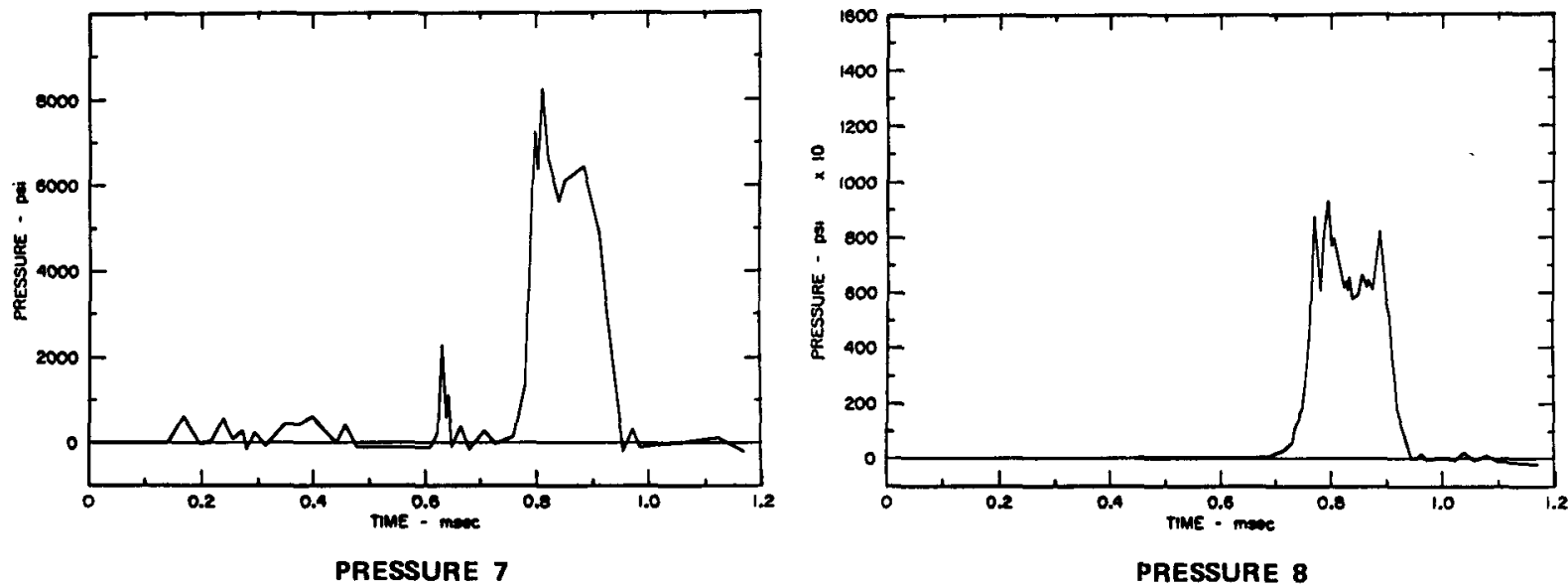

PRESSURE 8

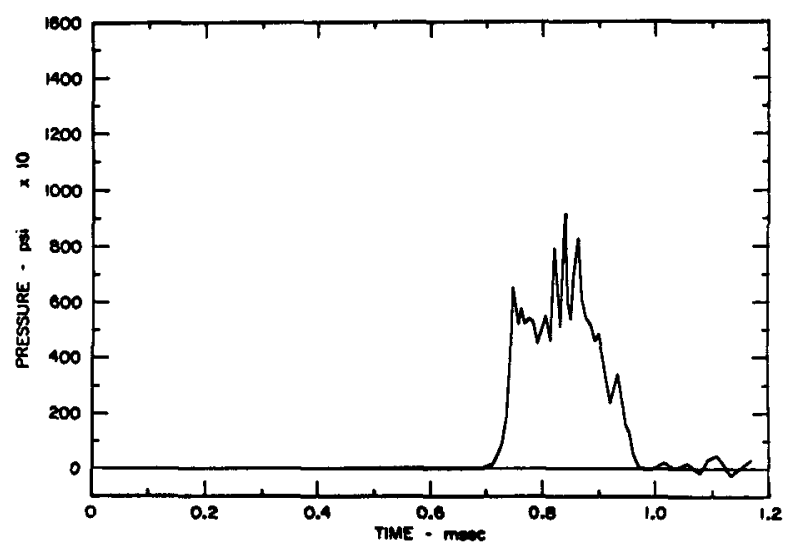

PRESSURE 9

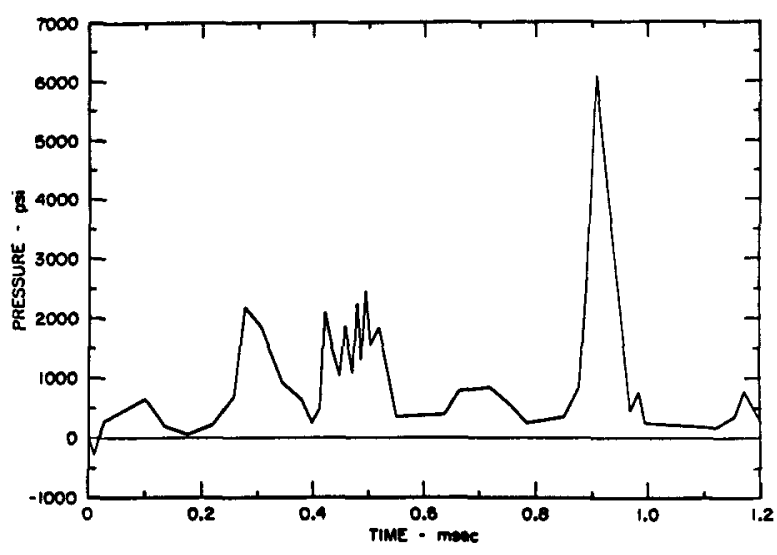

PRESSURE 10

MA-1960-254

FIGURE B.6 PRESSURE-TIME LOADING: EXPERIMENT RV 113 (Concluded) 


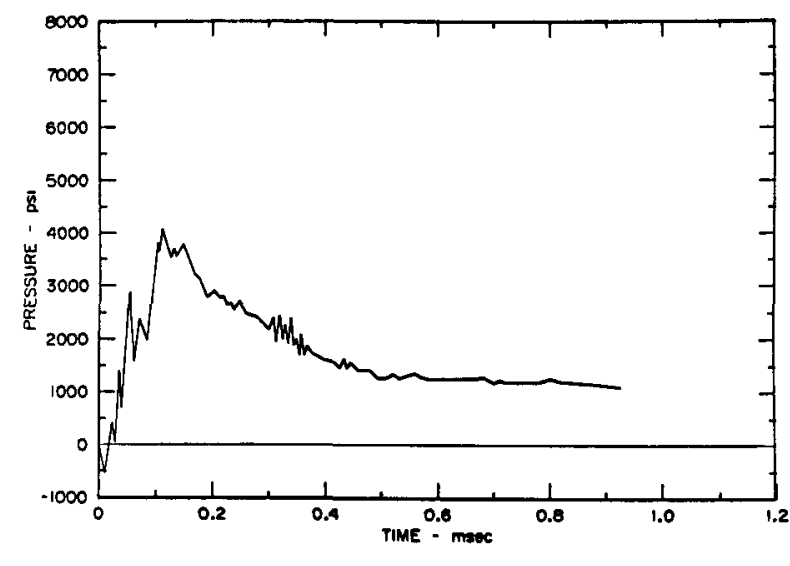

PRESSURE 1

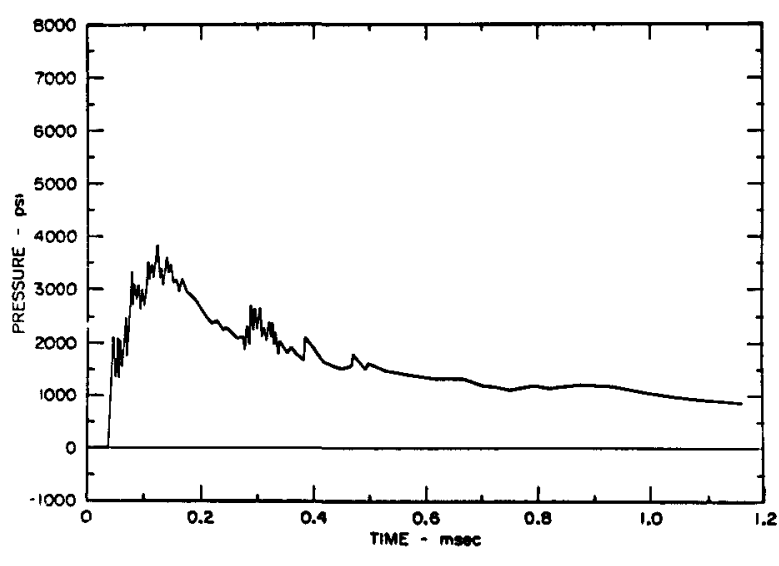

PRESSURE 3

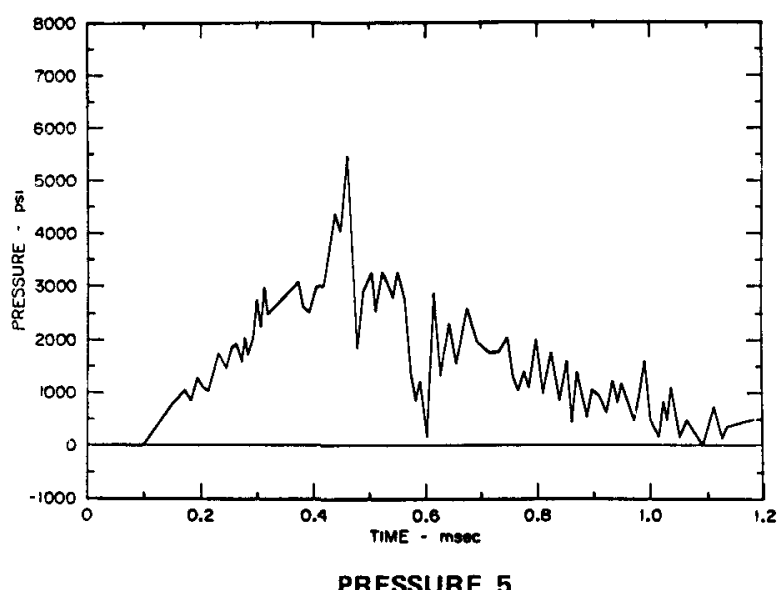

PRESSURE 5

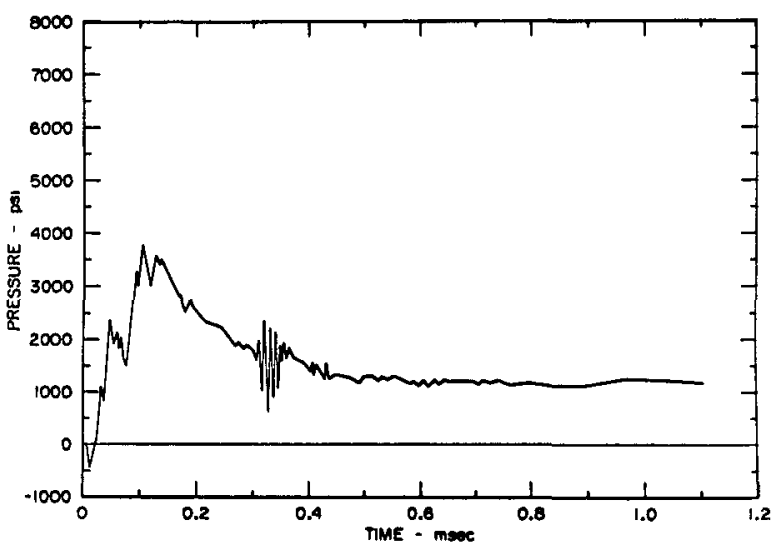

PRESSURE 2

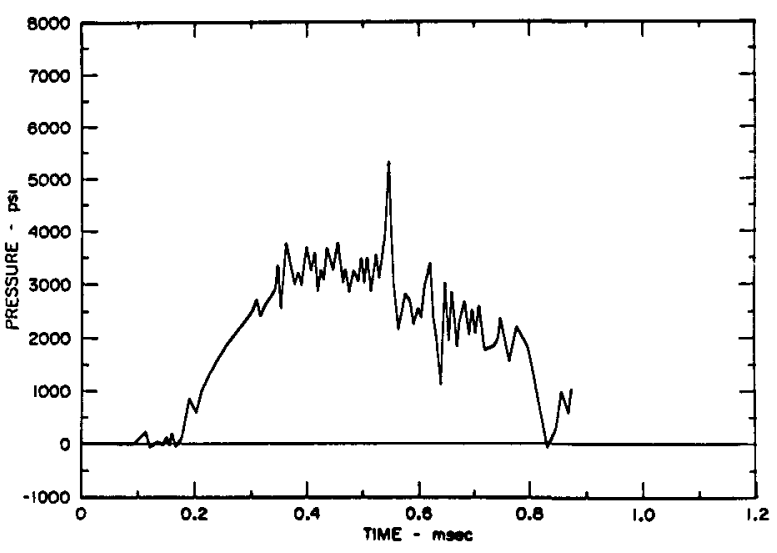

PRESSURE 4

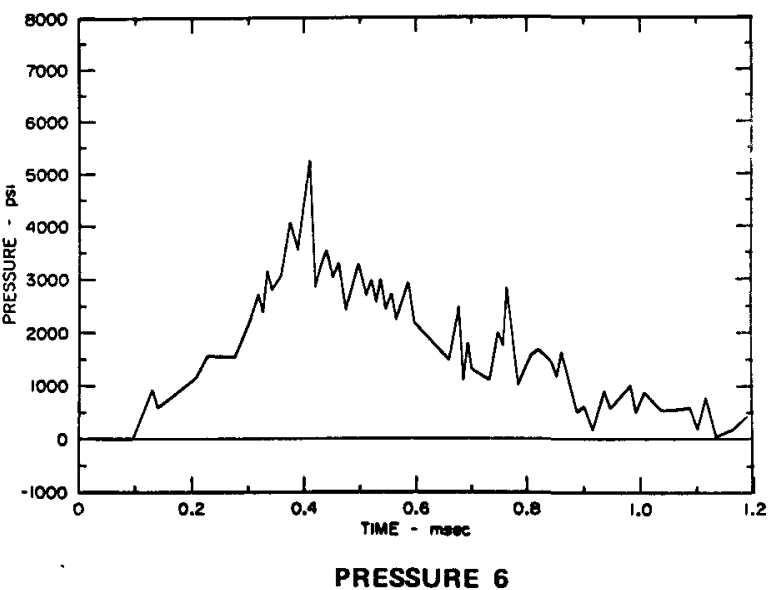

MA-1960-255

FIGURE B.7 PRESSURE-TIME LOADING: EXPERIMENT RV 114 

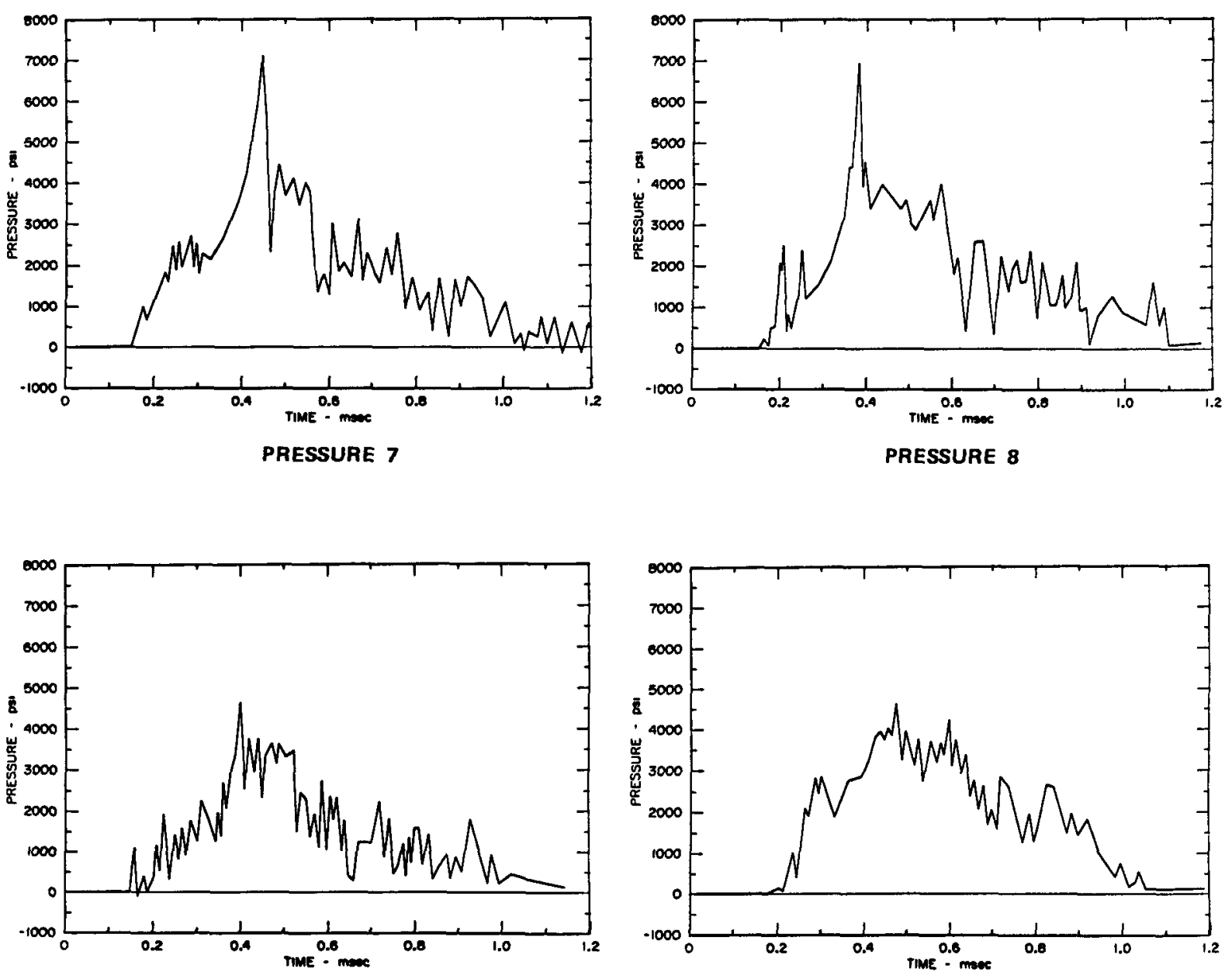

PRESSURE 9

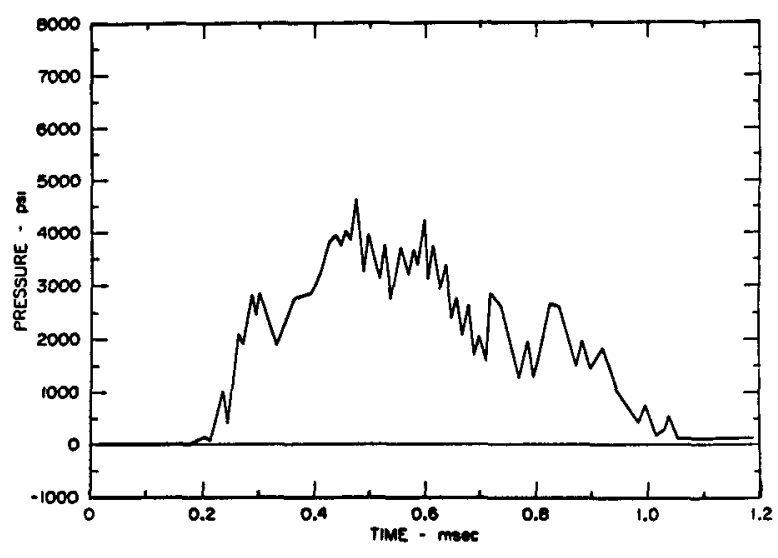

PRESSURE 10

MA-1960-256

FIGURE B.7 PRESSURE-TIME LOADING: EXPERIMENT RV 114 (Concluded) 


\section{Appendix C}

STRESS-STRAIN PROPERTIES OF FLEXIBLE VESSEL MATERIALS

\section{Ni 200 Stress-Strain Tests}

Stress-strain tests were performed on specimens cut from sections of each of the billets from which the flexible vessels were machined. The specimens were cut so that their axes were in the circumferential direction of the vessels. To ensure that the tensile specimens experienced the same heat treatment as the vessels, each batch of specimens went through the heat treating cycle (anneal at $1400^{\circ} \mathrm{F}$ for 10 minutes and then rapidly air cool) with its corresponding vessel. Figure C.1 shows a schematic drawing of a tensile specimen, including the strain gages that were applied to both sides of the active area of each specimen.

An MTS testing machine (Model TTCL-M1.6 Universal Testing Machine) was used to test the specimen. To provide information on strain rate effects in $\mathrm{Ni} 200$, tensile tests were performed at two strain rates. A low strain rate of about $4 \times 10^{-5} \mathrm{sec}^{-1}$ simulated a static loading condition, and a high strain rate of about $4 \times 10^{-2} \mathrm{sec}^{-1}$ simulated a dynamic loading condition. For comparison the maximum strain rate noted during the flexible vessel tests varied from $1.3 \times 10 \mathrm{sec}^{-1}$ to $1 \times 10^{2} \mathrm{sec}^{-1}$. Strain and axial force as a function of time were obtained for both types of stress-strain tests. During low-strain-rate tests, load and strain were recorded on a two-track $x-y$ plotter. For the high-strain-rate tests, load and strain data were recorded on dua1beam oscilloscopes. These data were then digitized for later computer analysis.

Table C.1 summarizes the stress-strain tests performed. The values of stress and strain listed in this table are engineering stress and strain; engineering stress is defined as $\sigma_{E}=F / A_{0}$, where $F$ is axial force and 


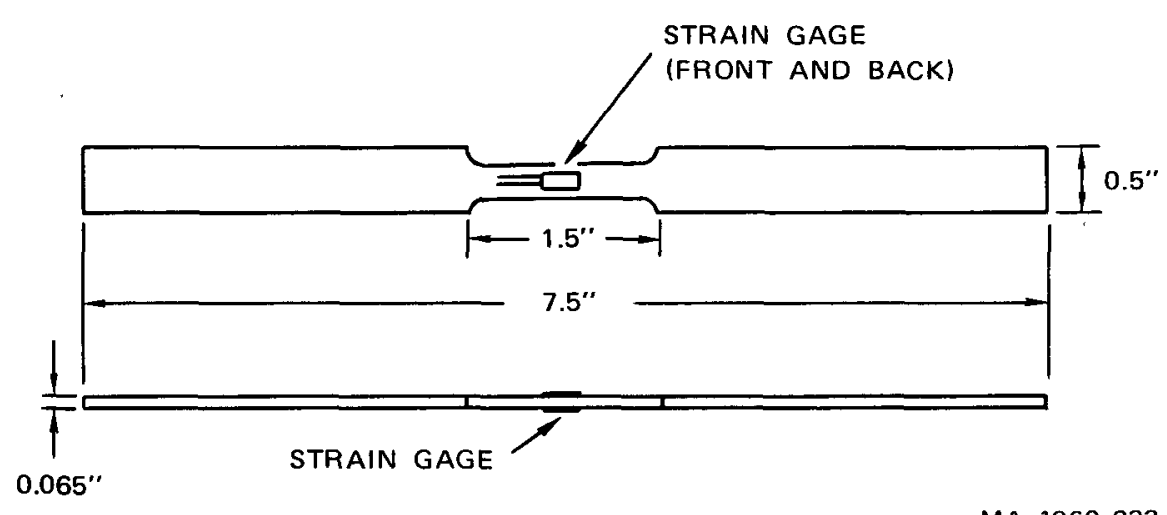

MA-1960-222

FIGURE C.1 TENSILE SPECIMEN FOR Ni 200 STRESS-STRAIN TEST

Table C.1

STRESS-STRAIN TESTS OF NI 200

\begin{tabular}{|l|c|c|c|c|}
\hline Specimen & $\begin{array}{c}\epsilon_{\mathrm{y}}^{*} \\
(\%)\end{array}$ & $\begin{array}{c}\sigma_{\mathrm{y}}^{*} \\
(\mathrm{psi})\end{array}$ & $\begin{array}{c}\dot{\epsilon} \\
\left(\mathrm{sec}^{-1}\right)\end{array}$ & $\begin{array}{c}\mathrm{E} \\
\left(10^{7} \mathrm{psi}\right)\end{array}$ \\
\hline Pretest & 0.04 & 15,000 & $5 \times 10^{-5}$ & 2.9 \\
$101 \mathrm{~A} 1$ & 0.04 & 13,000 & $2.5 \times 10^{-4}$ & 2.9 \\
$101 \mathrm{~A} 3$ & 0.08 & 14,000 & $4.7 \times 10^{-2}$ & 2.7 \\
$101 \mathrm{~B} 1$ & 0.08 & 14,000 & $3.6 \times 10^{-2}$ & 2.6 \\
$102 \mathrm{~B} 2$ & 0.05 & 14,000 & $4.3 \times 10^{-2}$ & 2.8 \\
$102 \mathrm{~B} 3$ & 0.04 & 12,500 & $4.5 \times 10^{-2}$ & 3.1 \\
\hline
\end{tabular}


$A_{0}$ is the initial cross-sectional area of the specimen, and engineering strain is defined as $\epsilon_{\mathrm{E}}=\delta l / \ell$ where $\delta l$ is the change in strain gage length and $l$ is the initial length of the strain gage. Listed in the table are the yield strain, $\epsilon_{y}$, the yield stress $\sigma_{y}$, the strain rate $\dot{\epsilon}$ and the Young's modulus $E$ for each specimen.

Figure C.2 shows the pretest, static, and dynamic stress-strain curves for each vessel. Figure C.3 shows the average dynamic stressstrain curve for each vessel.

\section{Stress-Strain Relationships for Core Barrel Materials}

Figure C.4 gives the stress-strain curves for the materials used in the flexible core barrel--the lead inner cylinder and the aluminum outer cylinder. The curves are based on measurements ${ }^{*}$ for aluminum and handbook data for lead. $\dagger$

*C. M. Romander, S. Klein, D. J. Cagliostro, "Lethality Tests and Analysis of Monocoque Shells." SRI Final Report, Contract DNA001-72-C-0095 (March 1974). (C).

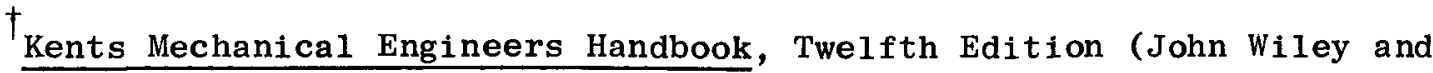
Sons, New York, 1965); Materials Selector, Materials Engineering (Reinhold Publications, Stamford, Conn., 1972). 


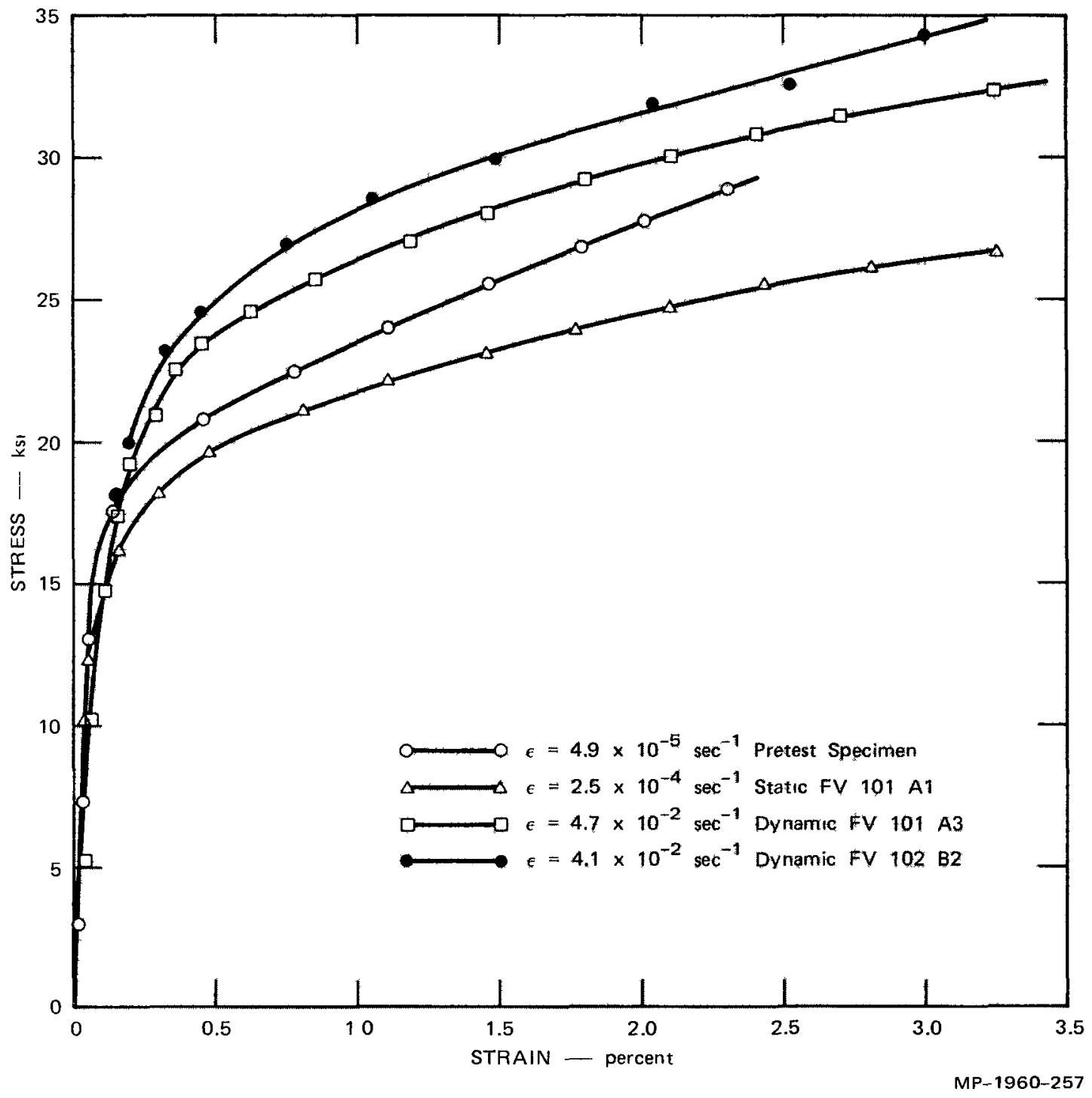

FIGURE C.2 MEASURED STRESS-STRAIN CURVES FOR N 200 


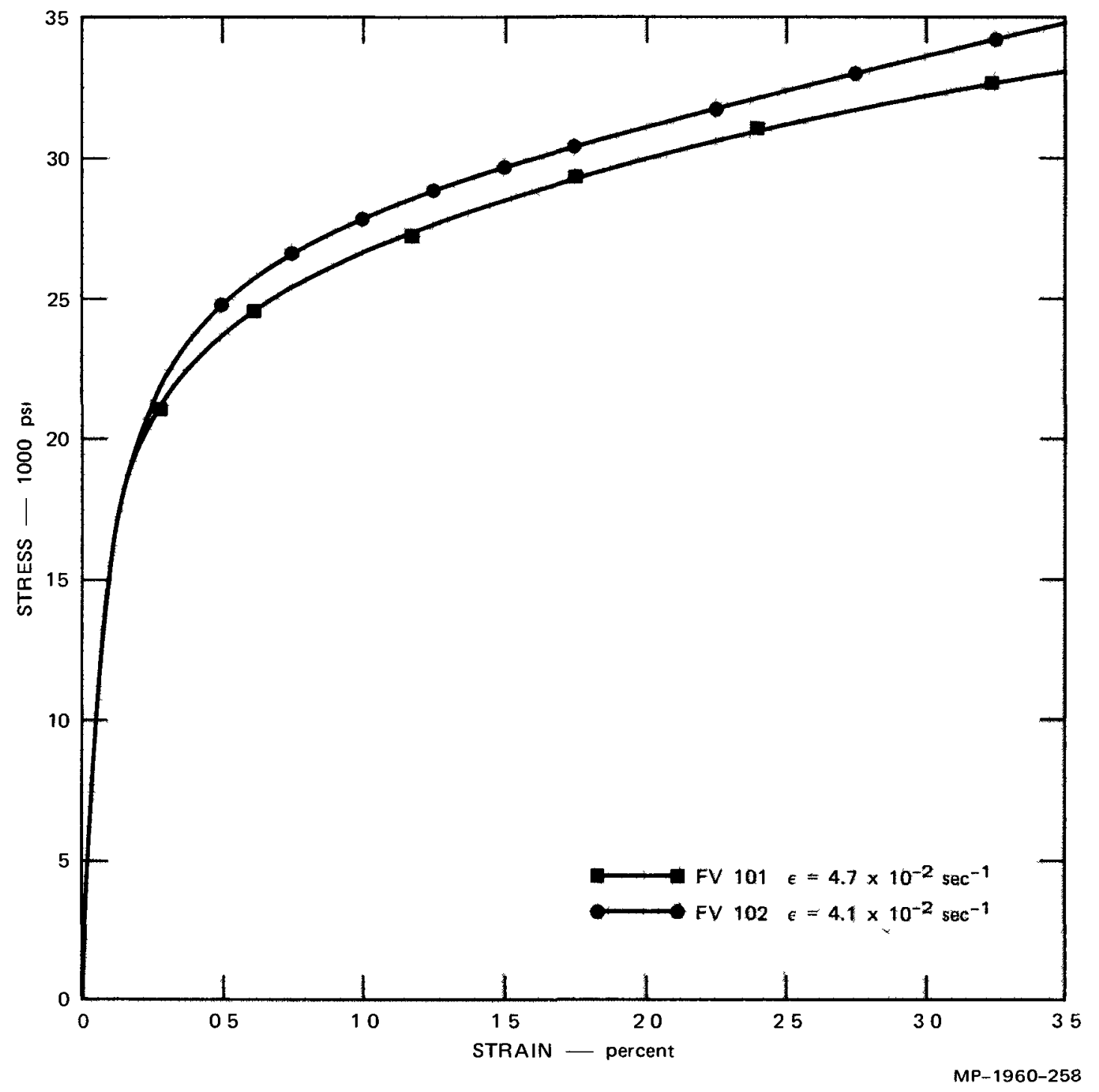

FIGURE C.3 AVERAGED DYNAMIC STRESS-STRAIN CURVES FOR EACH FLEXIBLE VESSEL 


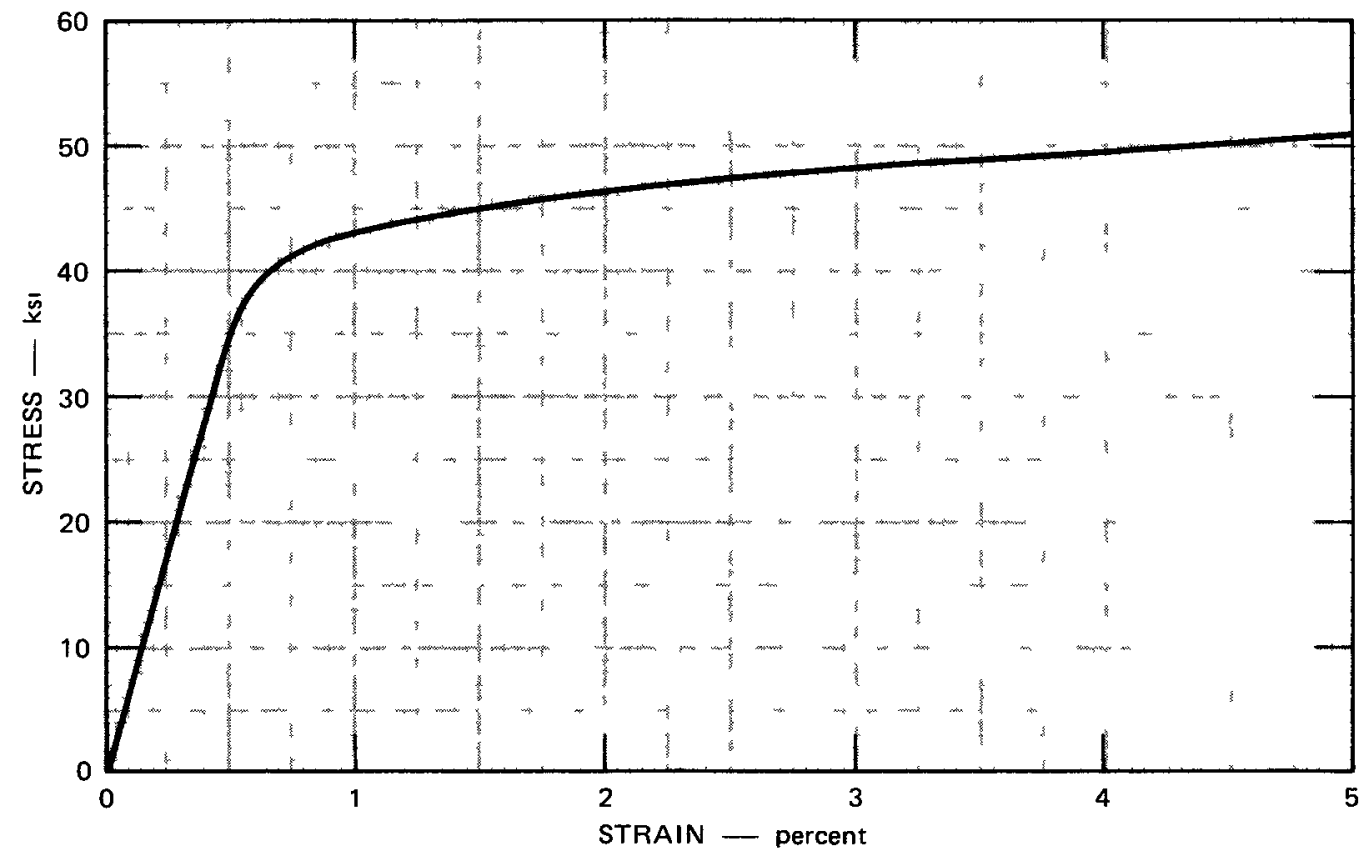

(a) STRESS-STRAIN CURVE FOR 6061-T6 ALUMINUM (ROMANDER, 1973)

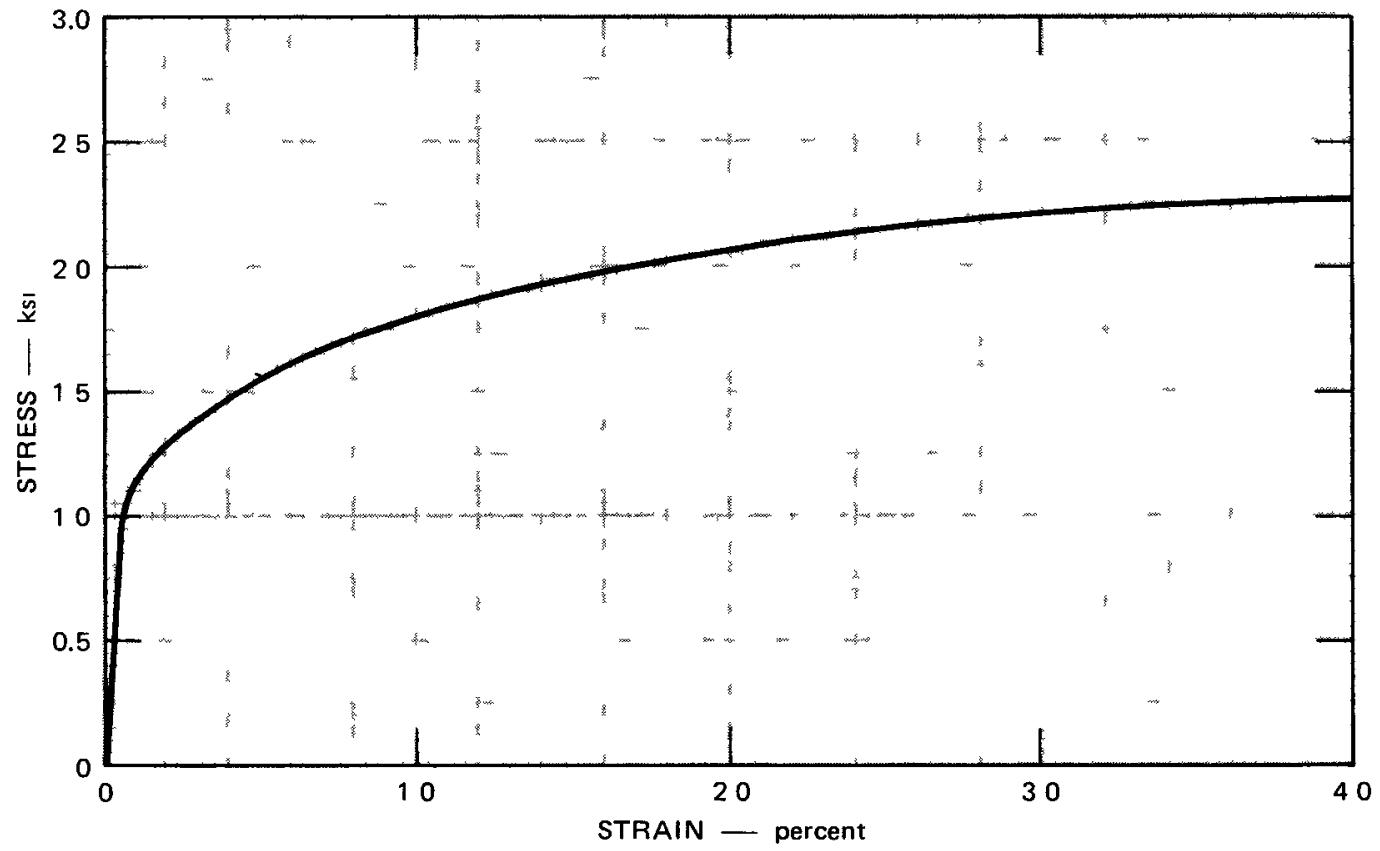

(b) STRESS-STRAIN CURVE FOR LEAD (KENT, 1965. MATERIALS ENGINEERING, 1972)

MP-1960-286

FIGURE C.4 STRESS-STRAIN PROPERTIES FOR FLEXIBLE CORE BARREL MATERIALS 


\section{Appendix D}

DETAILS OF THE FLEXIBLE VESSEL EXPERIMENTS

\section{Apparatus}

\section{Flexible Vesse1s}

The flexible vessel experiments were carried out in the apparatus shown in Figure D.1. The main components of this apparatus are the flexible vessel, the core, and the support fixture. The flexible vessels were machined from 1.5-inch-thick, 9-inch-diameter cylindrical billets of $\mathrm{Ni} 200$ produced under the same heat number at the forge. After machining, the vessels had an inside diameter of $8.000+0.002$ inches an overall length of $12.500 \pm 0.010$ inches and a wall thickness of $0.200+0.000$ inch. These tight tolerances were necessary to ensure precise vessel dimensions and to ensure proper fit of the vessel in the support fixture. The vessels were annealed by heating them to $1400^{\circ} \mathrm{F}$ for 10 minutes and then rapidly air cooling them. Three pressure gage bosses were welded to the vessel before final grinding of the inside diameter of the vesse1. Two of these bosses were located on opposite sides of the vesse1, 6 inches above the platform of the mode1. The third pressure gage boss was located 8.75 inches above the platform. This position was called out as the potential location of peak pressure and strain in the vessel wall based on analysis at Argonne National Laboratory.

The platform of the vessel model is a 1-inch-thick steel plate that is pressed into the bottom of the vessel. Close machining tolerances plus an O-ring around the perimeter of the base plate ensure a watertight fit. A single pressure gage is mounted in the base plate to measure 


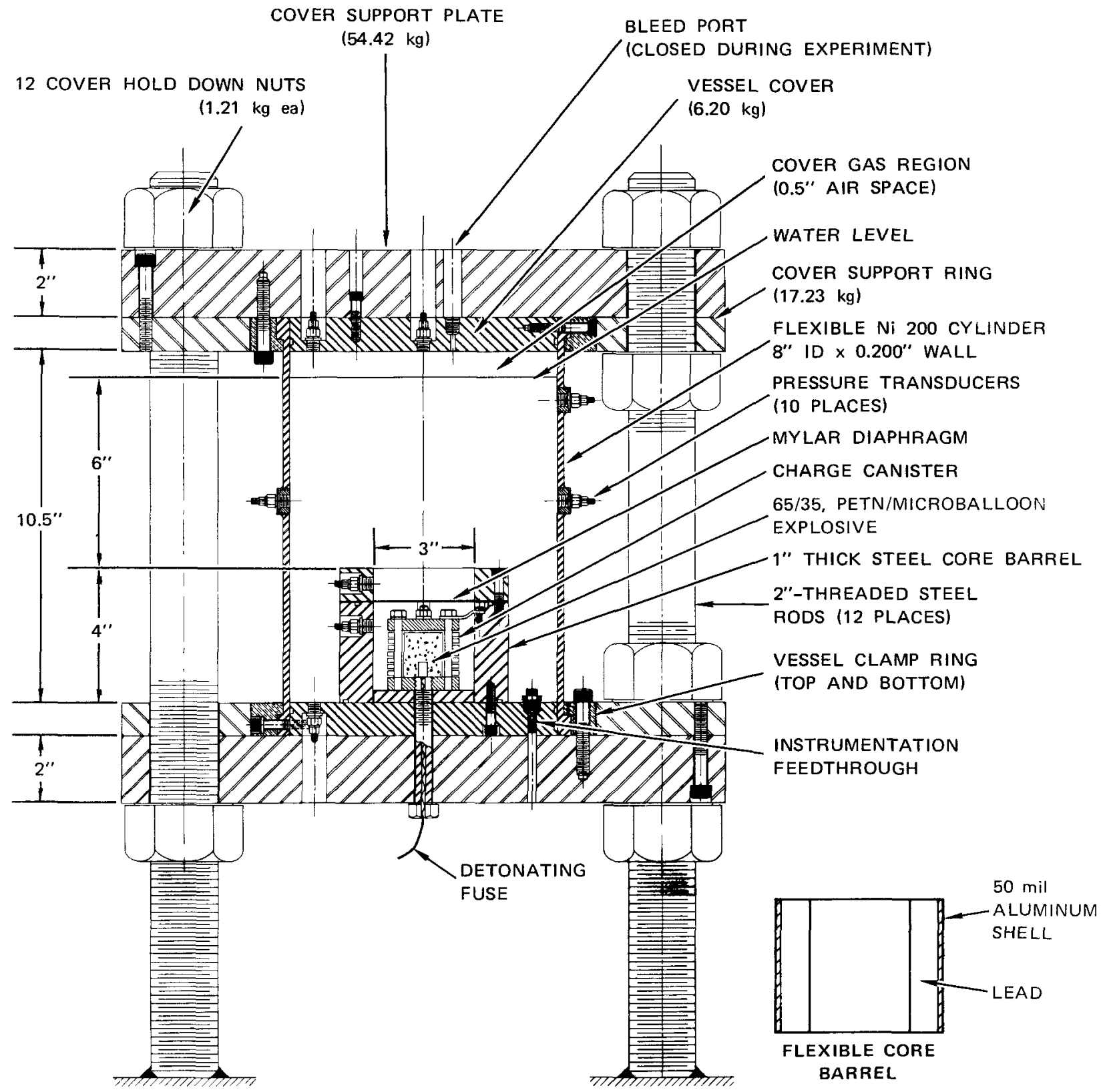

MA-1960-232

FIGURE D.1 FLEXIBLE VESSEL ASSEMBLY 
platform pressure. The cover plate is a l-inch-thick steel plate weighing $6.20 \mathrm{~kg}$ and machined to close tolerance so that it just fits into the vessel. Three pressure gages were mounted into the cover, one at the center of the plate and two spaced 90 degrees apart near the edge of the vesse1.

Two different core designs were used, one on each of the flexible vessel experiments. The rigid core used on the first flexible vessel experiment consists of a steel cylinder l-inch thick with an inside diameter of 3 inches and a length of 4 inches. The core barrel is thick enough to limit radial motion to less than 1 mil ( $0.03 \%$ strain). A Mylar diaphragm is clamped to the core barrel 3 inches above the base to prevent water from intruding into the air space volume of the energy source. The core barrel is bolted to the base plate to prevent any radial motion or gas leakage.

The flexible core used on the second flexible vessel experiment is shown in Figure D.2. The overall dimensions of the flexible core barrel are the same as for the rigid core but consists of a 0.950-inchthick cylinder of pure lead surrounded by a 0.050-inch-thick cylinder of 6061-T6 aluminum. The lead and aluminum were machined so that there is no gap between them. A Mylar film was placed 3 inches above the platform to prevent water intrusion. To ensure that no radial motion could take place at the base of the core, the core was recessed into the platform 0.375 inch and bolted in place.

Both flexible vessels were filled with water to a depth of 10 inches above the platform ( 6 inches above the top of the core) leaving a 0.5inch-thick cover gas region between the water and the cover. 


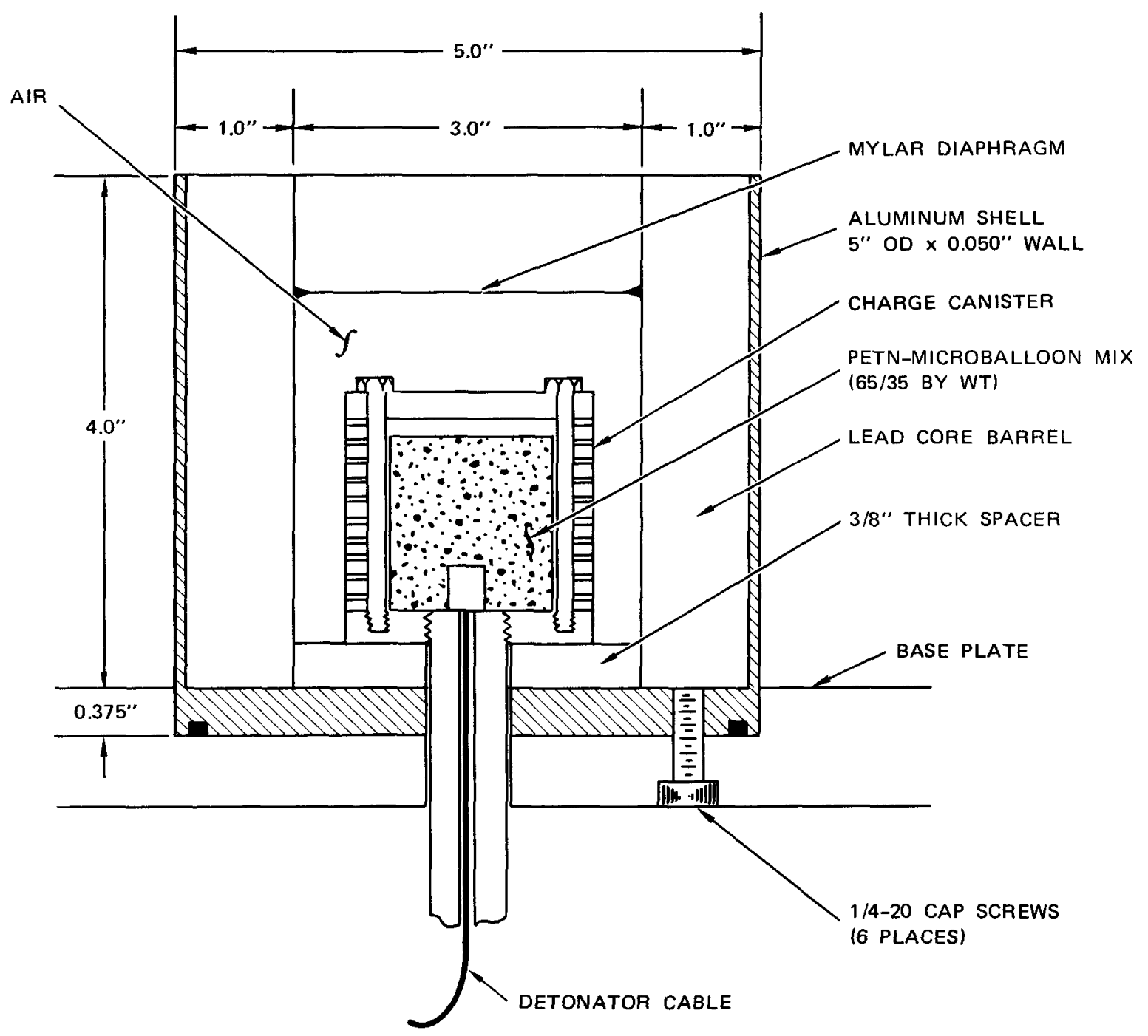

MA-1960-259

FIGURE D.2 FLEXIBLE CORE BARREL ASSEMBLY 


\section{Boundary Conditions}

To provide a precise experiment, great care was taken to ensure that the boundary conditions of the vessels were well defined. These conditions are: that there be no axial motion of the vessel; that there be no radial motion of the ends of the vessel; and that there be no rotation of the ends of the vessel. To prevent axial motion, the vessels were bolted between two massive 2-inch-thick steel support plates each weighing $54.4 \mathrm{~kg}$. The axial constraint was provided by twelve 2-inch-diameter threaded steel studs (cross sectional area of $\left.2.67 \mathrm{in}^{2} \mathrm{each}\right)$. The hold-down nuts $(1.2 \mathrm{~kg}$ each) were secured on both sides of the top and bottom plates to prevent extension or compression of the vessel.

Radial motion and rotation of the ends of the vessel were prevented by rings clamped to each end of the vessel. These rings were segmented into three parts each and had a cross-sectional L-shape. Figure D.3 shows one of the sections of the ring being installed on the bottom of the vesse1. The ring segments clamped down over a flange that was machined out of the vessel wall. The segmented clamp rings were bolted to the vessel by a total of 24 radial bolts ( 4 per segment; top and bottom). The rings were then bolted to the cover and base support plates by a total of 24 axial bolts ( 4 per segment, top and bottom). To provide additional radial and rotational support, a 1-inch-thick steel support ring was placed over the outside of the segmented rings and over the 2-inch-diameter studs (see Figure D.1). The combination of the segmented rings and the support ring prevented any radial motion of the vessel, and the close tolerances and tight fit of the vessel and rings prevented rotation of the ends of the vessel. 


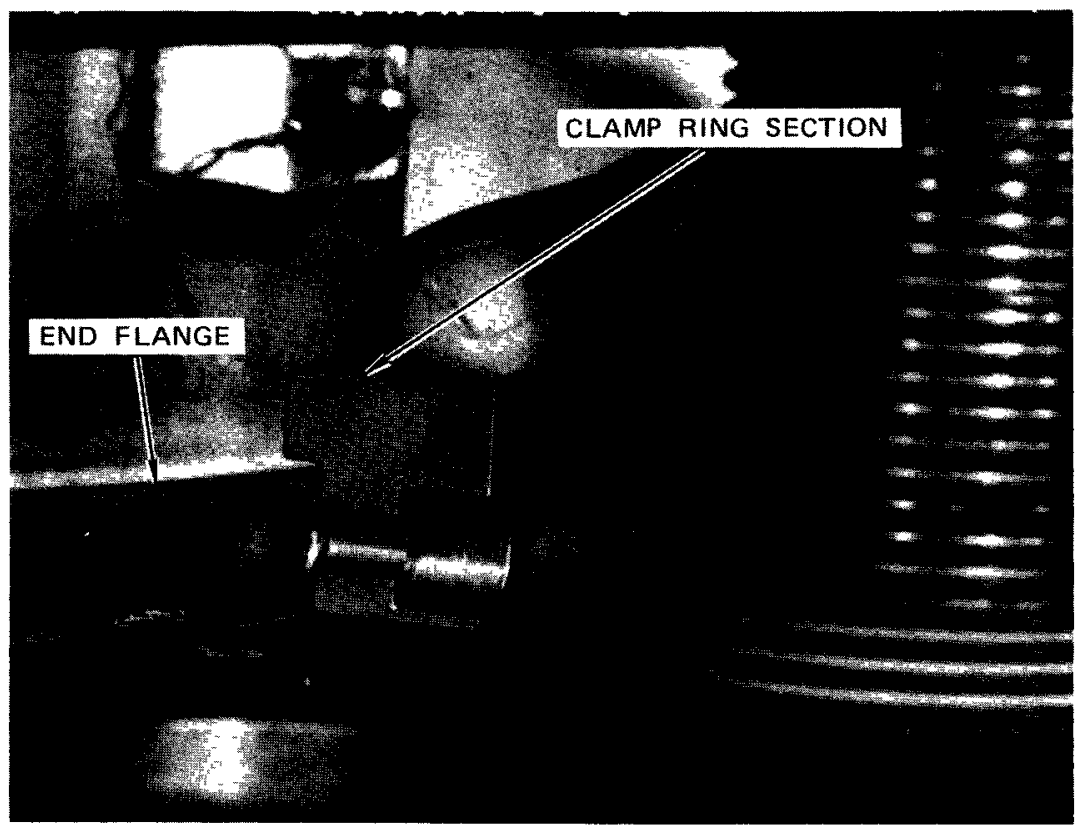

$M P-1960-260$

FIGURE D.3 VESSEL END FLANGE AND CLAMP RING

$$
\text { D-6 }
$$


Figure D.4 shows the detailed instrumentation layout for both flexible vessel experiments. Piezoelectric pressure gages (PCB Model $113 \mathrm{A03} / 61$ ) with a natural frequency of $450 \mathrm{kHz}$ were used for the pressure transducers on both experiments. High elongation strain gages capable of measuring strains up to $5 \%$ were used on both experiments. Two linear potentiometers (linipots) were used on both experiments to measure cover displacement.

For the flexible vessel model with a rigid core, 10 pressure transducers were used. Three of these transducers were mounted in the core, one in the platform, two in the vessel wall 6 inches above the platform, one in the wall 8.75 inches above the platform, and three in the cover. On this experiment, 15 strain gages were used in the locations shown in Figure D.4(a). A single linipot measured the cover motion.

For the flexible vessel model with a flexible core, 7 pressure transducers were used. Their layout was identical to the first vessel experiment except that the pressure gages mounted in the core were replaced by strain gages. A total of 16 strain gages were used in the locations shown in Figure D.4(b). Two linipots were used on this experiment, one to measure cover motion and the other to measure the motion of the table to which the model was attached.

\section{Experiment Specifications}

Table D.l lists the two flexible vessel experiments performed on this program. The table gives all the pertinent dimensions of the models and the specifications for the experiments.

* Catalog No. EP-08-250EG-120, Manufactured by Micro Measurements, Romulus, Michigan. 


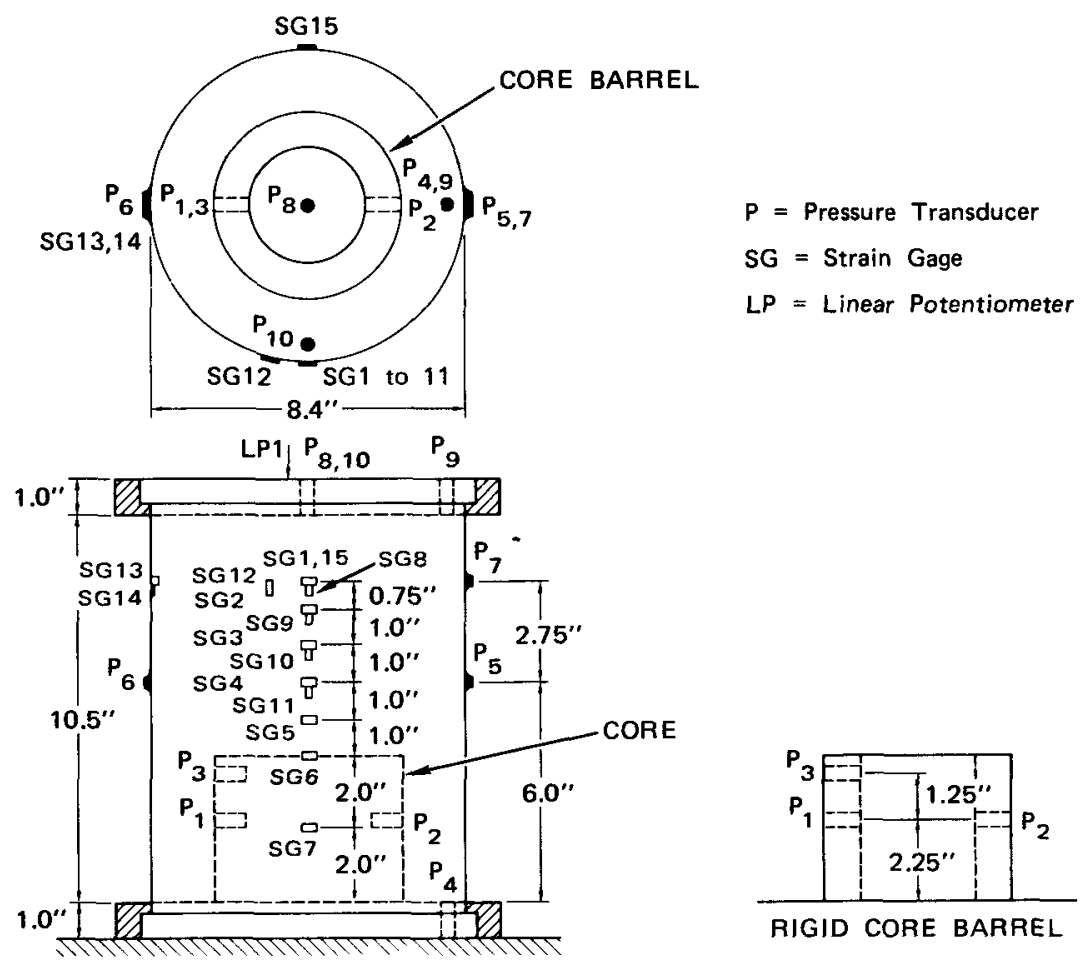

(a) EXPERIMENT FV 101 FLEXIBLE VESSEL WITH A RIGID CORE BARREL
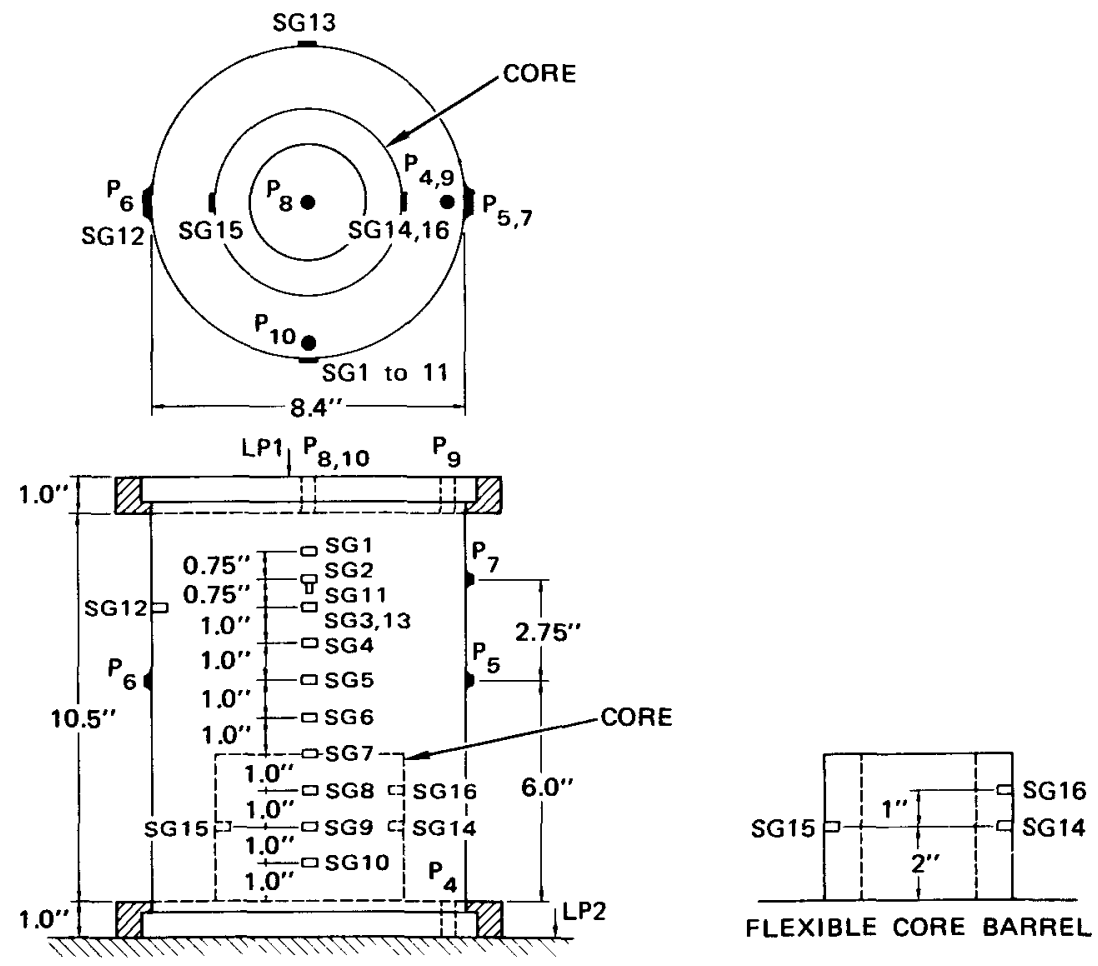

(b) EXPERIMENT FV 102 FLEXIBLE VESSEL WITH A FLEXIBLE CORE BARREL

MA-1960-261

FIGURE D.4 INSTRUMENTATION LAYOUT FOR FLEXIBLE VESSEL EXPERIMENTS 
Table D. 1

SPECIFICATIONS OF FLEXIBLE VESSEL EXPERIMENTS

\begin{tabular}{|c|c|c|c|c|c|c|c|c|c|}
\hline $\begin{array}{c}\text { Experiment } \\
\text { Number }\end{array}$ & $\begin{array}{c}\text { Vesse } 1 \\
\text { I.D. } \\
\text { (in.) }\end{array}$ & $\begin{array}{c}\text { Wa11 } \\
\text { Thickness } \\
\text { (in.) } \\
\end{array}$ & $\begin{array}{c}\text { Vesse1 } \\
\text { Height } \\
\text { (in.) }\end{array}$ & $\begin{array}{l}\text { Initial } \\
\text { Core } \\
\text { Volume } \\
\left(\mathrm{cm}^{3}\right) \\
\end{array}$ & $\begin{array}{l}\text { Cover Gas } \\
\text { Volume } \\
\left(\mathrm{cm}^{3}\right) \\
\end{array}$ & Material & $\begin{array}{c}\text { Core Barrel } \\
\text { Dimensions } \\
\text { I.D. } \times 0 . \text { D. } \times \text { L } \\
\text { (in.) }\end{array}$ & $\begin{array}{c}\text { Charge } \\
\text { (g) }\end{array}$ & $\begin{array}{l}\text { Charge } \\
\text { Mixture } \\
\text { (by wt) }\end{array}$ \\
\hline FV 101 & 8.00 & 0.200 & 10.5 & 226.5 & 411.9 & Steel & $3 \times 5 \times 4$ & 8 & $65 / 35$ \\
\hline FV 102 & 8.00 & 0.200 & 10.5 & 226.5 & 411.9 & $\begin{array}{l}\text { Lead } \\
\text { Aluminum }\end{array}$ & $\begin{array}{l}3 \times 4.900 \times 4 \\
4.900 \times 5 \times 4\end{array}$ & 8 & $65 / 35$ \\
\hline
\end{tabular}


Measurements

\section{Sample Records}

Figure D.5 shows oscilloscope records from experiment FV 101. The records do not begin at time $t_{0}$ (the time the electronic detonating unit was triggered) because a length of mild detonating fuse was placed between the EDU and the charge in the core. The fuse was used to isolate in time any noise bursts produced by the dumping of the capacitors in the detonating unit. The burn time for the fuse results in a delay of several hundred microseconds from time $t_{0}$ to the charge detonation in the core. Five feet of fuse were used on experiment RV 101, resulting in a delay of 210 Hsec. Ten feet of fuse were used on experiment FV 102, resulting in a delay of $420 \mu \mathrm{sec}$.

\section{Data Reduction}

A11 data were also recorded on high speed tape recorders and played back on a recording oscillograph (Visicorder Model No. 5-124) to obtain a visual record of the data. Figure D.6 shows a sample record from the Visicorder. These three records are of strain measurements taken from the vessel wall in test FV 101. The records are preceded by a calibration record that is recorded on the magnetic tape before the test. The test records clearly show the time the EDU is triggered $(t=0)$ and the time for the fuse to burn. The signal at the bottom of the record is the timing channel showing a 10-kHz signal (100 Hsec between peaks). The timing channel also shows the EDU trigger pulse.

For analysis, the magnetic tape records (analog records) were played back through an analog-to-digital converter (A/D) to produce a digital form of the data. The digital data were then processed to provide computer plots of the data and a tabular record of each measurement. The $A / D$ converter samples at a rate of up to 5000 points 

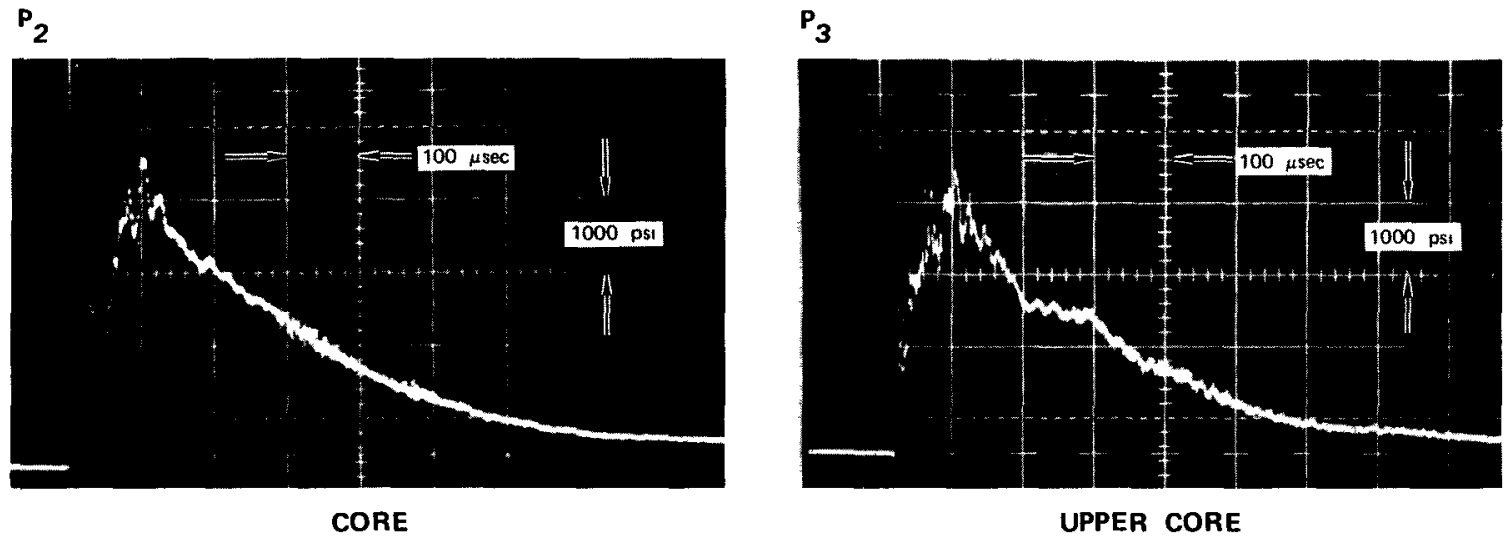

UPPER CORE

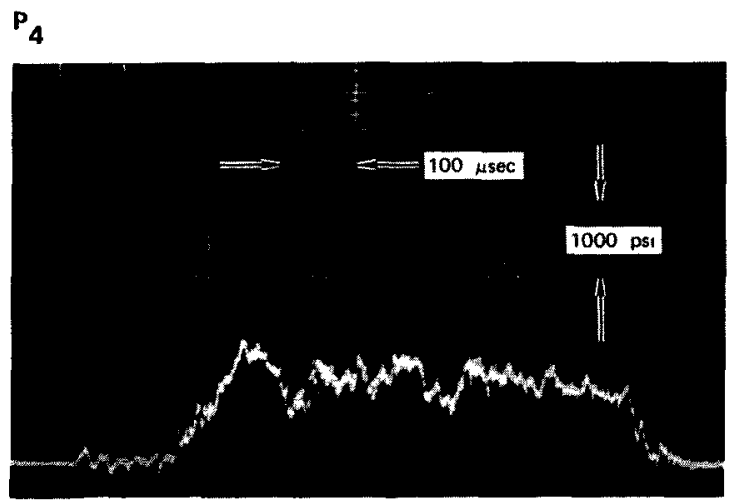

PLATFORM

NOTE Records start $110 \mu \mathrm{sec}$ before detonation of charge.

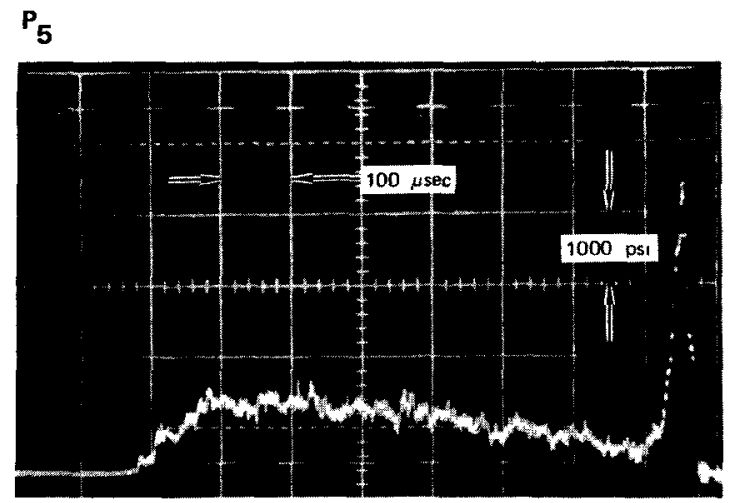

WALL

MP-1960-262

FIGURE D.5 SAMPLE PRESSURE OSCILLOGRAMS FROM FLEXIBLE VESSEL EXPERIMENT FV 101 


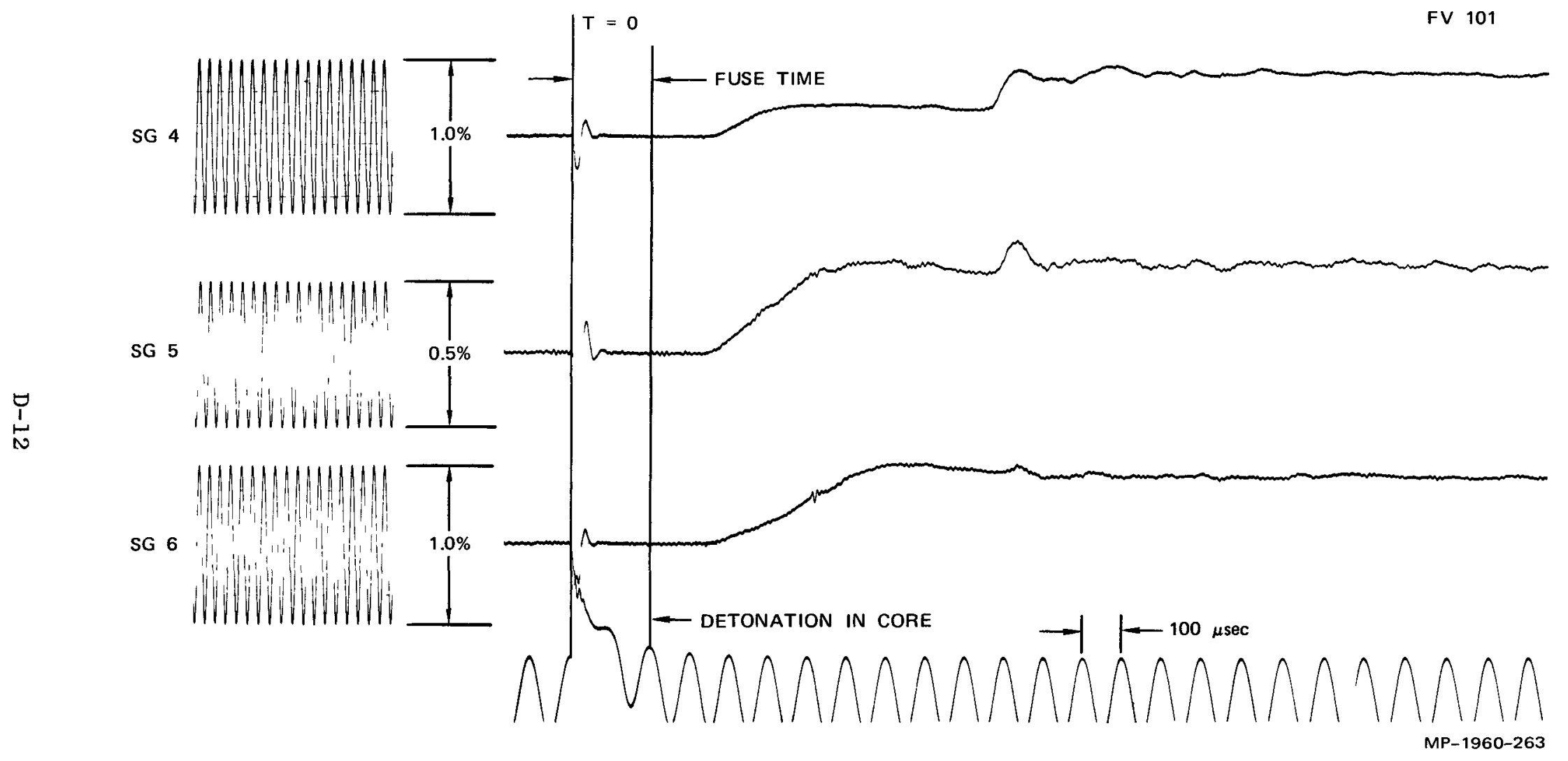

FIGURE D.6 SAMPLE STRAIN RECORDS FROM FLEXIBLE VESSEL EXPERIMENT FV 101 Oscillograph records from tape recorder playback. 
per second and can sample up to 7 channels at a time at this rate. The tape is played back at a speed that is $1 / 32$ the recording speed. The slower playback speed, combined with the sampling rate, results in a sampling rate of $5000 \times 32$ or 160,000 samples per second at the recording speed. This high sampling rate converts to a time interval between points of $6.25 \mu \mathrm{sec}$. The A/D converter records 1600 points for each record, giving a total window of $10 \mathrm{msec}$ for each channel of recorded data. The A/D sampling device is triggered by the EDU pulse. Both the calibration records and the shot records are sampled by the A/D converter. A computer program converts the digital tape record to real units of pressure or strain and time.

\section{Experiment Records}

Figures D.7 to D.9 show the pressure, strain, and displacement records for test FV 101. These records are computer plots made from the digital tape. The fuse burn time has been subtracted from each record so that the zero time in each record is the detonation time of the charge in the canister. Figure D.10 shows the final deformed shape of the flexible vessel on test FV 101, and Table D.2 give the deformation data.

Figures D.11 to D.12 show the pressure, strain, and displacement records for test FV 102. Again, fuse burn time has been subtracted from each record. Figure D.13 shows the final deformed shape of the flexible vessel and flexible core, and Table D. 3 gives the deformation data. 

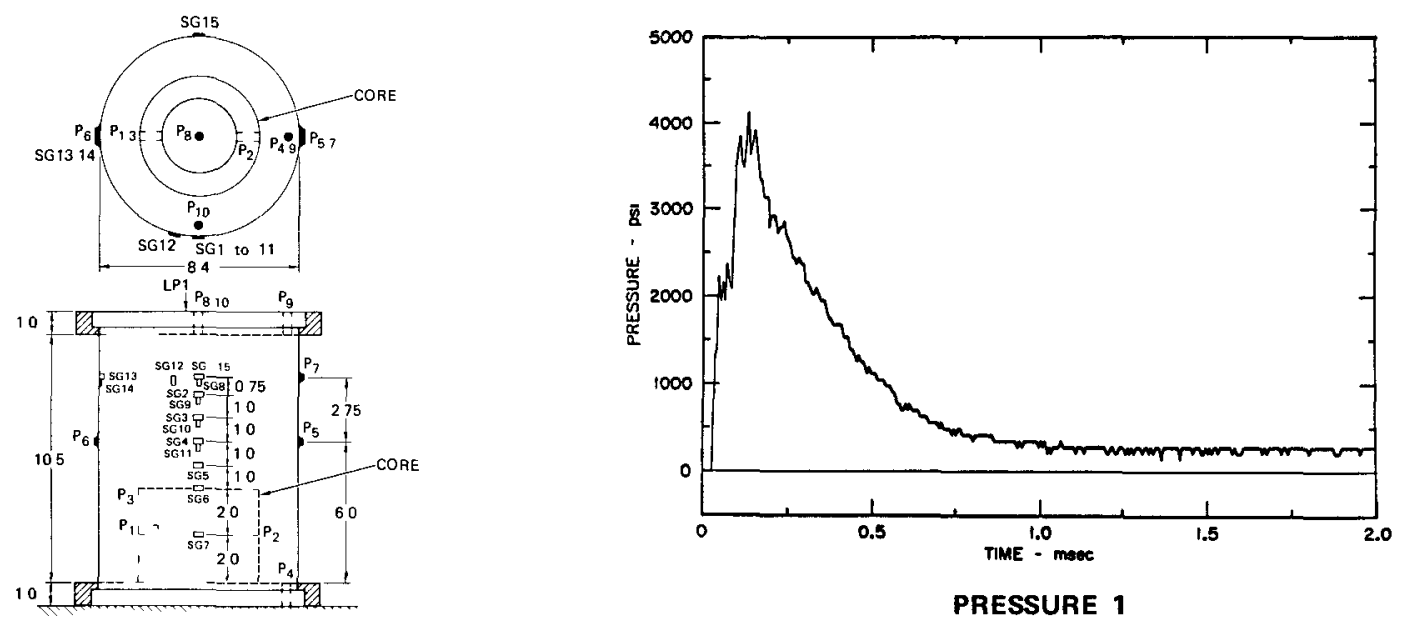

PRESSURE 1
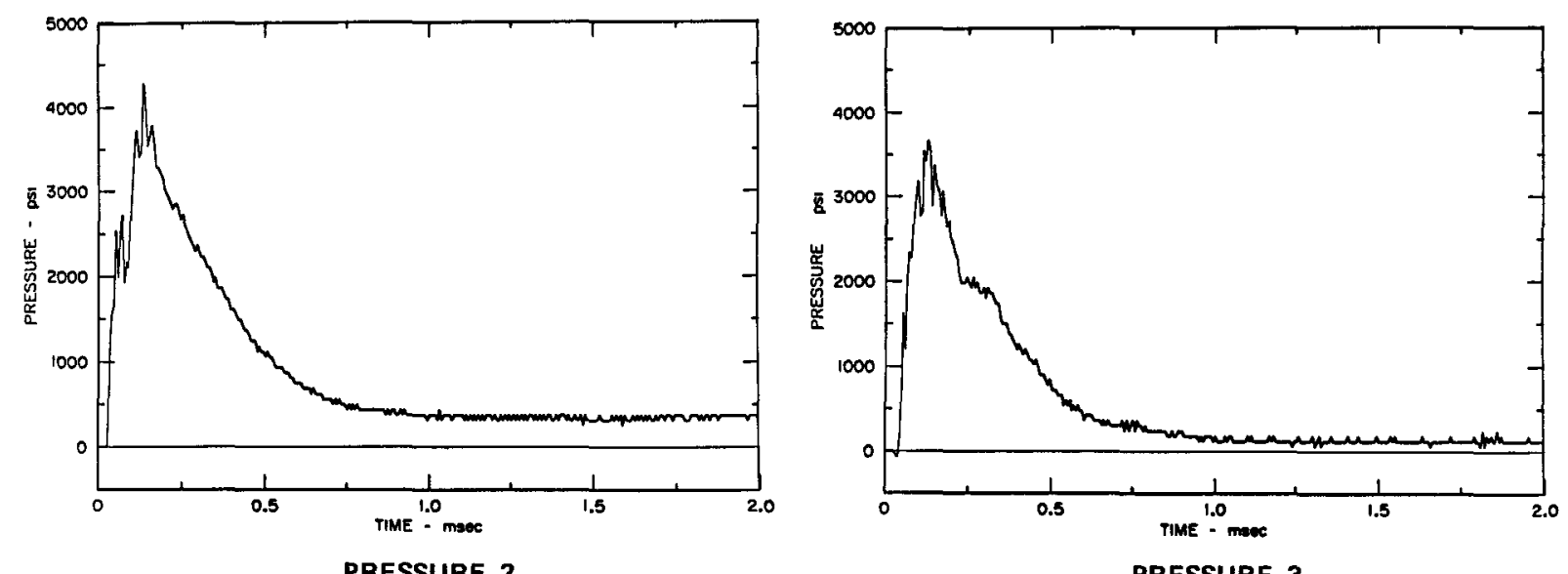

PRESSURE 3

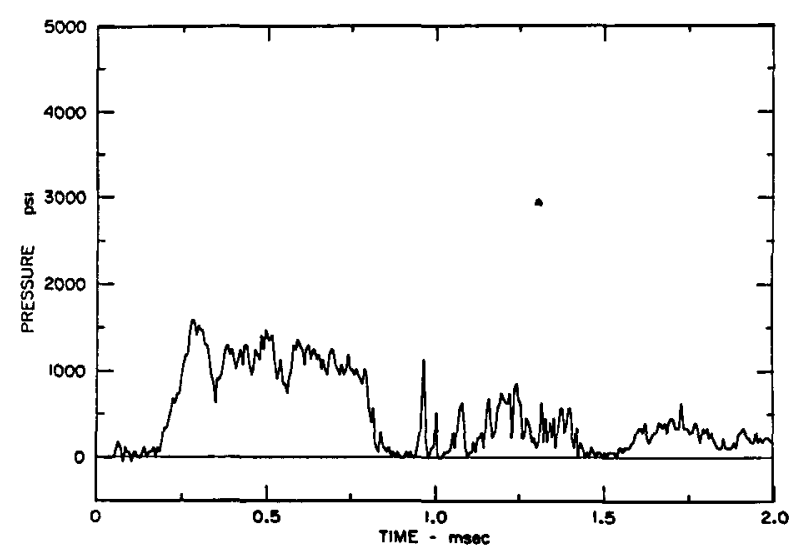

PRESSURE 4

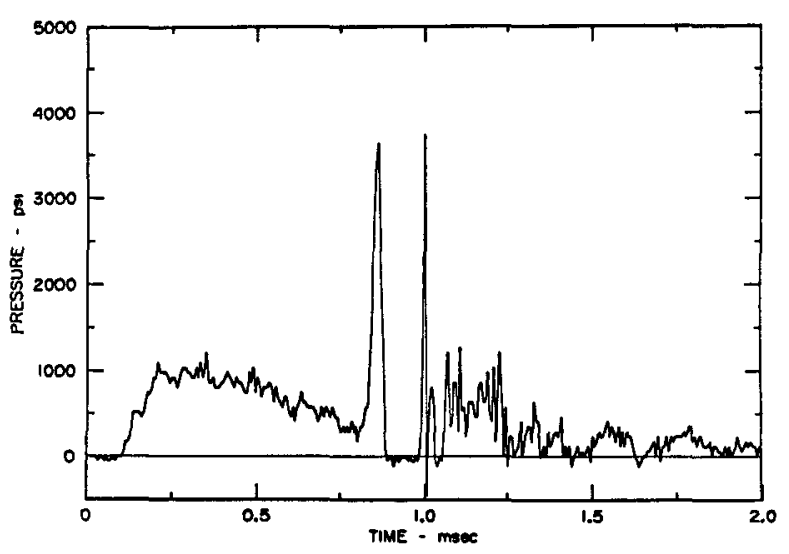

PRESSURE 5

FIGURE D.7 PRESSURE-TIME LOADINGS: EXPERIMENT FV 101 

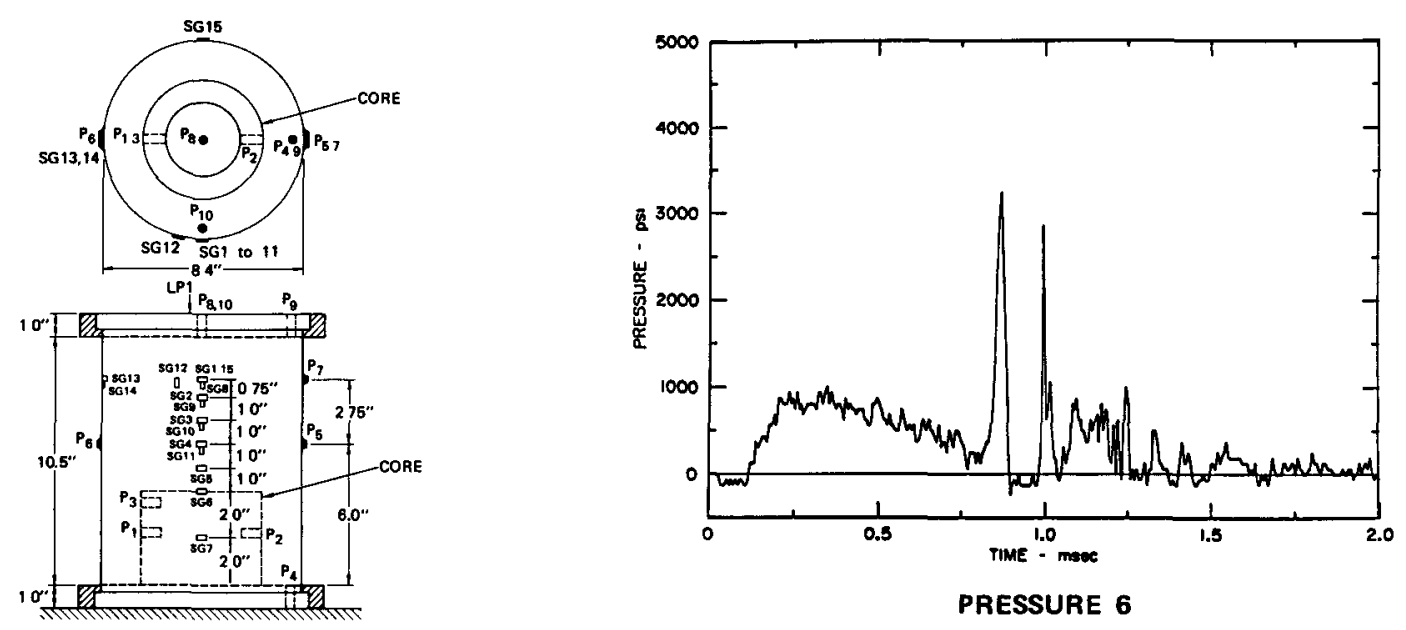

PRESSURE 6

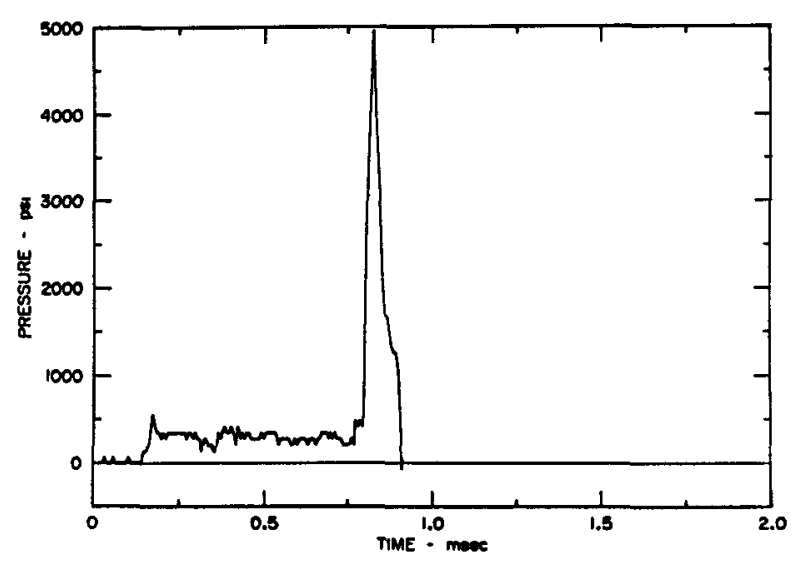

PRESSURE 7

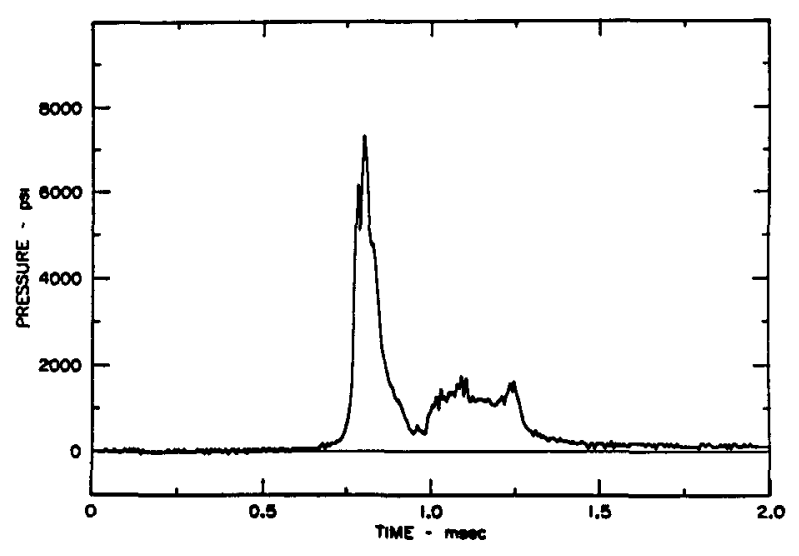

PRESSURE 9

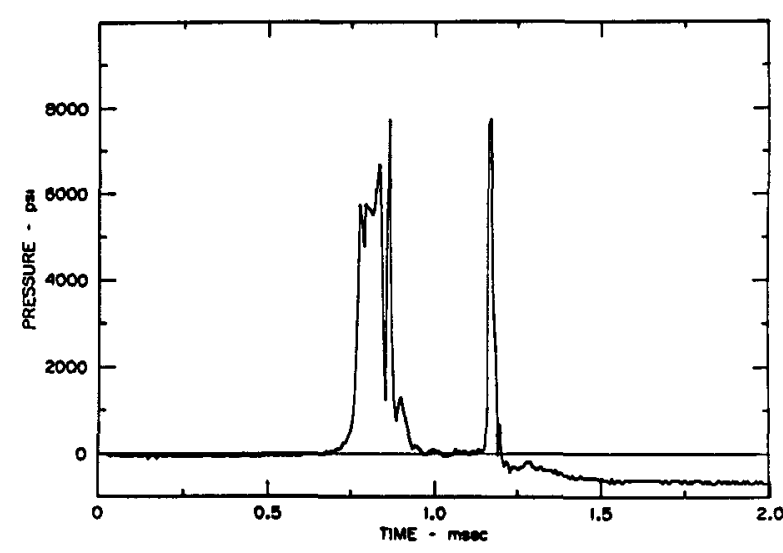

PRESSURE 8

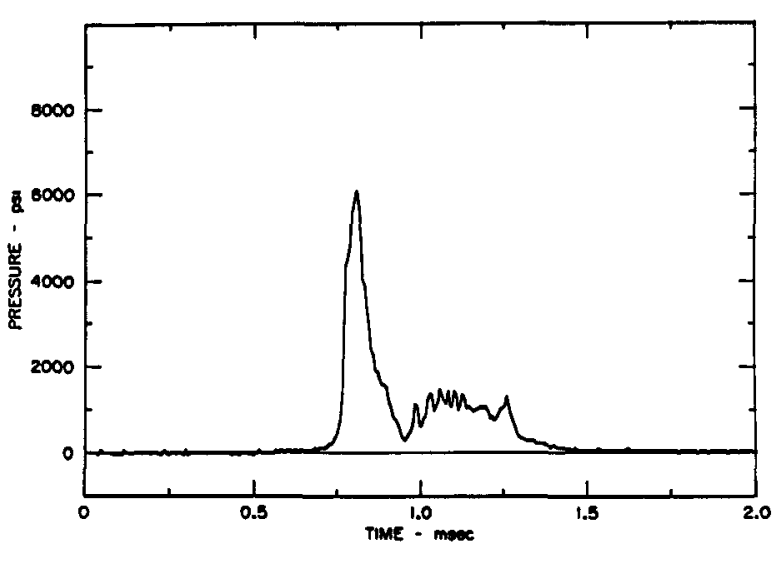

PRESSURE 10

FIGURE D.7 PRESSURE-TIME LOADINGS: EXPERIMENT FV 101 (Concluded) 

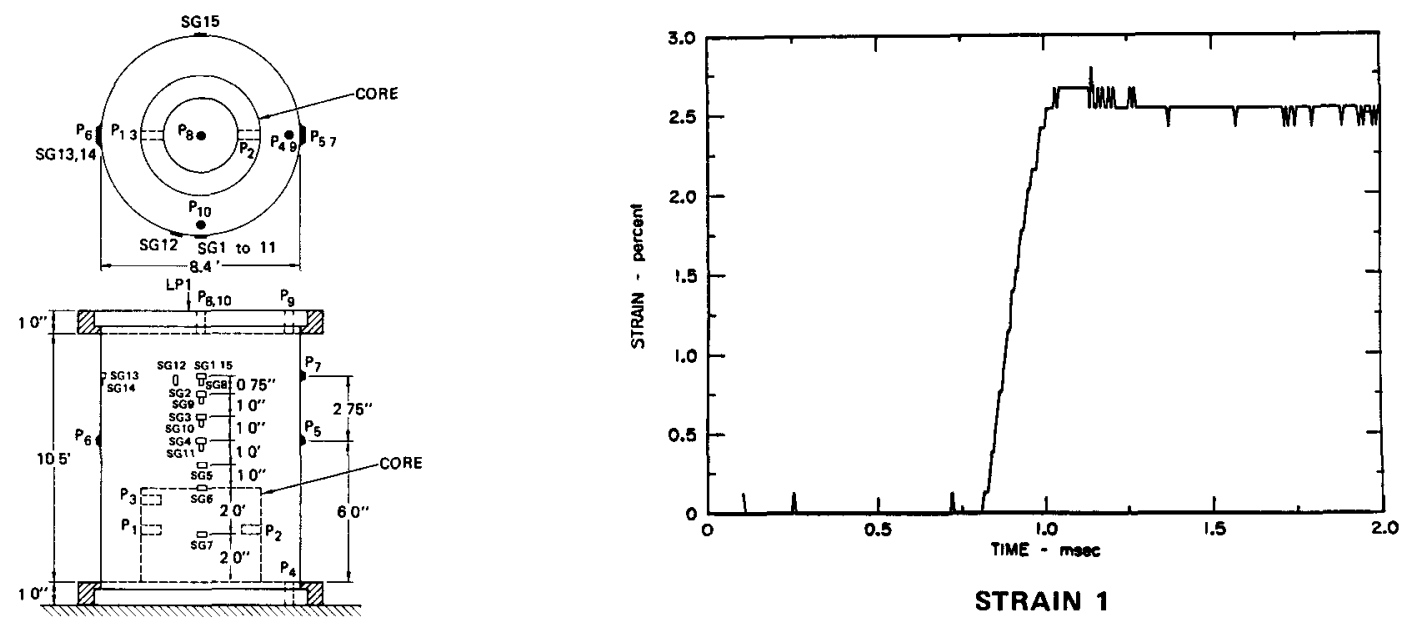

STRAIN 1

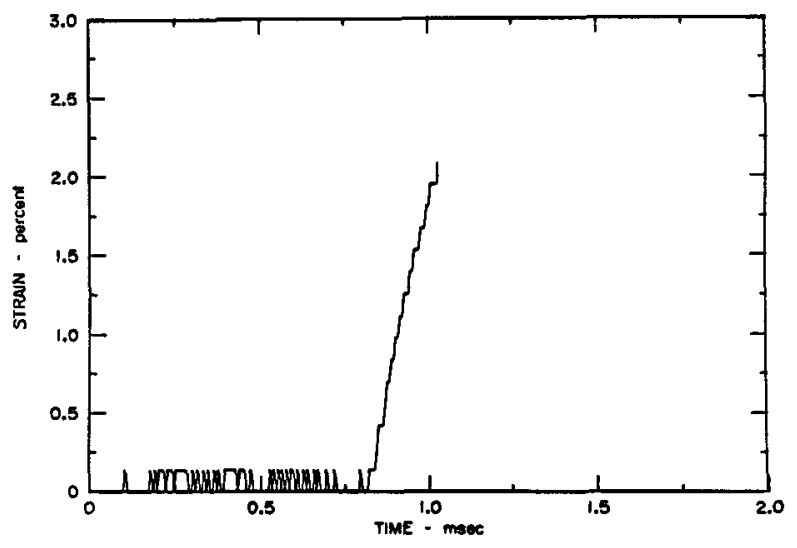

STRAIN 2

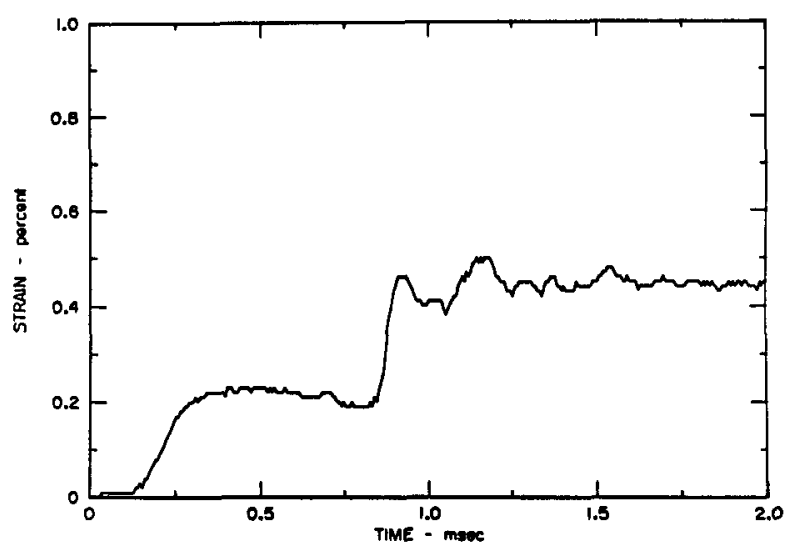

STRAIN 4

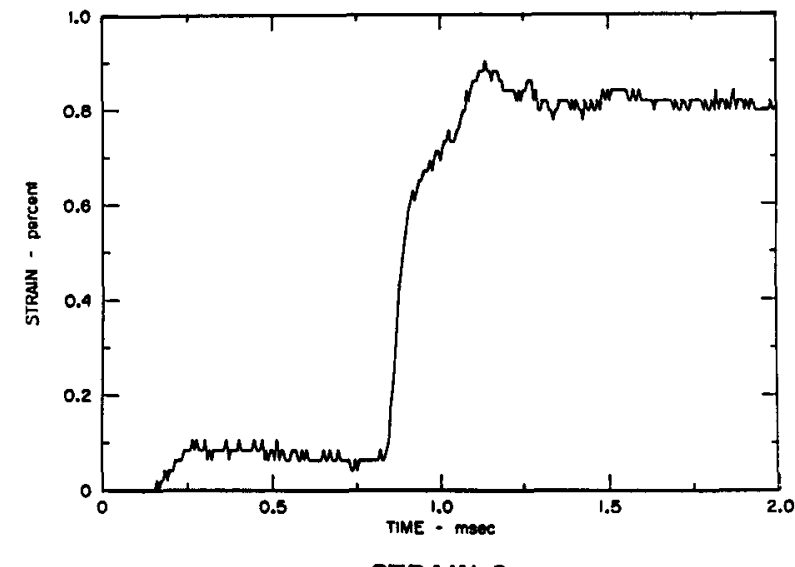

STRAIN 3

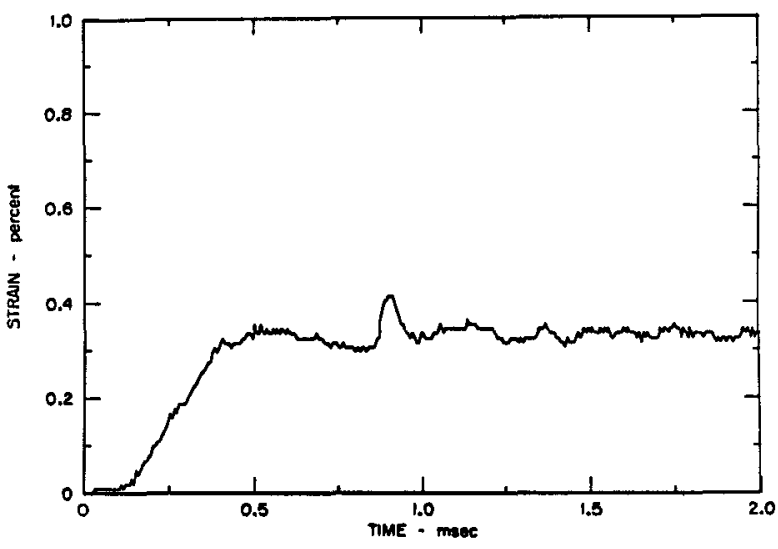

MA-1960-266

FIGURE D.8 STRAIN-TIME RESPONSE: EXPERIMENT FV 101 

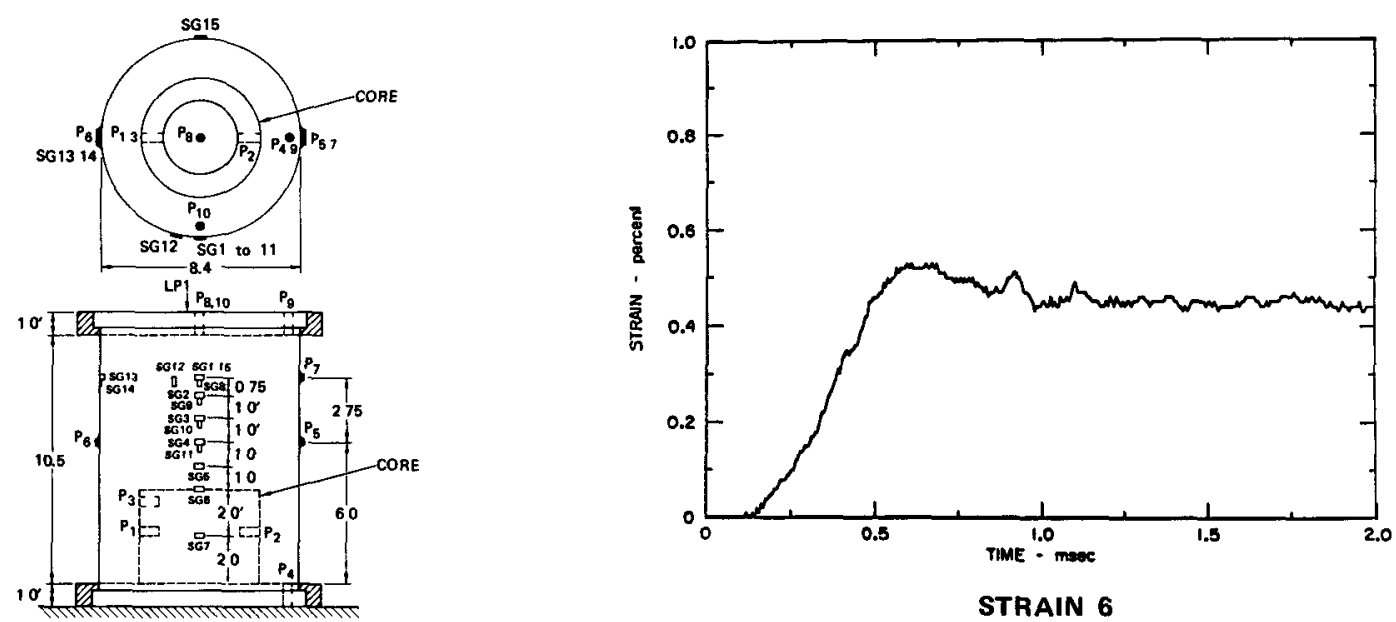

STRAIN 6
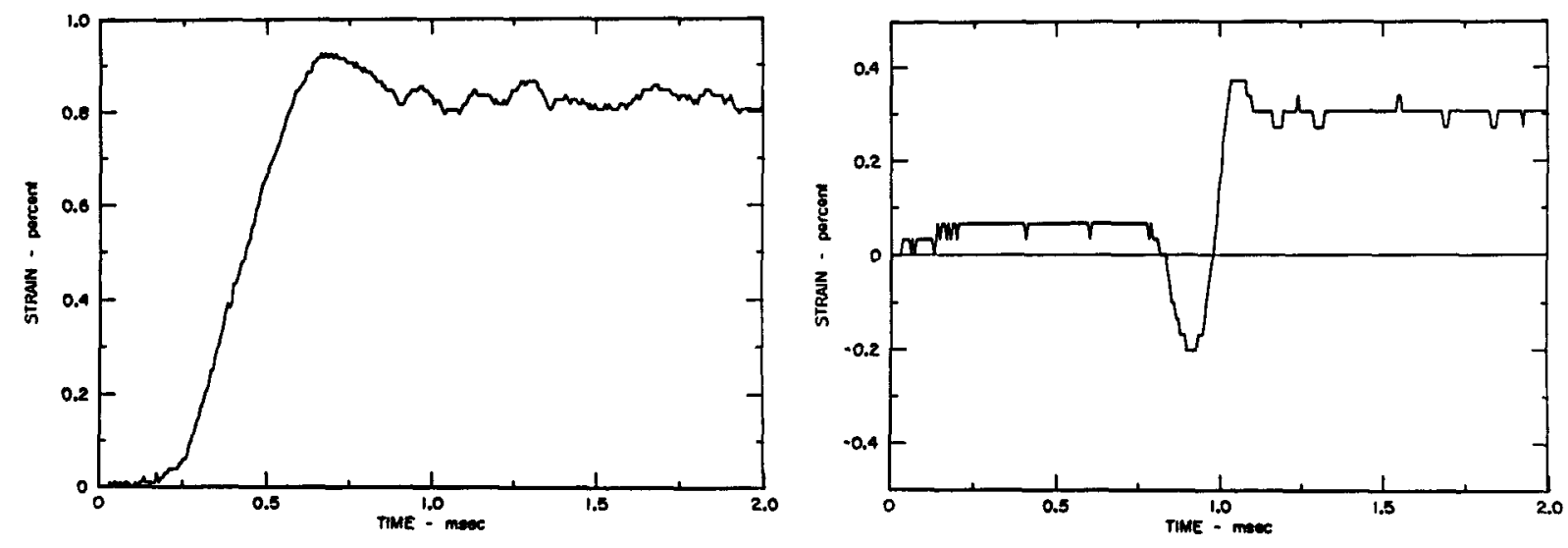

STRAIN 7

STRAIN 8

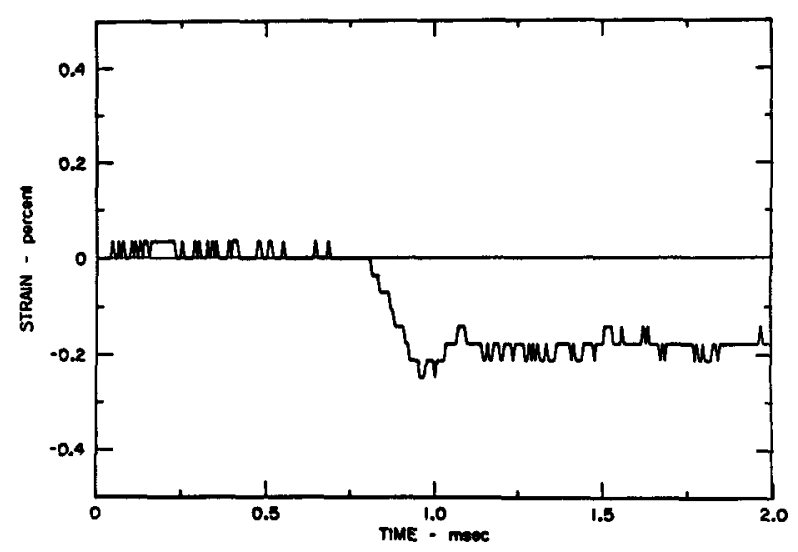

STRAIN 9

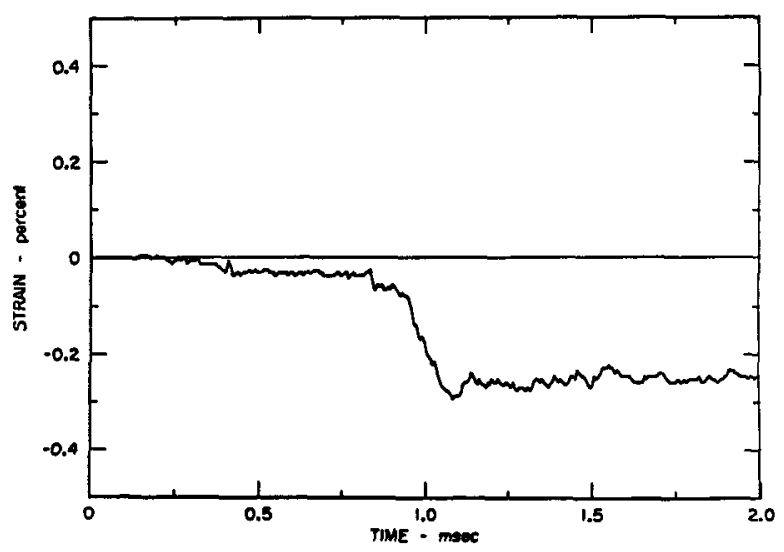

STRAIN 10

MA-1960-267

FIGURE D.8 STRAIN-TIME RESPONSE: EXPERIMENT FV 101 (Continued) 

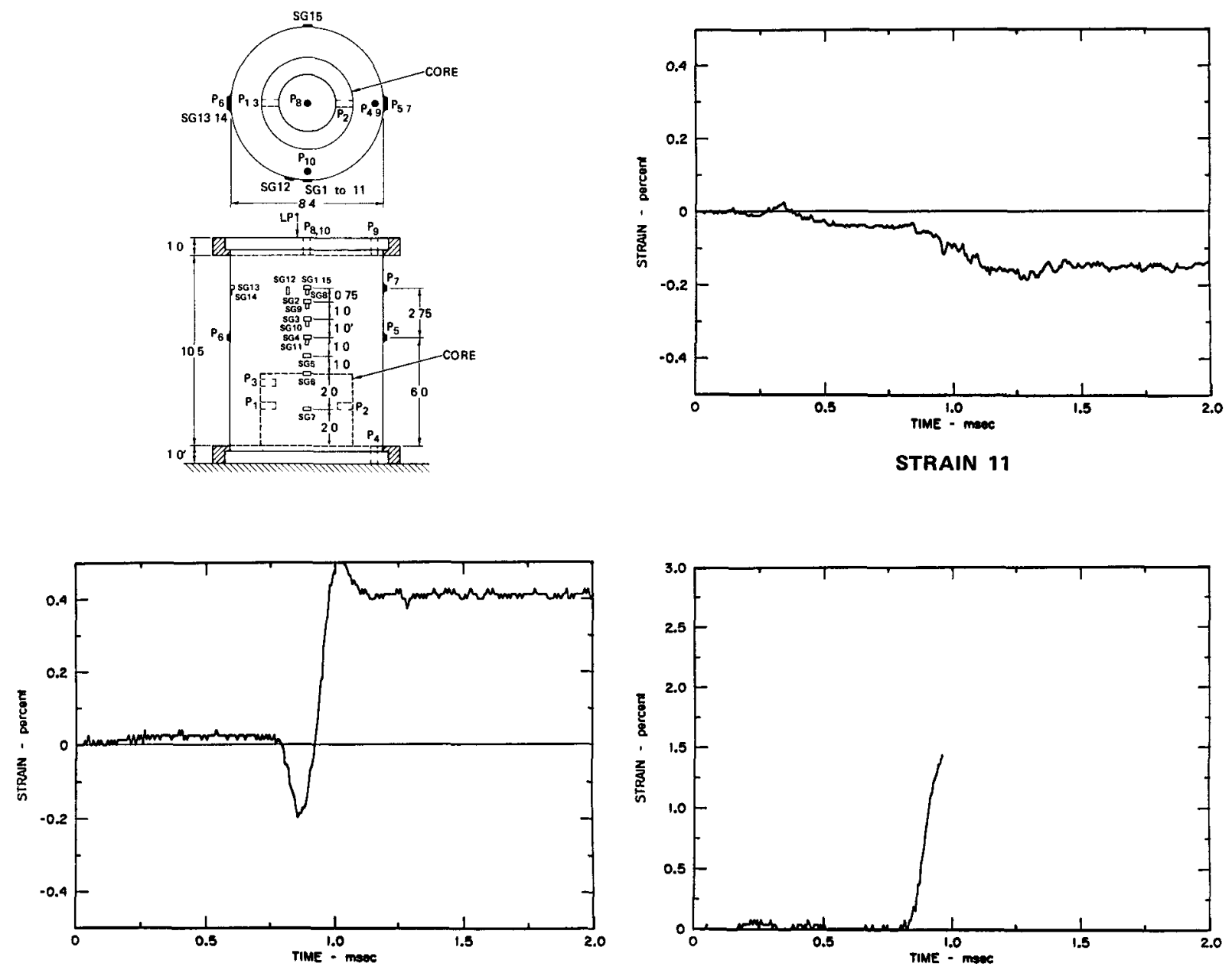

STRAIN 12

STRAIN 13
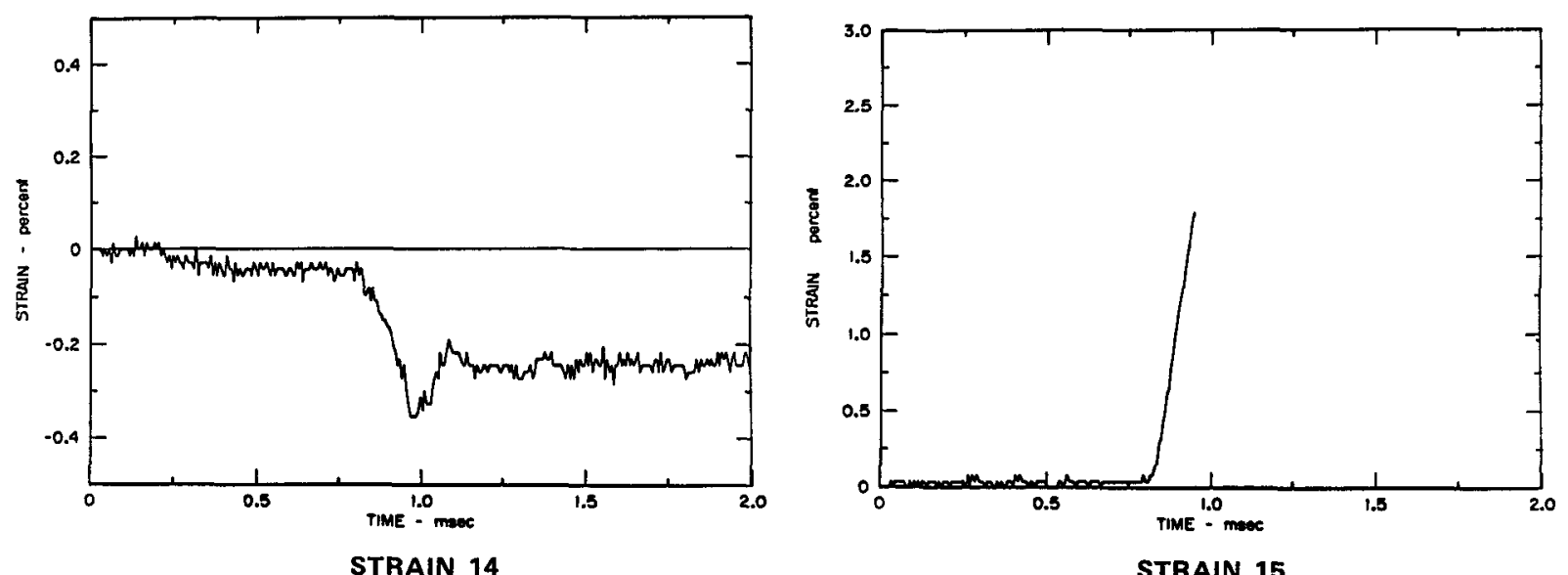

MA-1960-268

FIGURE D.8 STRAIN-TIME RESPONSE: EXPERIMENT FV 101 (Concluded) 

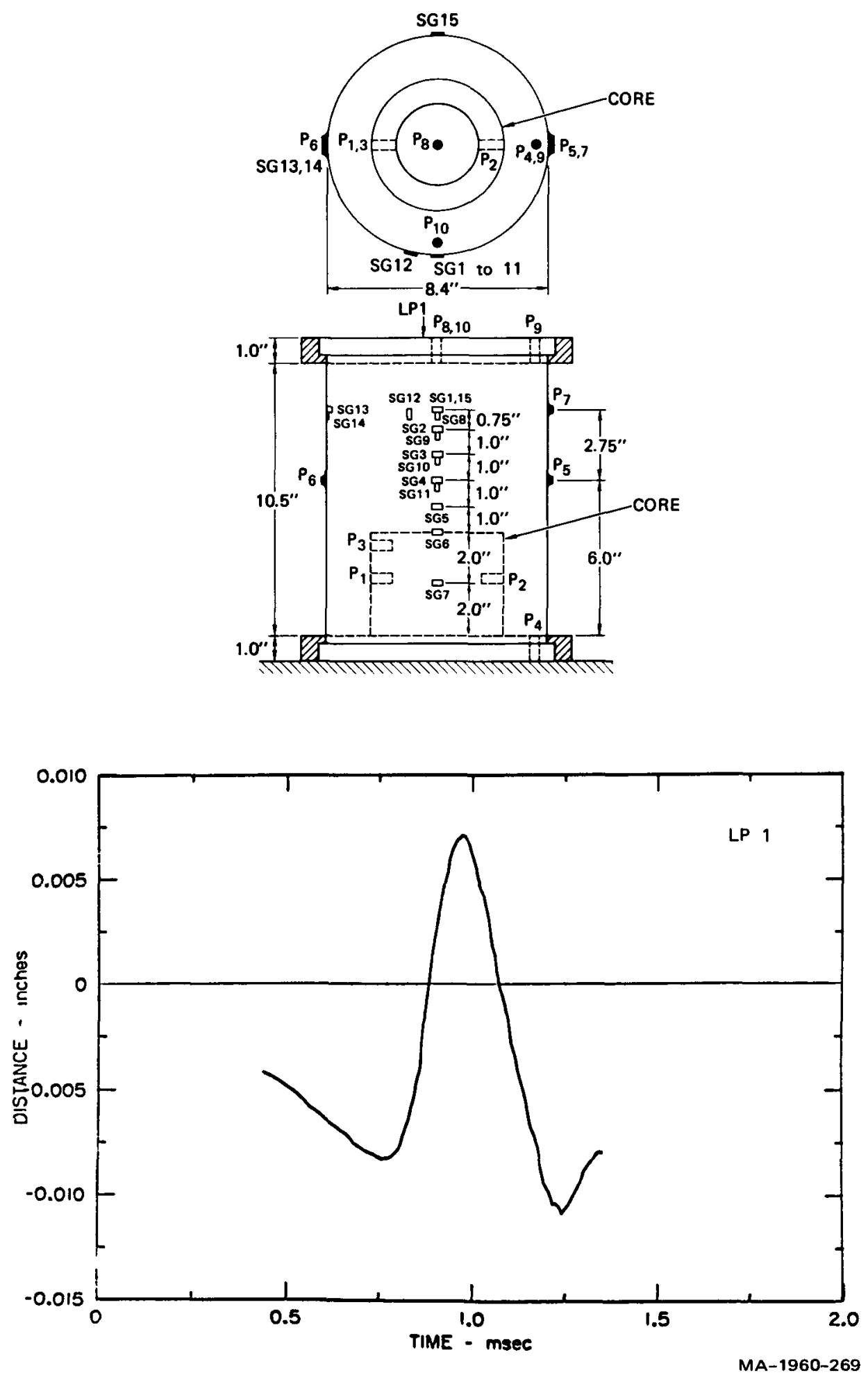

FIGURE D.9 COVER DISPLACEMENT: EXPERIMENT FV 101 


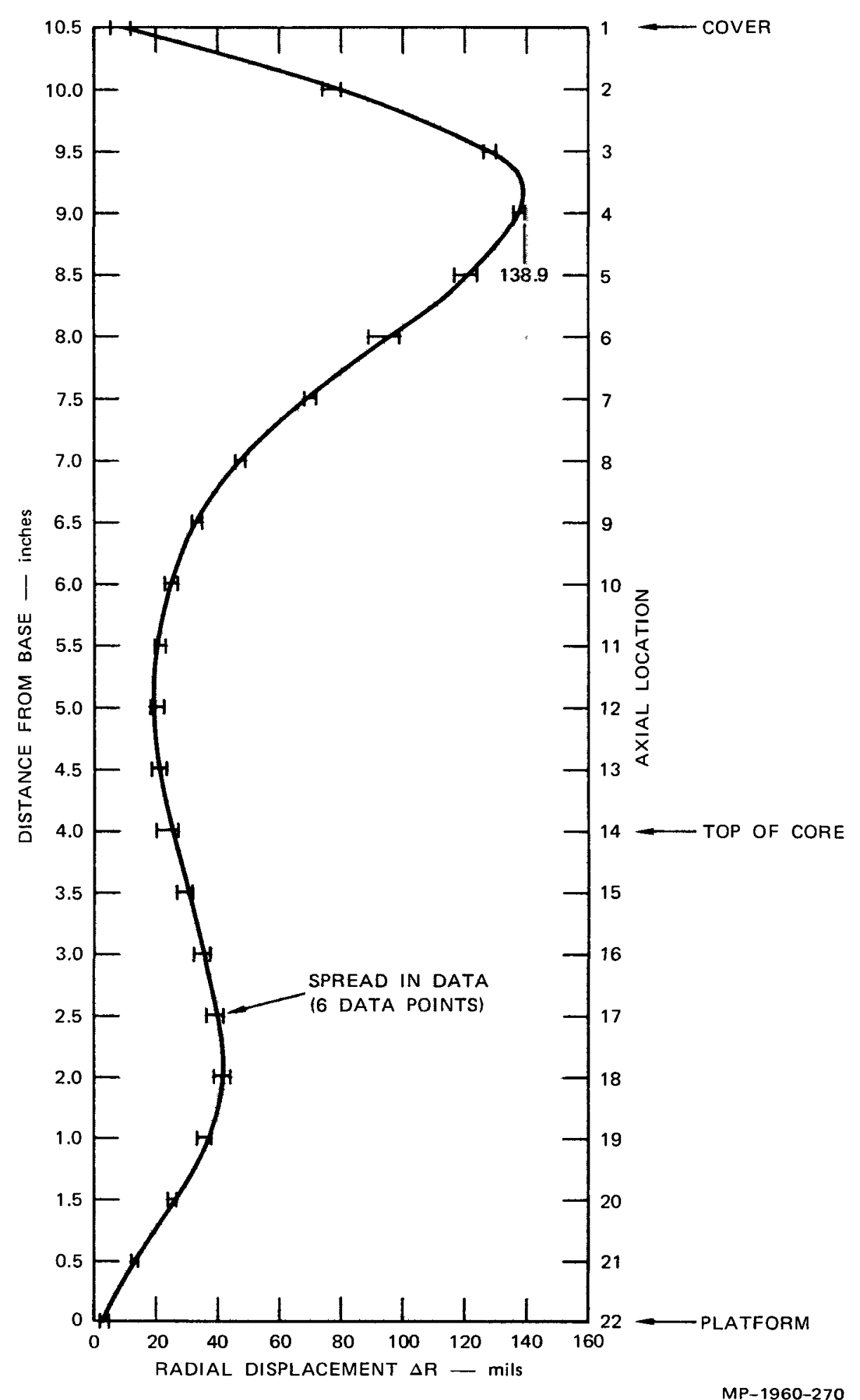

FIGURE D.10 FINAL DEFORMED SHAPE OF FLEXIBLE VESSEL FV 101 
Table D.2

RADIAL DISPLACEMENTS OF FLEXIBLE VESSEL EXPERIMENT FV 101
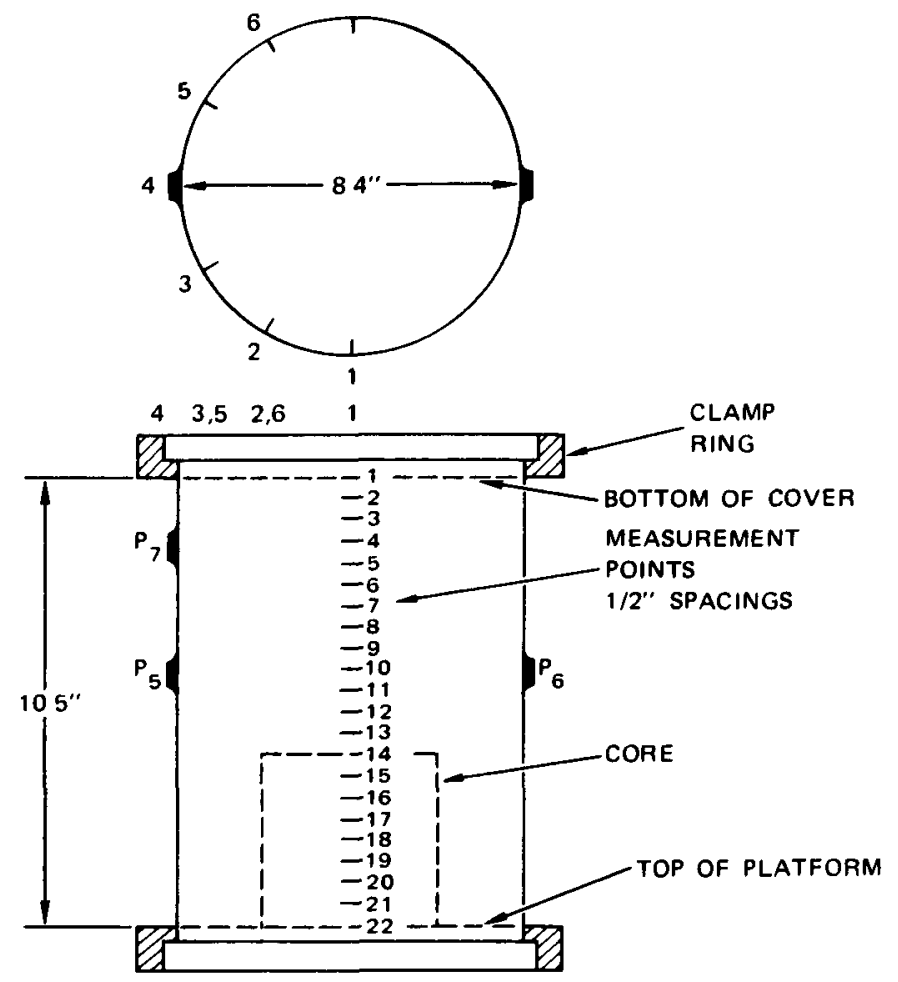

\begin{tabular}{|c|c|c|c|c|c|c|c|}
\hline POSITION & $\begin{array}{c}\text { MERIDIAN } \\
1\end{array}$ & $\begin{array}{c}\text { MERIDIAN } \\
2\end{array}$ & $\begin{array}{c}\text { MERIDIAN } \\
3\end{array}$ & $\begin{array}{c}\text { MERIDIAN } \\
4\end{array}$ & $\begin{array}{c}\text { MERIDIAN } \\
5\end{array}$ & $\begin{array}{c}\text { MERIDIAN } \\
6\end{array}$ & AVERAGE \\
\hline 1 & $100^{\circ}$ & 100 & 110 & 50 & 90 & 95 & 91 \\
\hline 2 & 785 & 800 & 745 & 760 & 775 & 800 & 778 \\
\hline 3 & 1270 & 1270 & 1300 & $1215^{\dagger}$ & 1265 & 1290 & 1279 \\
\hline 4 & 1355 & 1380 & 1385 & boss & 1390 & 1395 & 1381 \\
\hline 5 & 1165 & 1210 & 1240 & boss & 1245 & 1230 & 1218 \\
\hline 6 & 890 & 955 & 990 & $880^{\dagger}$ & 975 & 940 & 950 \\
\hline 7 & 685 & 690 & 720 & $640^{\dagger}$ & 700 & 685 & 696 \\
\hline 8 & 460 & 470 & 485 & $420^{\circ}$ & 485 & 460 & 472 \\
\hline 9 & 320 & 340 & 340 & boss & 350 & 330 & 336 \\
\hline 10 & 230 & 250 & 255 & boss & 270 & 245 & 250 \\
\hline 11 & 205 & 200 & 230 & $190^{\dagger}$ & 225 & 205 & 213 \\
\hline 12 & 180 & 185 & 210 & 180 & 225 & 185 & 194 \\
\hline 13 & 190 & 220 & 220 & 215 & 230 & 195 & 212 \\
\hline 14 & 200 & 250 & 255 & 255 & 265 & 235 & 243 \\
\hline 15 & 275 & 315 & 310 & 300 & 315 & 285 & 300 \\
\hline 16 & 325 & 365 & 365 & 360 & 370 & 345 & 355 \\
\hline 17 & 370 & 405 & 410 & 405 & 405 & 390 & 398 \\
\hline 18 & 385 & 420 & 440 & 440 & 425 & 415 & 421 \\
\hline 19 & 335 & 370 & 380 & 380 & 375 & 375 & 369 \\
\hline 20 & 235 & 265 & 275 & 265 & 270 & 265 & 263 \\
\hline 21 & 120 & 135 & 130 & 130 & 135 & 130 & 130 \\
\hline 22 & 15 & 15 & 15 & 30 & 30 & 30 & 23 \\
\hline
\end{tabular}

* Displacements in mils

t Strain gage at this location 

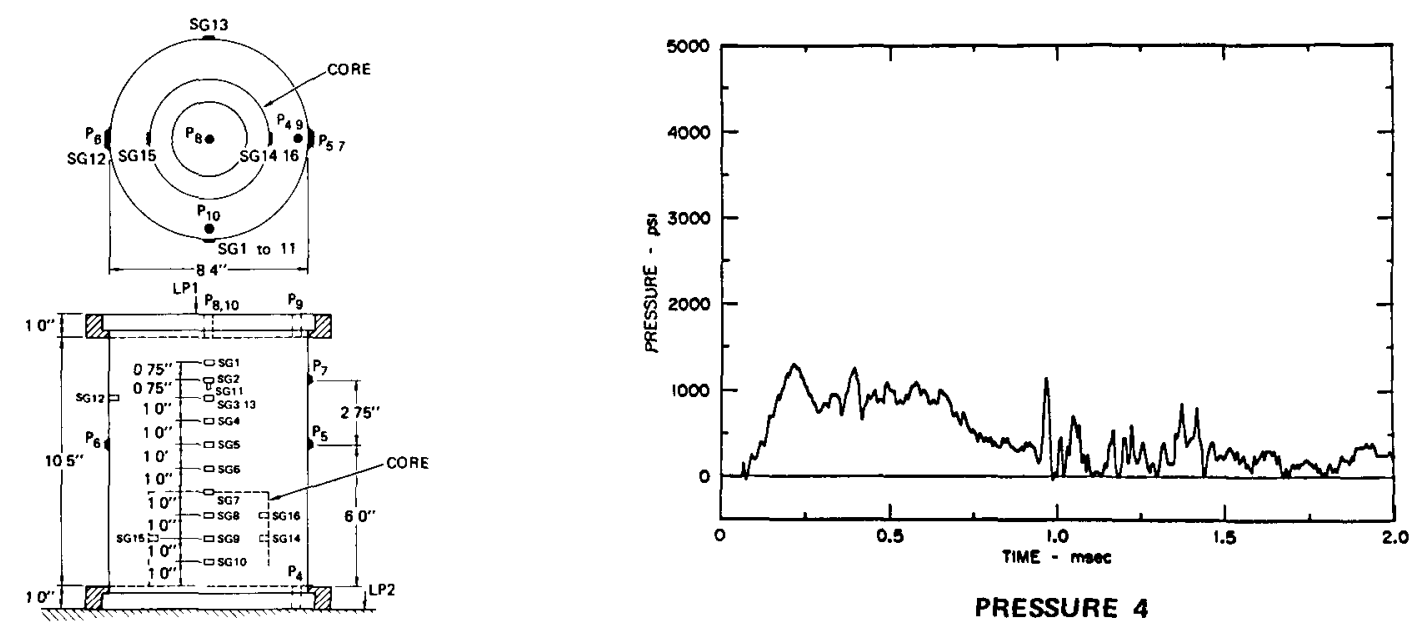

PRESSURE 4
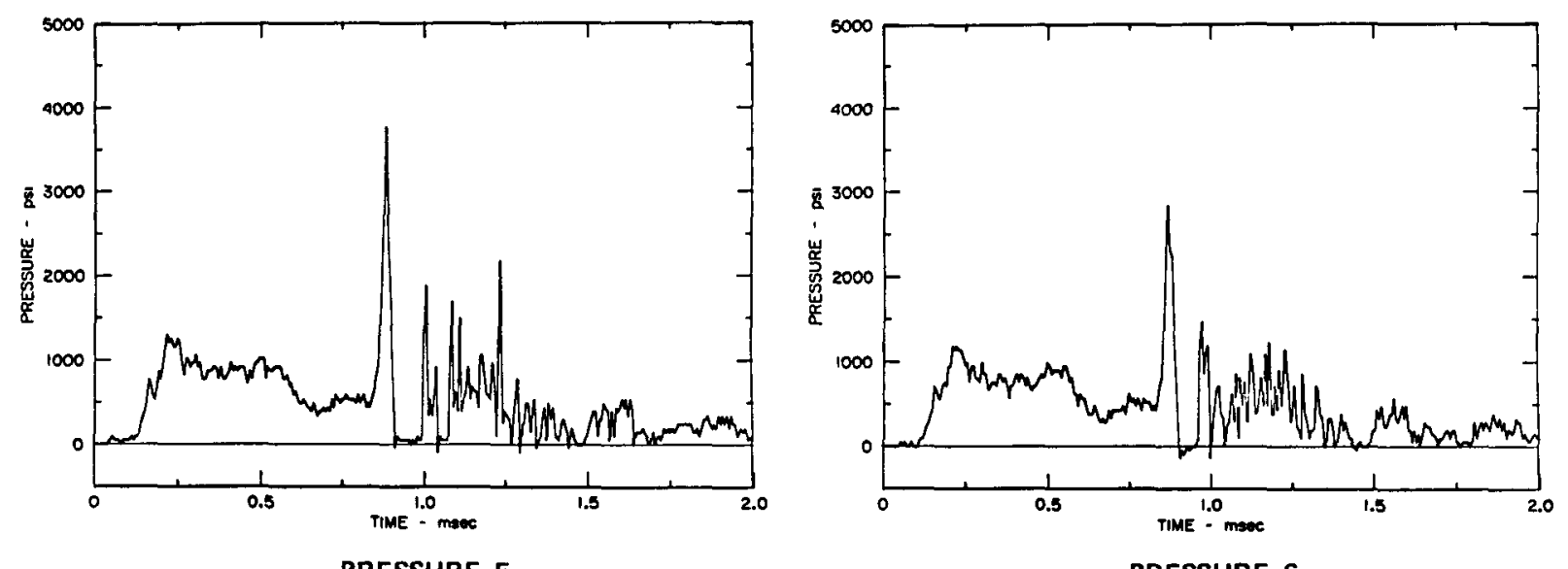

PRESSURE 6

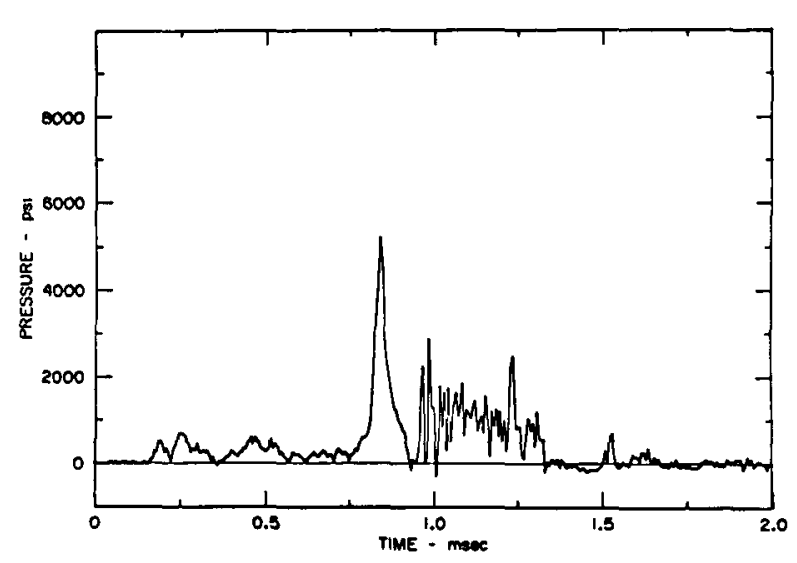

PRESSURE 7

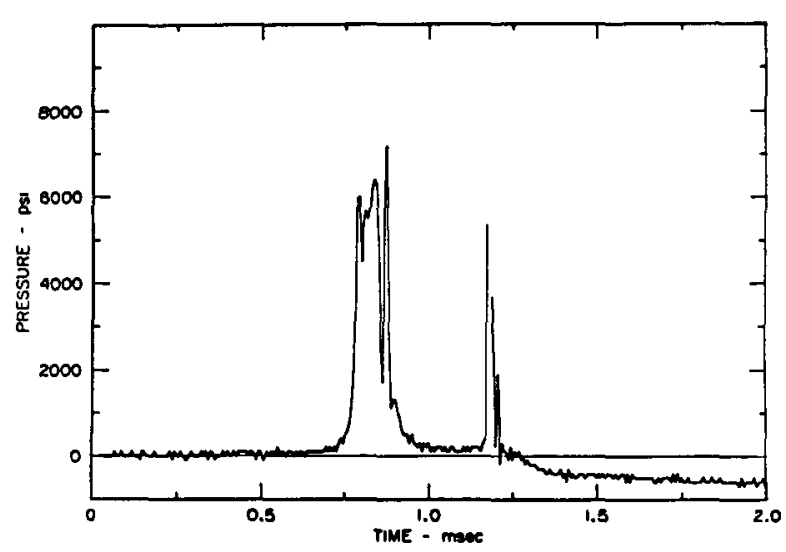

PRESSURE 8

FIGURE D.11 PRESSURE-TIME LOADINGS: EXPERIMENT FV 102 

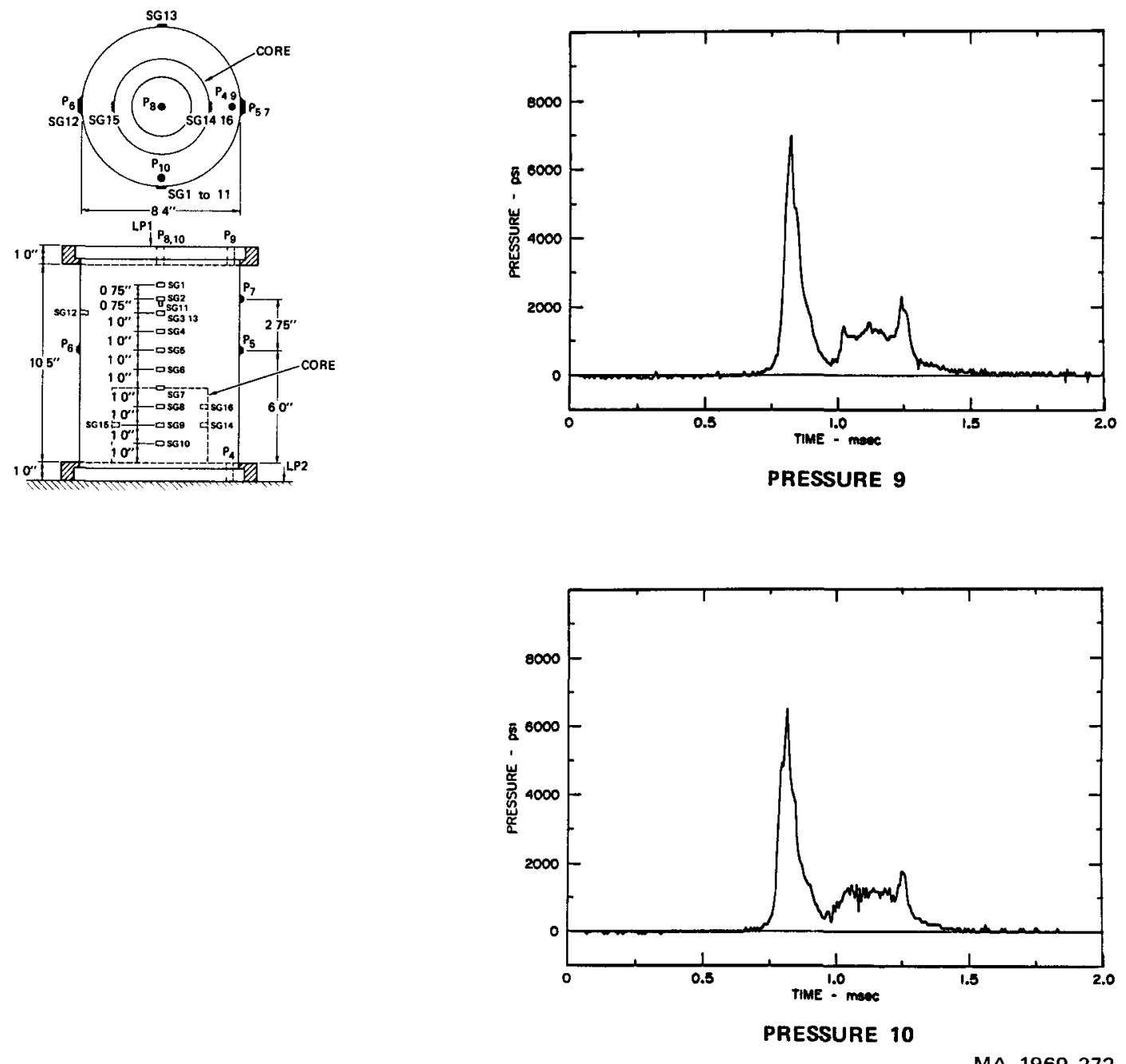

FIGURE D.11 PRESSURE-TIME LOADINGS: EXPERIMENT FV 102 (Concluded) 

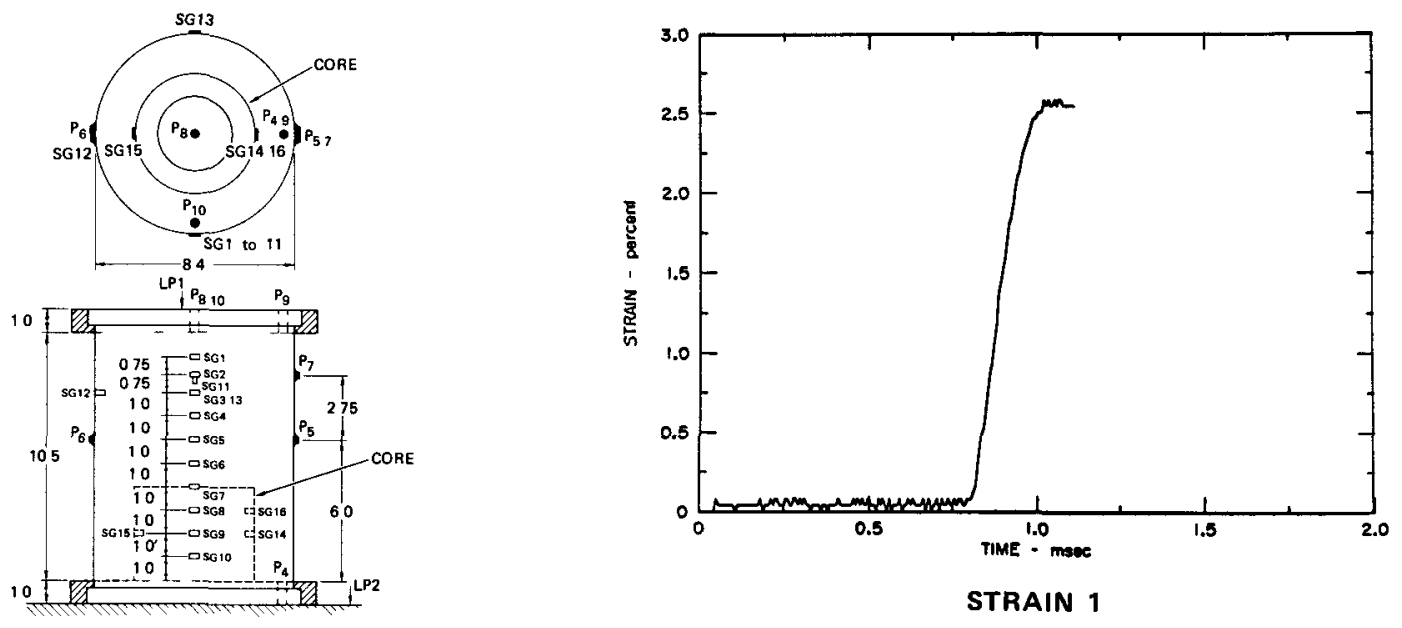

STRAIN 1

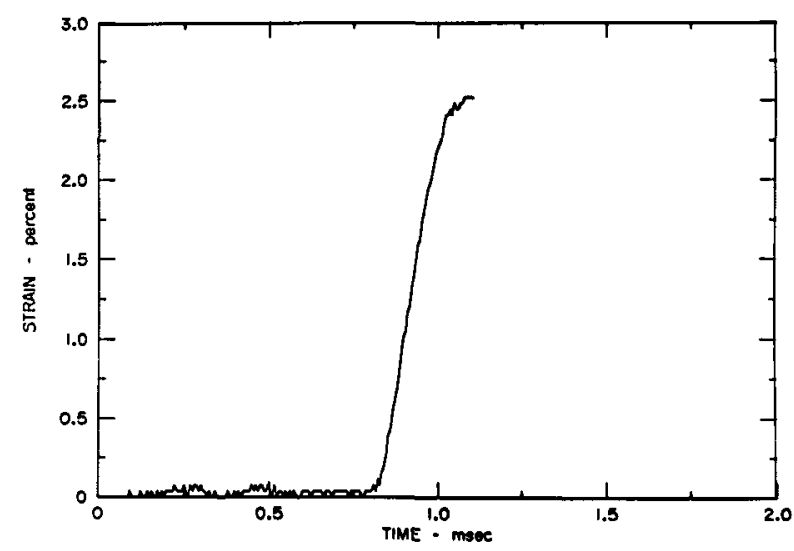

STRAIN 2

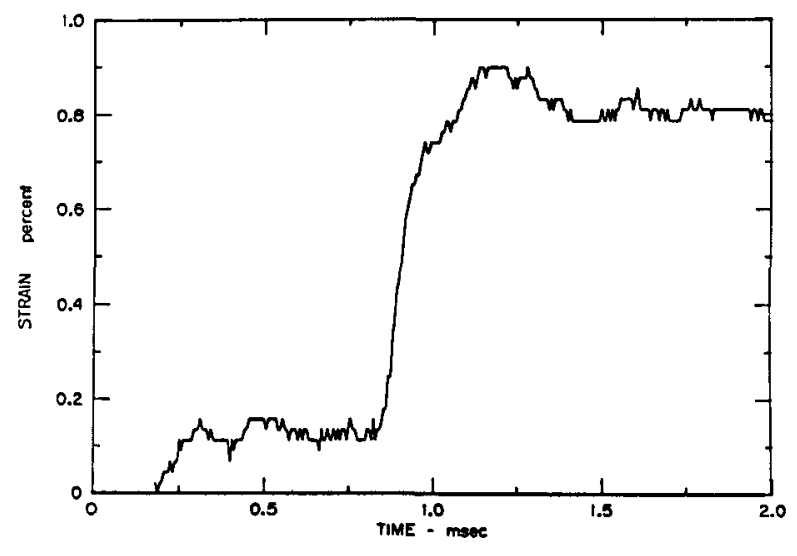

STRAIN 4

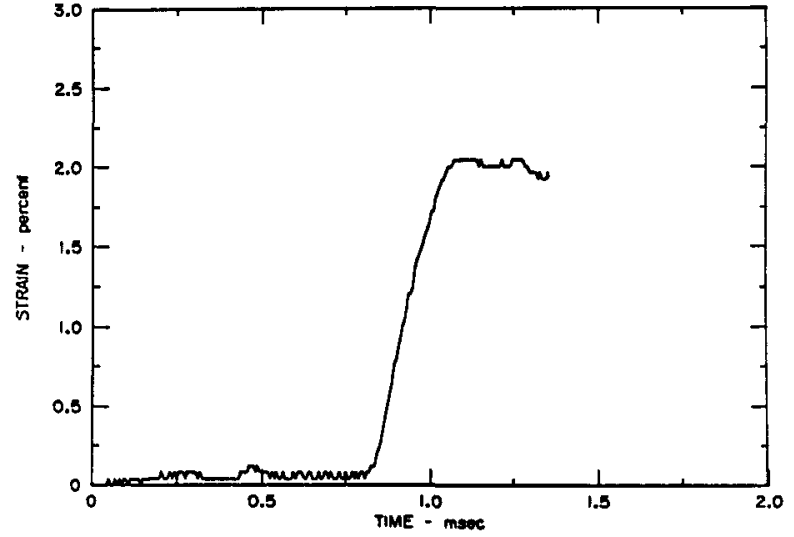

STRAIN 3

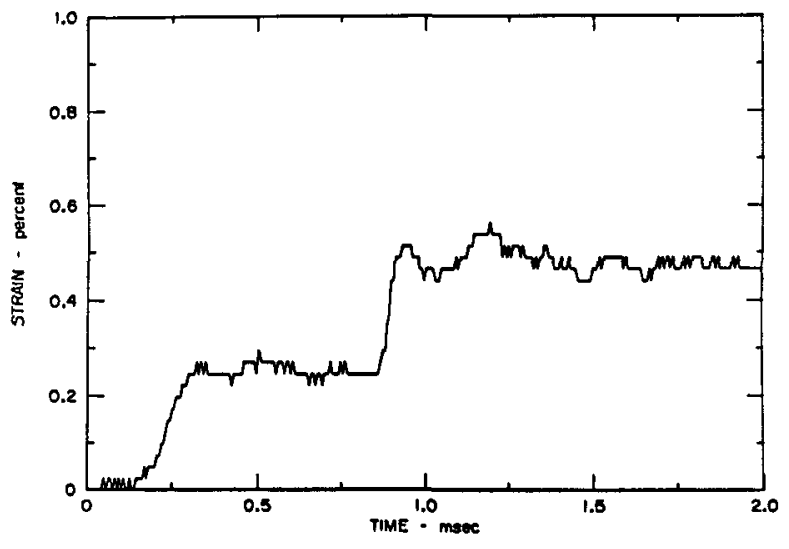

STRAIN 5

MA-1960-273

FIGURE D.12 STRAIN-TIME RESPONSE: EXPERIMENT FV 102 

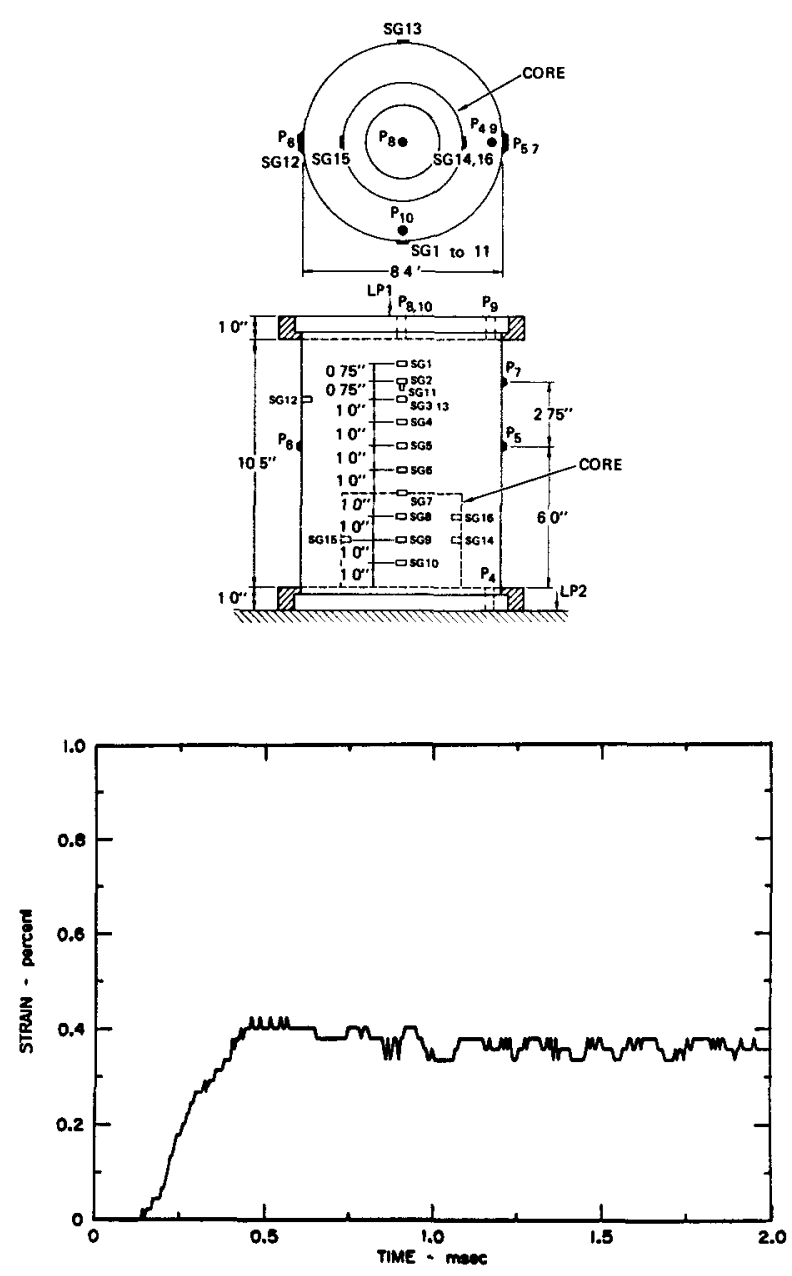

STRAIN 7

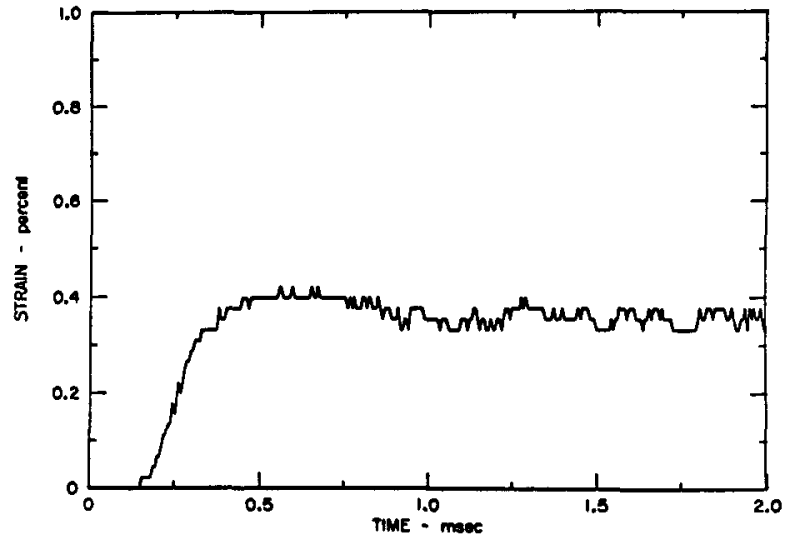

STRAIN 9

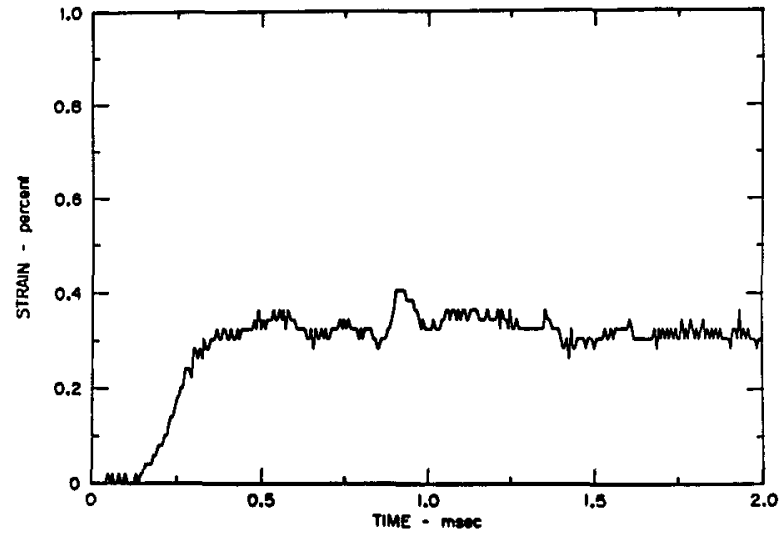

STRAIN 6

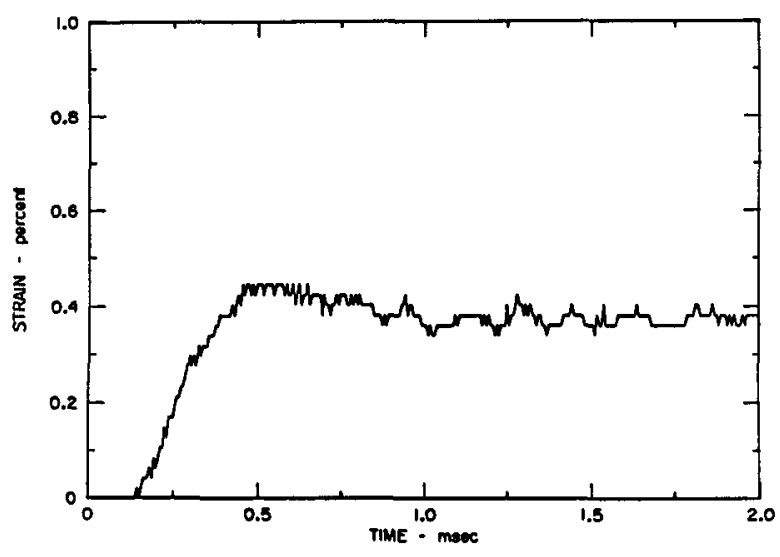

STRAIN 8

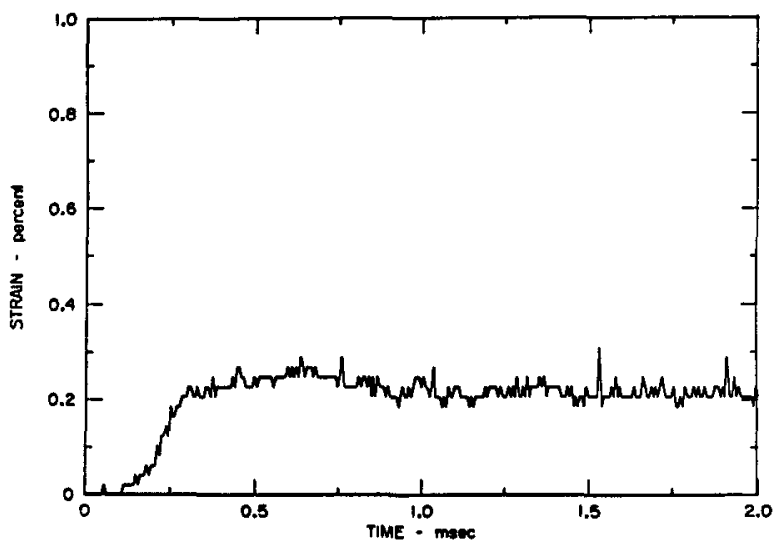

MA-1960-274

FIGURE D.12 STRAIN-TIME RESPONSE: EXPERIMENT FV 102 (Continued) 

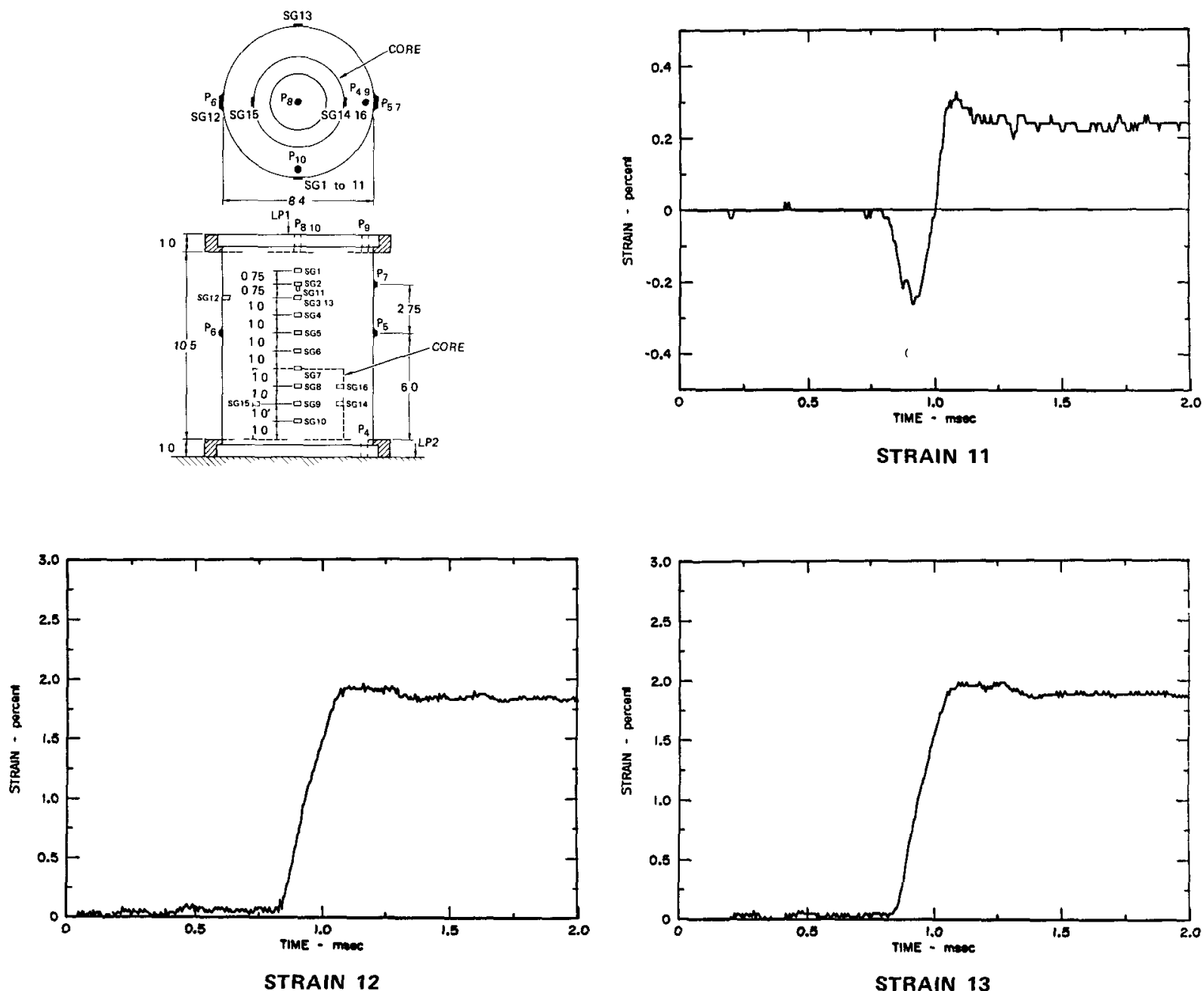

MA-1960-275

FIGURE D.12 STRAIN-TIME RESPONSE: EXPERIMENT FV 102 (Continued) 

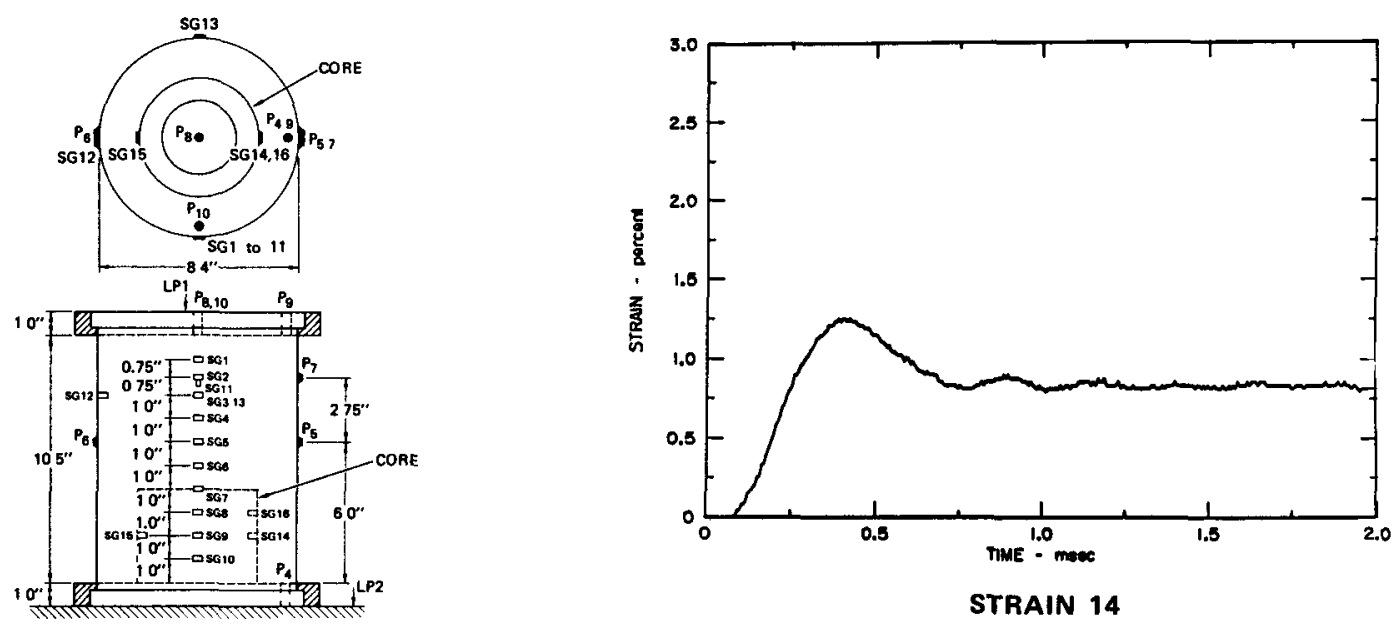

STRAIN 14
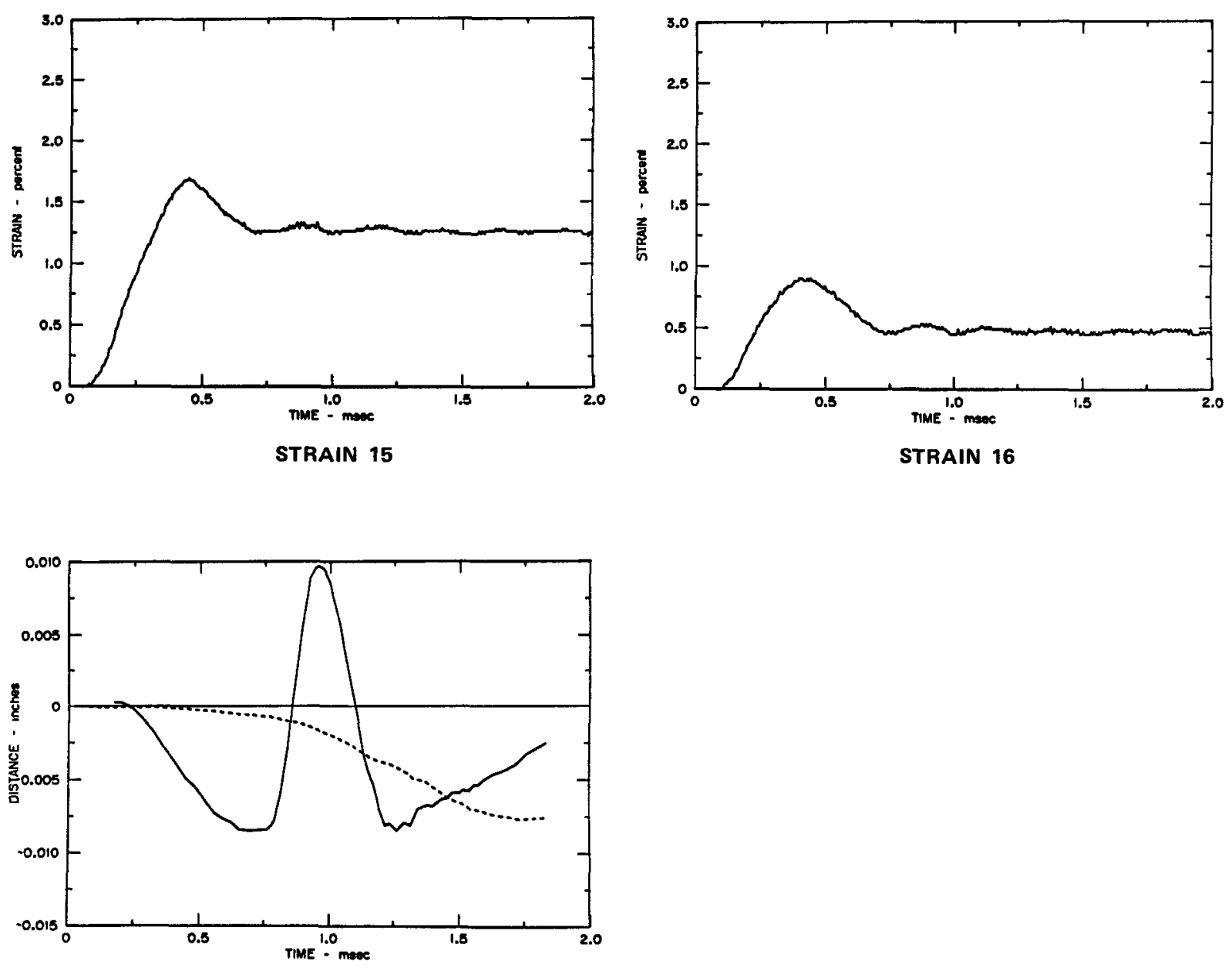

LP1 (SOLID), LP2 (SHORT)

FIGURE D.12 STRAIN-TIME RESPONSE: EXPERIMENT FV 102 (Concluded) 


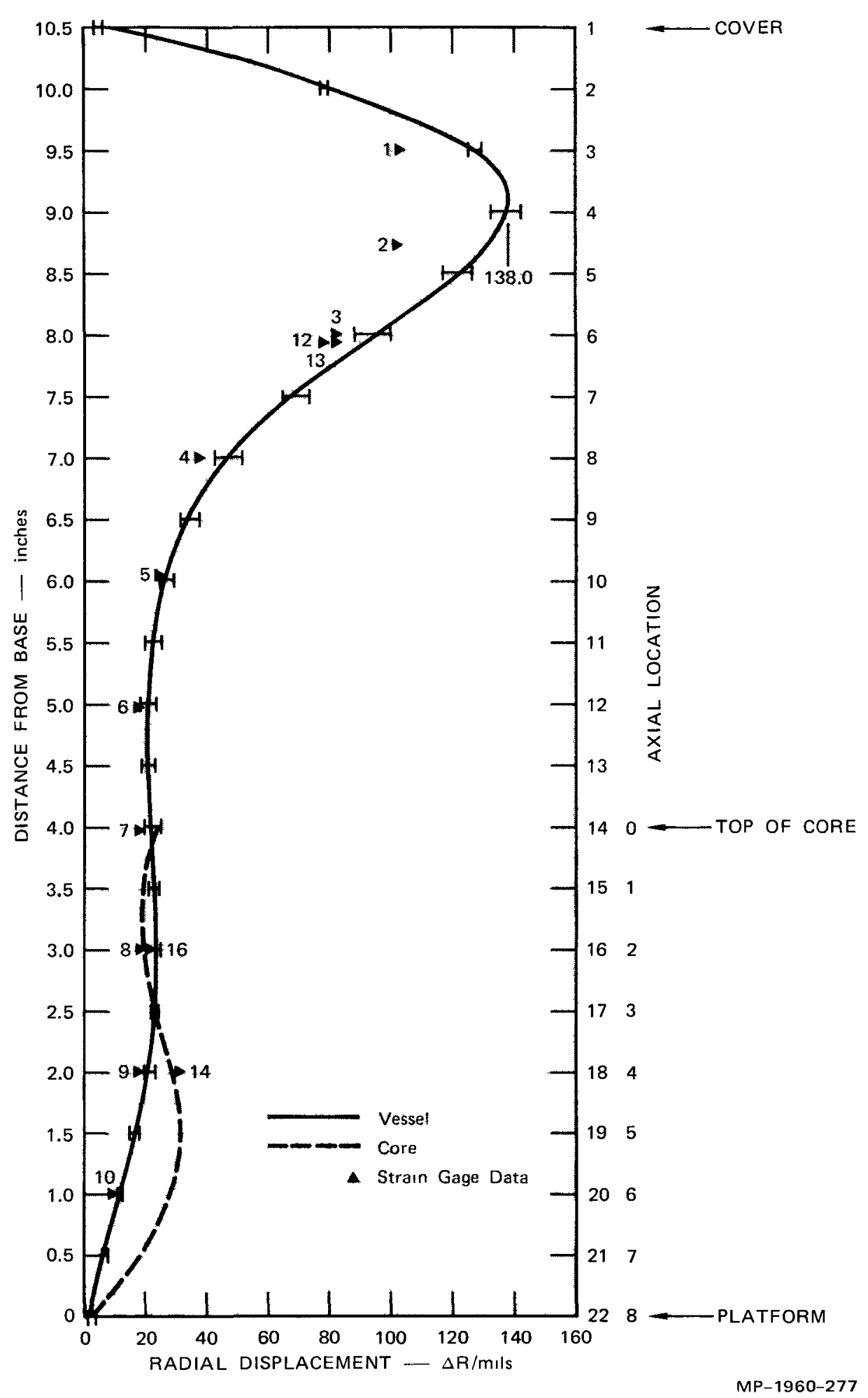

FIGURE D.13 FINAL DEFORMED SHAPE OF FLEXIBLE VESSEL FV 102 
Table D.3

RADIAL DISPLACEMENTS OF FLEXIBLE VESSEL EXPERIMENT FV 102
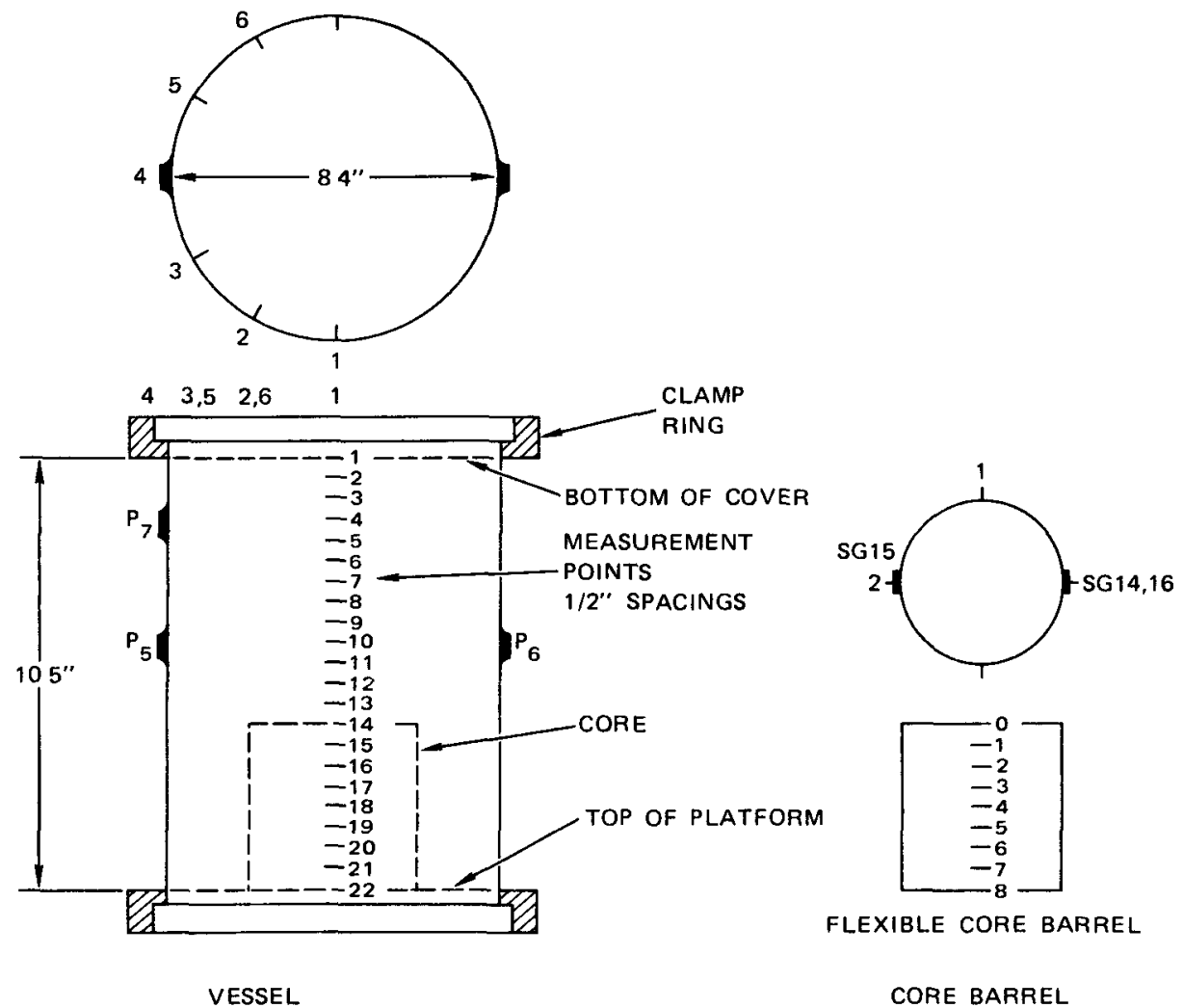

VESSEL

\begin{tabular}{|c|c|c|c|c|c|c|c|}
\hline \multirow{2}{*}{ POSITION } & \multicolumn{6}{|c|}{ MERIDIAN } & \multirow{2}{*}{ AVERAGE } \\
\hline & 1 & 2 & 3 & 4 & 5 & 6 & \\
\hline 1 & $35^{\circ}$ & 55 & 60 & 55 & 65 & 60 & 55 \\
\hline 2 & 780 & 775 & 785 & 795 & 795 & 785 & 786 \\
\hline 3 & 1250 & 1275 & 1295 & 1265 & 1280 & 1260 & 1271 \\
\hline 4 & 1340 & 1375 & 1420 & boss & 1400 & 1360 & 1379 \\
\hline 5 & 1175 & 1215 & 1265 & boss & 1240 & 1205 & 1220 \\
\hline 6 & 880 & 960 & 995 & -- & 970 & 930 & 947 \\
\hline 7 & 645 & 685 & 725 & 650 & 685 & 655 & 674 \\
\hline 8 & 425 & 475 & 510 & 445 & 485 & 450 & 465 \\
\hline 9 & 315 & 340 & 370 & boss & 350 & 330 & 341 \\
\hline 10 & 230 & 260 & 290 & boss & 270 & 250 & 260 \\
\hline 11 & 190 & 215 & 250 & 200 & 225 & 205 & 214 \\
\hline 12 & 180 & 205 & 235 & 195 & 215 & 185 & 203 \\
\hline 13 & 185 & 205 & 230 & 200 & 210 & 185 & 203 \\
\hline 14 & 195 & 205 & 240 & 215 & 220 & 195 & 212 \\
\hline 15 & 205 & 220 & 240 & 225 & 225 & 205 & 220 \\
\hline 16 & 210 & 230 & 245 & 225 & 230 & 230 & 228 \\
\hline 17 & 215 & 215 & 230 & 215 & 220 & 230 & 221 \\
\hline 18 & 185 & 200 & 210 & 195 & 195 & 195 & 197 \\
\hline 19 & 145 & 165 & 170 & 165 & 165 & 160 & 166 \\
\hline 20 & 100 & 105 & 215 & 115 & 115 & 105 & 108 \\
\hline 21 & 45 & 50 & 65 & 60 & 65 & 55 & 57 \\
\hline 22 & 05 & 10 & 15 & 20 & 20 & 20 & 15 \\
\hline
\end{tabular}

- Displacement in mils

\begin{tabular}{|c|c|c|c|}
\hline \multirow{2}{*}{ POSITION } & \multicolumn{2}{|c|}{ MERIDIAN } & \multirow{2}{*}{ AVERAGE } \\
\cline { 2 - 3 } & 1 & 2 & \\
\hline 0 & $240^{\circ}$ & 245 & 243 \\
1 & 190 & 195 & 193 \\
2 & 190 & 190 & 190 \\
3 & 245 & 225 & 235 \\
4 & 285 & 270 & 277 \\
5 & 310 & 295 & 303 \\
6 & 270 & 265 & 268 \\
7 & 185 & 175 & 180 \\
8 & 00 & 00 & 00 \\
\hline
\end{tabular}

